\title{
ACTIVITY CONFINEMENT SYSTEM OF THE \\ SAVANNAH RIVER PLANT REACTORS
}
W. S. DURANT
R. C. MILHAM
D. R. MUHLBAIER
A. H. PETERS

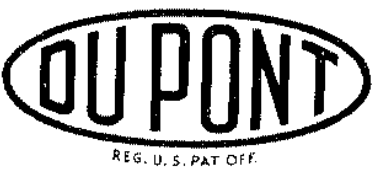

Savannah River Laboratory

Aiken, South Carolina 


\section{LEGAL NOT ICE}

This report was prepared as an account of Government sponsored work. Nelther the United States, nor the Commission, nor any person acting on behalf of the Commission:

A. Makes any warranty or representation, expressed or impited, with respect to the accuracy, completeness, or usefulness of the information contained in this report, or that the use of any information, apparatus, method, or process disclosed in this report may not infringe privately owned rights; or

B. Assumes any liabllities with respect to the use of, or for damages resulting from the use of any information, apparatus, method, or process disclosed in this report.

As used in the above, "person acting on behalf of the Commission" includes any employee or contractor of the Commission, or employee of such contractor, to the extent that such employee or contractor of the Commission, or employee of such contractor prepares, disseminates, or provides access to, any information pursuant to his employment or contract with the Commission, or his employment with such contractor.

$$
\text { Printed in USA. Price } \$ 4.00
$$

Available from the Clearinghouse for gederal scientific

and Technical Information, National Bureau of Standarcs,

U. S. Department of Commerce, Springfield, Va. 22151 


\section{ACTIVITY CONFINEMENT SYSTEM \\ OF THE \\ SAVANNAH RIVER PLANT REACTORS}

by

William S. Durant

Robert C. Milham

David R. Muhlbaier

Albert $H$. Peters

Approved by

E. C. Nelson, Research Manager

Reactor Engineering Division

August 1966

E. I. DU PONT DE NEMOURS \& COMPANY

SAVANNAH RIVER LABORATORY

AIKEN, S. C. 29801

CONTRACT AT(07-2)-1 WITH THE

UNITED STATES ATOMIC ENERGY COMMISSION 


\begin{abstract}
A filtration-adsorption system is installed in the ventilation exhaust of each reactor bullaing at the Savannah River Plant for confinement of alrborne particulate and lodine vapor activity that might be released in the highly unlikely event of a reactor accident. Air from the process areas of each bullding is passed continuously through moisture separators, then through particulate filters, and finally through lodine adsorber beds of activated carbon. The system has the experimentally demonstrated ability to confine more than $99 \%$ of airborne particulate activity and more than $99.9 \%$ of alrborne halogen activity, even with allowance for methyl lodide, under emergency conditions that could exist following a reactor accident. A mechanism for methyl lodide formation was developed from published data for general application to reactor confinement. Under Savannah River Plant conditions, less than $0.0001 \%$ of the total lodine inventory in the reactor would be converted to methyl iodide.
\end{abstract}




\section{CONTENTS}

$\underline{\text { Page }}$

List of Tables and Figures. . . . . . . . . . . . . v1

Introduction. . . . . . . . . . . . . . . . . 1

Summary . . . . . . . . . . . . . . . . 2

Discussion. . . . . . . . . . . . . . . . . I-1

I. Potential Reactor Accidents. ............ I-l

II. Description of SRP Activity

Confinement System . . . . . . . . . . . . II-I

A. Reactor. ................ . II-1

B. Reactor Room . . . . . . . . . . . IIII

1. Volume, Surface Area, Surface Finishes,

and Materials................. II-1

2. Structural IImitations........... II-2

C. Pressure Relief Paths from Reactor Room. . . . II-3

D. Supply and Exhaust Air Vent1lation....... II-4

1. Supply Air . . . . . . . . . . . . II-4

a. Fans . . . . . . . . . . . . II-4

b. Dampers and Controls......... II-5

c. Prefilters . . . . . . . . . . II-6

d. Air Ducts and Flows. . . . . . . . II-7

2. Exhaust Air II-7

a. Reactor Room Exhaust Header. . . . . II-7

b. Dampers and Controls . . . . . . . . II-8

c. Filter Compartments. . . . . . . . . II-9

1) Description and Location.... . . II-9

2) Moisture Separators. . . . . . . II-10

3) Particulate Filters. ....... . II-II

4) Carbon Beds. . . . . . . . II-15 
d. Fans. . . . . . . . . . . II-I8

e. Stacks. . . . . . . . . . II-18

3. Flow-Pressure Drop Characteristics. . . . II-19

E. Equipment operation ............. II-20

F. Contaminated Water Retention System . . . . . . II-23

III. Kinetics of Iodine Compound Formation and Iodine

Transport . . . . . . . . . . . . . . . IIIII

A. Kinetics of Formation of Iodine Compounds . . . III-2

1. Formation of Iodine Compounds in Fuel . . . . III-2

2. Formation of Iodine Compounds upon Meltdown. III-5

3. Formation of Iodine Compounds in the Gas

Phase Outside Reactor Vessel. . . . . . . III-12

4. Formation of Iodine Compounds on Surfaces

Outside Reactor vessel.......... III-14

B. SRP Conditions With Respect to Iodine Compounds. III-25

1. Formation of Methyl Iodide in Fuel. . . . III-27

2. Formation of Methyl Iodide upon Meltdown. . - III-27

3. Formation of Methyl Iodide in Reactor Room. - III-29

4. Decomposition of Methyl Iodide on

Adsorber Beds . . . . . . . . . . . . III-30

5. Summary of Methyl Iodide Release to the

Atmosphere. . . . . . . . . . III-30

C. Transport and Deposition of Fission Products in

the SRP System. . . . . . . . . . . . III-30

1. Transport and Deposition Through Exhaust

Ventilation System. ........... III-3I

2. Transport to Emergency Storage Basin. . . . III-32

IV. Fission Product Collection. . . . . . . . . . . IV-1

A. Particulate Matter. . . . . . . . . . IV-1

B. Halogens. . . . . . . . . . . . . IV-I

1. Factors in Evaluating Adsorber Units. . . . IV-I

a. Elemental Iodine Efficiency of In-Service

Activated Carbon. . . . . . . . . . IV-3

b. Penetration of Carbon Beds by Iodine in

Particulate Matter. . . . . . . . IV -4 
c. Gasket Leaks. . . . . . . . . . . . IV-4

d. Iodine Compound Penetration. . . . . IV-5

2. Removal of Decay Heat from Filter-

Adsorber Units. . . . . . . . . . IV-5

C. Noble Gases ............. . IV-6

V. Operating Experience. . . . . . . . . . . . V-1

A. F1lter Compartments ............. . V-l

B. Mo1sture Separators.............. V-1

c. Particulate Filters............. V-l

D. Activated Carbon Beds............ V-3

VI. Experimental and Development Program. . . . . . . VI-I

A. Nondestruct1ve Leak Test of Carbon Beds . . . . VI-1

I. "Freon-12" Leak Tests Before Installation

of Carbon Beds. . . . . . . . . . . . . . VI-I

2. "Freon-112" In-Place Test of Installed

Carbon Beds.............. . VI-2

B. Iodine Tests. . . . . . . . . . . . VI-4

1. Small-Scale Tests............ VI-4

2. Full-Size Tests............. VI-4

3. Analytical Techniques . . . . . . . . VI-4

C. Methyl Iodide Tests............. VI-5

D. Ignition Temperature of Halogen Adsorbers . . . VI-7

1. Literature Survey of Adsorptive Materials . . VI-7

2. Small-scale Ignition Temperature Apparatus. . VI-8

3. Ignition Tests of Full-Size Carbon Bed. . . . VI-8

E. Removal of Iodine and Noble Gases by

Isotop1c Exchange . . . . . . . . . . . VI-9

References .. . . . . . . . . . . . . . R-1

Appendix A Specifications for Moisture Separators . . . . . A-1

Appendix B Specifications for Water Repellent

Particulate Filters. . . . . . . . . B-1

Appendix C Specifications for Activated Carbon Beds . . . . C-1

$-\mathrm{v}-$ 


\section{LIST OF TABLES AND FIGURES}

Table

Page

II- 1 Surface Conditions in Reactor Room. . . . . . . II-2

II-2 Structural Iimitations of Activity Confinement System. . . . . . . . . . . . . . II-2

II-3 Reactor Room Vent Paths............ II-3

II-4 Process Area Supply Air Fans. . . . . . . . . . II-5

II-5 Schedule of Supply Air Dampers. . . . . . . . . . II-6

II-6 Schedule of Exhaust Air Dampers . . . . . . . . II-8

II-7 Pressure Losses in Exhaust Vent1lation System at Rated Alr flow . . . . . . . . . . . II-19

III-1 UKAEA Estimates of Methyl Iodide Released from

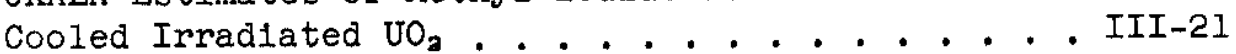

III-2 Summary of Literature Data on Methyl Iodide Formation.................. III-22

III-3 Average Rate Constants for Methyl Iodide Formation on Surfaces of Containment Test Fac1lit1es.... III-23

III-4 Summary of Average Rate Constants for Methyl Iodide Formation on Surfaces. . . . . . . . III-24

III-5 Qualitative Comparison of Conditions Affecting Fraction of Iodine Converted to Methyl Iodide... III-25

III-6 Decomposition of Methyl Iodide in the Reactor Vessel by Radiolysis........... III-29 
$\underline{\text { Table }}$

Page

IV-1 Iodine Penetration of Activated Carbon Beds. . . IV-2

V-I Iodine. Tests of Used Carbon Samples from SRP

Reactor Areas. . . . . . . . . . . V $\mathrm{V}-5$

VI-1 Small-Scale Methyl Iodide Tests of SRP Act1vated

Carbon . . . . . . . . . . . . . VI-6

Figure

$\underline{\text { Page }}$

II-l Savannah River Reactor . . . . . . . . . II-24

II-2 Savannah River Reactor Room. . . . . . . . II-25

II-3 Flow Diagram of Reactor Ventilation System . . . II-26

II-4 Reactor Room Supply Air System . . . . . . . II-27

II-5 Ventilation System for $-20 \mathrm{ft}$ and $-40 \mathrm{ft}$ Levels . II-28

II-6 Process Area Exhaust Air System. . . . . . . . II-29

II-7 Filter Compartment . . . . . . . . . . II-30

II-8 Activated Carbon Bed Frame......... II-3I

II-9 Exhaust Rate from Reactor Room to Stack. .... . II-32

II-10 Vent Rate Through Discharge Canal. . . . . . II-33

II-11 Effect of Bed Depth on Calculated Efficiency of Carbon Beds for Removing Elemental Iodine Vapor. . II- 34

II-12 Sectional Schematic of SRP Activated Carbon Bed. - II- 35

II-13 Savannah River Plant Filtration - Adsorption Un1ts II- 36 
Figure

III-1 Maximum Possible Equilibrium Amount of Methyl Iodide in Irradiated Uranium-Aluminum Alloy . . . III-33

III-2 Equilibrium Constants for Iodine and Hydrogen Iodide. . . . . . . . . . . . . . III-34

III-3 Rate of Formation of Methyl Iodide in HydrogenIodide-Rich Atmosphere. . . . . . . . . . III-35

III-4 Specific Rate Constant for Methane-Iodine Reaction. . . . . . . . . . . . III-36

III-5 Rate of Decomposition of Methyl Iodide by Reaction with Hydrogen Iodide. . . . . . . . . . III-37

III-6 Rate of Formation in Ga.s Phase of Methyl Iodide in Containment Buildings. . . . . . . . III-38

III-7 Equilibrium Amount in Gas Phase of Methyl Iodide in Containment Buildings. . . . . . . . . III-39

III-8 Methyl Iodide Formation on Surfaces in Air Environment .............. III-40

III-9 Methyl Iodide Formation on Surfaces in Steam-Air Environment .............. III-4I

III-10 Airbome Iodine Concentration in SRP Reactor Room . III-42 1

III-11 Amount of Iodine Depositing on SRP Reactor Building Surfaces ............. III-43 
VI-1 "F-112" Adsorption Efflelency of Banks of Carbon Beds Installed in $C$ Reactor . . . . . . . . VI-10

VI-2 Equipment for In-Place Testing of Plant Carbon Beds. . . . . . . . . . . . . V VI-11

VI-3 Iodine-131 Test Facility. ........... VI-12

VI-4 Flow Diagram of Test Development Facillty for Full-S1ze Iodine Adsorbers. . . . . . . . . VI-13

VI-5 Small-Scale Ignition Test Equipment . . . . . VI-14

VI-6 Full-Size Ignition Test Equipment ........ VI-15

C-1 Assembly and Sections of SRP Activated Carbon Bed Frame. . . . . . . . . . . . c C-8 


\section{ACTIVITY CONFINEMENT SYSTEM OF THE SAVANNAH RIVER PLANT REACTORS}

\section{INTRODUCTION}

The activity confinement system for the Savannah River Plant (SRP) production reactors is designed to collect alrborne particulate and halogen activity and waterborne activity that might be released from the reactor in the highly unlikely event of a mafor reactor accident. It represents one of many lines of defense that include preventing accidents, limiting the consequences of accidents, and confining activity that may be released from the fuel and reactor.

The confinement system for alrborne activity consists of molsture separators, particulate filters, and halogen adsorbers in the exhaust air portion of the ventilation system. Air is exhausted from the reactor process areas through the filters and adsorbers, and discharged to a stack. The system will not contain noble gases. A 50-million-gallon basin is provided near the reactor bullding to collect waterborne activity. The system has been in full operation in all reactor areas since 1964.

Development work on the confinement system started in 1960 and has been a continuing major effort of both the Savannah River Laboratory (SRL) and Savannah River Plant (SRP) organizations. Considerable laboratory work was required to develop a satisfactory system that would function properly under possible accident conditions. SRL and SRP personnel particlpated closely in the design, installation, and operation of the system. Comprehensive evaluations of the performance of the operating system have led to several improvements to increase rellablilty and efficiency. A substantial technical effort is continuing, and further improvements will continue, as more knowledge is galned.

This report presents the results of this extensive program of development and evaluation of the operating system. It covers:

- A brief review of reactor accidents.

- A description of the confinement system.

- A discussion of lodine compound formation and lodine transport.

- An evaluation of the effectiveness of the confinement system.

- Operating experience.

- A review of development programs. 


\section{SUMMARY}

The SRP activity confinement system has the demonstrated ablilty to collect over 99\% of airborne particulate activity and over 99.9\% of alrborne halogen activity under emergency conditions that could exist following a reactor accident. These efficiencies are applicable even after the minor deterioration which the units might incur during operation prior to an accident.

The filtration-adsorption system is on-line continuously during normal operation and requires no manual or automatic operating action when an emergency occurs. A negative pressure is maintained in process areas so that air that could be contaminated in an accident is exhausted through the filters and adsorbers. The system would operate at full ain flow even after an accident. It is adequately designed so that even if an exhaust fan, normal electrical power, or reactor room seals fail, particulate or lodine activity will be confined without action by the operator.

A large number of actions can be taken by an operator during an emergency to provide backup protection or to counteract additional fallures. Control and monitoring are possible either in the reactor central control room or in the remote control station located about 10 miles from the reactors.

Comprehensive and continuing evaluations of each type of unit in the system ensure good performance of the system. Tests of each particulate filter, before and after installation, with dioctylphthalate (DOP) demonstrated that the filters remove $99+\%$ of submicron particules. Representative moisture separators and particulate filters (which had been exposed to serivice conditions in the SRP facilities for up to 2 years) successfully withstood exposure to steam and steam-air-entrained water mixtures ( $f \circ g$ ) for 10 days and still malntained a filter efficiency of $99+\%$. These tests demonstrated that the combination of moisture separator and particulate filter selected for the SRP facilities will withstand the conditions during any accldent that does not seriously damage the reactor bullding.

Tests of activated carbon before use showed that at least $99.99 \%$ of elemental lodine is removed consistently under a variety of adverse conditions. Periodic tests have shown that after more than 2-1/2 years of service the efficlency for removing all forms of lodine that might be released from the SRP reactors and transported to the beds remains greater than $99.9 \%$, even with allowance for penetration of methyl lodide and lodine in particulate matter. The expected performance is summarized in the following table: 


\section{Average Iodine Penetration of Activated Carbon Beds (a)}

\begin{tabular}{|c|c|c|c|c|c|}
\hline Mechanism $\rightarrow$ & $\begin{array}{l}I_{2}(b) \\
\text { Vapor }\end{array}$ & Particulates & $\begin{array}{l}\text { Gasket } \\
\text { Leaks }\end{array}$ & $\begin{array}{l}\operatorname{Methy} 1(\mathrm{~b}) \\
\text { Iodide }\end{array}$ & Total \\
\hline $\begin{array}{l}\text { Iodine reaching beds, } \\
\% \text { of total inventory } \\
\text { applicable to mechanism } \\
\text { shown }\end{array}$ & 50 & $<0.0003$ & 50 & $<0.0001$ & - \\
\hline $\begin{array}{l}\text { Penetration, } \% \text { of that } \\
\text { reaching the beds. }\end{array}$ & 0.02 & 100 & $<0.03$ & 100 & - \\
\hline $\begin{array}{l}\text { Iodine leaving beds, } \\
\text { \% of total inventory }\end{array}$ & 0.01 & $<0.0003$ & $<0.015$ & $<0.0001$ & $<0.026$ \\
\hline
\end{tabular}

(a) $50 \%$ of the lodine was assumed to remain in the reactor. Average refers to four banks on-line.

(b) Assumes steam-a1r conditions; penetration would be less for air. because:

The high efficiency of the installed carbon beds is known

- The efficlency of representative samples is measured routinely in laboratory tests to establish that the carbon is an efficient adsorber.

- Leak paths of the installed beds are now measured routinely using "Freon-112"* as a tracer.

- A comprehensive analysis and laboratory test program has characterized the mechanism for collection of lodine under normal and accldent conditions.

Evaluation showed that the probability of lgniting the carbon in the event of a nuclear accident is acceptably low. In the critical period after a possible accldent, air flow of less than 10\% of normal will remove the decay heat from fission products trapped on the filters and adsorbers and will maintain the carbon temperature below the measured ignition temperature of $340^{\circ} \mathrm{C}$. Two exhaust air fans are always operating and a third fan is available. Power for the fans is fed in a loop circuit from two or three power plants that are widely separated.

* "Freon" and combinations of "Freon-" or "F-" with numerals are Du Pont's registered trademarks for its fluorinated hydrocarbons. 
A review, analysis, and correlation of published data showed that less than $0.0001 \%$ of the total lodine inventory in the reactor fuel core would be converted to nonremovable compounds of lodine under SRP conditions. The conditions that reduce the percentage of elemental lodine converted to methyl lodide include:

1. In Reactor VesseI

- Intense radiation field which decomposes practically all methyl lodide released from molten fuel.

- Rich hydrogen 1odide atmosphere which precludes formation of slgnificant amounts of methyl lodide.

\section{Outside Reactor Vessel}

- Negligible "aging" because of high once-through ventilation flows.

- Low surface-to-volume ratios.

- Low deposition of lodine on surfaces.

- Relatively clean air and building surfaces.

- Low hydrogen content in fuel.

- Oxidizing and/or condensing steam atmospheres.

- Relatively low temperatures.

- High initial gas-phase lodine concentration. 


\section{DISCUSSION}

\section{POTENTIAL REACTOR ACCIDENTS}

The activity confinement system is only one of several lines of defense that limit off-site exposure to radiation or radioactive contamination. It is designed for use in the highly unlikely event that a serious reactor accident occurs. Its purpose is to confine 1) airborne particulate and halogen activity after the activity leaves the reactor hydraulic complex but before it leaves the reactor building and 2) waterborne activity after it leaves the building but before it enters the uncontrolled environment. Multiple lines of defense are provided to prevent accidents and to limit the course of accidents.

This section summarizes the conditions under which activity could be released from the reactor and reviews the bases for the design of the activity confinement system. There are basically only two potential reactor accidents that could lead to a substantial release of fission product activity: 1) loss of coolant followed by fuel melting from decay heat, or 2) an increase in reactor power that would cause bolling of the $\mathrm{D}_{2} \mathrm{O}$ followed by fuel melting. Theoretically, each of these can occur and can lead to a fairly wide range of activity releases.

The most serious potential accident is a mafor $\mathrm{D}_{2} \mathrm{O}$ leak followed by a significant delay in actuation of the emergency light-water cooling system. Under these conditions, fuel coolant could be lost in a short time and fuel melting would follow. Activity would be released first to the reactor tank and then to the above-grade process room through numerous vents in the top shield and plenum. Activity could be released also to the belowgrade process areas through the leak in the hydraulic system. If emergency cooling is not added rapidly after loss of the $\mathrm{D}_{2} \mathrm{O}$ coolant, the entire core could melt from the decay heat. Most of the fuel would be contained within the reactor tank or the piping system because heat transfer would be adequate to prevent melting of the reactor or piping. Only if the leak occurred below the bottom of the reactor tank, could a part of the fuel flow into the below-grade areas of the reactor bullding and release additional activity. The sequence fust described is the only known potential accident that could lead to release of $100 \%$ of the equilibrium inventory of noble gases, 50\% of the 1odine, and $1 \%$ of the particulates. This potential accident provides one of the bases for design of the activity confinement system. 
Loss of cooling could occur if all the $D_{2} O$ pumps falled (perhaps caused by light-water flooding of the reactor bullding) or if light-water flow to the process heat exchangers stopped. In neither case would melting occur unless there was also a serious delay in actuation of the emergency cooling system. If that occurred, fuel decay heat would vaporize the $\mathrm{D}_{2} \mathrm{O}$ in the reactor before the full core melted. At flrst, steam would escape through two vacuum breakers into the above-grade process room, and later (as the tank water level decreased) steam would vent through numerous other openings into the above-grade process room. Some fuel melting could be experienced during this stage; hence, the steam could be contaminated with fission product activity, but most of the core will not melt until most of the $\mathrm{D}_{2} \mathrm{O}$ has vaporized. Fuel melting then would take about the same course of action as previously described. The added time required to vaporize the $\mathrm{D}_{2} \mathrm{O}$ would allow signiflcant decay of fission product activity and would allow an appreciable time to add emergency cooling. Steam could be generated during the course of this accident, but the rate would be significantly lower than in some reactivity accidents.

For possible power-surge accldents, reactor power could increase and cause bolling of $D_{3} O$ in the reactor. Steam and water would be vented to the above-grade process room through vacuum breakers and other vent paths. After the start of steam generation, fuel would begin to melt because of vapor in the fuel coolant passages. After enough fuel melts, the power surge would stop because of loss in reactivity. Unless fuel cooling also was lost at the same time (this is considered to be unlikely) no further fuel melting would occur. Any activity released from the fuel would be vented to the above-grade process room. Because only part of the core would melt, release of activity would be less than that for a major loss-of-coolant accident.

The filtration-adsorption system was developed specifically for the SRP facilities to achieve high efficlencles for removal of particulate and halogen activity under the most unfavorable combination of accident conditions. As discussed in section II, filtration-adsorption units were exposed successively to tests that simulated the worst features of accidents involving potential complete core melting. 


\section{DESCRIPTION OF SRP ACTIVITY CONFINEMENT SYSTEM}

\section{A. REACTOR}

The SRP production reactors are $1 / 2$-1nch-thick stainless steel tanks, 11 ) 16 feet $2-3 / 4$ inches in diameter*, 15 feet 4 inches high, as shown in Figure II-I. The tank is surrounded on the sides by an iron and light-water thermal shield, and by a concrete biological shleld. Thermal shlelds, containing light water and stainless steel Raschig rings, are built into the top and bottom of the tank. Above the top thermal shield is a 12-inch-thick gas plenum which contains the top surface of the moderator for the reactor and through which helium blanket gas clrculates. Above the gas plenum is a 10-1nch-thick $\mathrm{D}_{2} \mathrm{O}$ plenum.

Heavy water, used as coolant and moderator, enters the reactor through six symmetrically spaced nozzles at the top of the reactor, flows from the plenum through the fuel assemblies and into the bottom of the reactor tank. $D_{2} \mathrm{O}$ is transported in six coolant loops out of the tank to the pumps, heat exchangers, and back into the plenum.

\section{B. REACTOR ROOM}

1. Volume, Surface Area, Surface Finishes, and Materials

Information in this section is used in calculating fission product deposition, organic compound formation, and residence time for airborne fission products. The information presented is for the reactor process room, but comparable conditions exist in other process areas.

The reactor room is in the center section of the reactor building and is approximately 125 feet long and 60 feet wide. The helght varies from 43 to 61 feet, and the contained volume is about 320,000 cublc feet. The $\mathrm{D}_{2} \mathrm{O}$ plenum and $\mathrm{six}$ inlet nozzles protrude above the floor of the room as shown in Figure II-2.

Surface materials, finishes, and areas are summarized in Table II-1.

Concrete surfaces are palnted with a vinyl coating, "Amercoat"** 33HB. Floors are painted annually; however, the celling and walls have not been repainted since the original application. "Amercoat" $33 \mathrm{HB}$ is used because of 1ts hard fintsh and ease of decontamination.

* The diameter of $\mathrm{C}$ reactor $1 \mathrm{~s}$ about 28 inches larger.

* Trademark of Amercoat Co. 
TABLE II-I

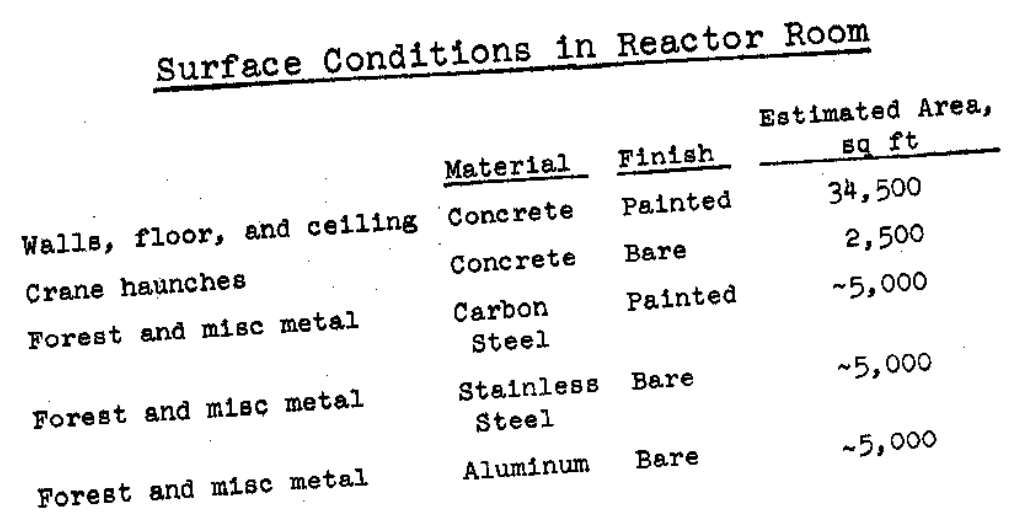

\section{Structural Limitations}

During certain accidents, large quantities of steam could be released from the reactor vessel into the reactor room. This steam must be vented to prevent rupture of the reactor fow primarily confinement system. The maximum contalnabsure in the reactor function of: l) the maximum allowable through the vent paths, 1.e.s room, and 2) the resistance to flowal between the reactor room exhaust system and the discharge cant pressure and estimated presand fuel disassembly area. The test are shown in Table II-2. sures for gross structural fal

\section{TABLE II-2}

Structural Limitations of Activity Confinement System

\begin{tabular}{|c|c|c|c|}
\hline & $\begin{array}{c}\text { Test } \\
\text { Pressure, } \\
\text { psig } \\
\end{array}$ & $\begin{array}{c}\text { Estimated } \\
\text { Pressure for } \\
\text { Gross Fallure, } \\
\text { psis } \\
\end{array}$ & $\begin{array}{c}\text { Max Pressure } \\
\text { During Worst } \\
\text { Postulated } \\
\text { Accident, } \\
\text { psig } \\
\end{array}$ \\
\hline Reactor building & - & 10 to 15 & 1.9 \\
\hline $\begin{array}{l}\text { Filter compartment } \\
\text { Momentary } \\
\text { Sustained }\end{array}$ & $\begin{array}{l}3 \\
2\end{array}$ & $\begin{array}{l}6 \text { to } 8 \\
4 \text { to } 5\end{array}$ & 0.4 to $1.3^{(a)}$ \\
\hline $\begin{array}{l}\text { Filter bank supports } \\
\text { Moisture separators } \\
\text { Particulate filters } \\
\text { Carbon beds }\end{array}$ & $\begin{array}{l}0.22 \\
0.22 \\
0.22 \\
0.4\end{array}$ & $\begin{array}{l}3 \\
3 \\
3 \\
2(b)\end{array}$ & $\begin{array}{c}0.1 \text { to } 0.8^{(a)} \\
0.1 \text { to } 0.4^{(a)} \\
0.1 \\
0.07\end{array}$ \\
\hline
\end{tabular}

Fan casings value is for clean separators and particulate fits. larger value is for worst expec

(b) Estimated from test pressure. 


\section{PRESSURE RELIEF PATHS FROM REACTOR ROOM}

Positive pressures could be created in process areas of the reactor bullding by a rapld steam release from the reactor. This section describes the passages from the reactor room through which the pressure could be relleved and the areas into which flow could occur; these are summarized in Table II-3. Pressure surges in other process areas are much less likely and would be slgniflcantly lower than could occur in the reactor room.

\section{TABLE II-3}

Reactor Room Vent Paths

\begin{tabular}{lcll} 
Vent Path & $\begin{array}{c}\text { Pressure Seal } \\
\text { Rating, } \Delta \mathrm{P}\end{array}$ & \multicolumn{1}{c}{ Adjacent Area } \\
Exhaust duct & - & Activity confinement system \\
D1scharge canal & 12 inches $\mathrm{H}_{2} \mathrm{O}$ & Disassembly area \\
Monorail transfer & $2 \mathrm{ps} 1$ & Assembly area \\
Crane door & $2 \mathrm{psi}$ & $\begin{array}{l}\text { Crane wash and maintenance } \\
\text { areas }\end{array}$ \\
Personnel access door & $2 \mathrm{psi}$ & General personnel areas
\end{tabular}

Normally, ventilation air flows from the reactor room through sixteen 9-inch $\times$ 9-1nch concrete ducts at elevation 42 feet $7 \frac{1}{2}$ inches, and nine 18-inch round ducts at elevation 60 feet 2 inches. These ducts discharge into a single header. The exhaust ports are on one wall of the reactor room at the celling. For pressures of up to 12 inches of water these ports would be the only pressure relief paths from the reactor room, other than leakage. The opposite wall contains the same number of exhaust ports, except that under present operating conditions they are closed.

Air 18 supplied to the reactor room through twenty-four 18Inch-diameter round ducts; these will not act as pressure relief paths because backflow dampers are installed in the system. 
At pressures greater than 12 inches of water, the water seal in the discharge canal between the reactor room and the disassembly area would be broken. Flow rates as a function of pressure differential are discussed in Section II, D, 3. Typically, the disassembly areas are about twice the slze of the reactor room and are connected to the remainder of the building by unsealed corridors, except below-grade process areas. The ventilation system for the disassembly area is separate from the main process area ventilation system. Air is discharged to the atmosphere and no filter or adsorber units are used.

Seals for all other vent paths from the reactor rooms are designed to withstand a differential pressure of 2 psi. All other areas connected to the reactor room by the 2-ps1 seals are unsealed and interconnected.

Although seals between the reactor room and adjacent areas might be broken during an accident, gases that may escape in the initial pressure surge were assumed to be clean because of the size of the process room, the relatively long distance of the reactor from these openings, the likelihood that fuel melting will not occur until after the inftlal steam surge, and the relatively short periods when positive pressures may exist in the reactor room. A negative pressure in the process room would be re-established rapidiy by the exhaust fans, because the duration of the pressure surge would be only a few seconds.

\section{SUPPLY AND EXHAUST AIR VENTILATION}

1. Supply Air

\section{a. Fans}

The process areas (reactor room, purification, and -20 foot and -40 foot levels) are continuously purged with fresh, outside air supplied by three sets of centrifugal fans. A schematic diagram of the supply and exhaust air systems is shown in Figure II-3. Figures II-4 and II-5 are schematic diagrams of the supply air system and show the location of the reactor room supply fans (902)* and the below-grade supply fans (911). A fan (907) supplies air to the purification area which is then exhausted by the building exhaust system, F1gure II-6. The supply air fans and their function are listed in Table II-4.

* Fans and dampers are identified in the text, tables, and figures by equipment plece number: 902, 907, etc., for fans; and $A, B$, etc., for dampers. 
TABIE II-4

Process Area Supply Alr Fans

\begin{tabular}{|c|c|c|c|c|}
\hline \multirow{2}{*}{$\begin{array}{l}\text { Fan } \\
\text { E.P. No. } \\
\end{array}$} & \multirow[b]{2}{*}{ Service } & \multirow{2}{*}{$\begin{array}{l}\text { Alr Flow to } \\
\text { Confinement } \\
\text { System(a), cfm }\end{array}$} & \multicolumn{2}{|c|}{ No. of Fans } \\
\hline & & & Operate (b) & Spare \\
\hline 902 & $\begin{array}{l}\text { Reactor room } \\
\text { supply }\end{array}$ & 37,700 & 1 & 2 \\
\hline 907 & $\begin{array}{l}\text { Purification } \\
\text { supply }\end{array}$ & 26,300 & 1 & 0 \\
\hline 911 & $\begin{array}{l}-20 \text { and }-40 \text { foot } \\
\text { levels supply }\end{array}$ & 64,000 & 1 & 1 \\
\hline
\end{tabular}

(a) Design value air flow with clean exhaust air filters.

(b) Normal operation.

b. Dampers and Controls

The supply air dampers are deslgned to control the flow of air to the process areas. Figures II-3, II-4, and II-5 show the location of many of the dampers, and Table II-5 lists the dampers and their type and class of operation. Several groups of dampers are interlocked to perform automatic action under certain conditions. Following is a brief description of the operation of the dampers.

The controls of dampers in the reactor room supply header (c) and in the actuator tower ( $F$ and $F$ ) are designed to prevent backfiow from the reactor room. The signal source is the $\Delta \mathrm{P}$ between the discharge plenum of the reactor room supply fans (902) and the reactor room. Normally the reactor room is at a lower pressure than the fan discharge plenum, but should the pressures become equal, the dampers will close and protect against release of possibly contaminated material to the atmosphere without pasing through the filtration-adsorption units.

The dampers between each supply fan (902) and the reactor room supply header are interlocked with their respective fan to open or close as the fan starts or stops. If a.ll three supply fans (902) are stopped, all three of the dampers (A) w1ll be opened automaticaliy. 


\section{TABLE II-5}

Schedule of Supply Air Dampers

\begin{tabular}{|c|c|c|c|c|}
\hline Damper & Class (a) & Location & Size, Inches & No. \\
\hline A & $\mathrm{C}_{2}$ & $\begin{array}{l}\text { Between each supply air fan } \\
\text { ( } 902) \text { and reactor room } \\
\text { supply header }\end{array}$ & $78 \frac{1}{4} \times 56 \frac{1}{4}$ & 3 \\
\hline B & $\mathrm{D}$ & $\begin{array}{l}\text { Between prefilters and supply } \\
\text { air fans }(902)\end{array}$ & $73 \frac{7}{8} \mathrm{DIa}$ & 3 \\
\hline $\mathrm{C}$ & A & In reactor room supply header & $102 \times 60$ & 1 \\
\hline $\mathrm{D}$ & F & $\begin{array}{l}\text { In fan room ventilation } \\
\text { supply header }\end{array}$ & $50 \times 24$ & $I$ \\
\hline $\mathbf{E}$ & A & In actuator tower supply & $63 \times 25$ & 2 \\
\hline $\mathbf{F}$ & B & In actuator tower exhaust & 42 Dia & 2 \\
\hline$T$ & $\mathrm{C}_{2}$ & $\begin{array}{l}\text { Between supply air fans (911) } \\
\text { and }-40 \text { foot level }\end{array}$ & $105 \times 75 \frac{3}{4}$ & 2 \\
\hline
\end{tabular}

(a) Class of Dampers

A: Rubber-lined butterfly; modulating and quick closing operation.

B: Rubber-lined butterfly; two position, quick closing operation.

$\mathrm{C}_{1}$ : Conventional louver blade; modulating and closing operation interlocked with respective fan.

$\mathrm{C}_{2}$ : Same a.s $\mathrm{C}_{1}$, except no modulating action.

D: Variable inlet vane; fastened wide open.

F: Louver damper, manual control.

The modulating dampers in reactor room supply header (C) and in actuator tower supply $(E)$ are used to adfust and balance the air flow to the process areas. They are interlocked to be failsafe (open fully) if the operating air pressure is lost. If air pressure is lost when the dampers are being positioned by another interlock, the dampers will remain in the position dictated by the first interlock signal.

\section{c. Prefilters}

On the suction side of the supply air fans are prefilters designed to remove relatively large particles of dust and to reduce the dust burden on the confinement system's high efficiency particulate filters. The existing prefilters are 5 ply and will remove $70 \%$ of $1-\mu$ particles and $81 \%$ of $2-\mu$ particles. Provisions 
are being made to increase the removal efficiency of the prefilters with the use of 10-ply filters that will remove $90 \%$ of $1-H$ particles and $96 \%$ of $2-\mu$ particles.

\section{d. Air Ducts and Flows}

The supply air fans discharge into a system of steel and concrete ducts that convey ventilation air to the process areas. The supply fans create a pressure of $\sim 4$ to 5 inches $\mathrm{H}_{2} \mathrm{O}$ at the discharge plenum, which is reduced to a negative value in the process areas by throttling the inlet dampers, and by the exhaust fans that discharge at atmospheric pressure.

Ducts downstream of backflow dampers that could be exposed to a 2-psig pressure surge in the reactor room are designed to withstand this pressure without failure. Figures II-4 and II-5 are schematic diagrams of the supply air system and the flows to the process areas.

The reactor room supply air system is deslgned to produce a flow pattern that will prevent localized activity concentrations. A concrete header 5 feet $x 8$ feet- 6 inches extends the full length of the reactor room (on one side) and provides 24 outlets to disperse $37,000 \mathrm{cfm}$ of air about the room. The outlets are schedule 10 steel pipe, 18 inches in diameter and about 13 to 20 feet long. An 18-inch-long nozzle is on the end of each outlet and tapers the pipe to 14 inches in diameter.

\section{Exhaust Air}

\section{a. Reactor Room Exhaust Header}

Exhaust air is removed from the reactor room through a concrete header duct, 5 feet $\times 8$ feet-61nches, located on one side of the room. A similar header is on the opposite side of the room, but is closed. Twenty-five nozzles are open to the header in the reactor room and exhaust the air flow. The nozzles (typ1fled by $C$ Area) are of three sizes and include: sixteen 19 inches $x 9$ inches $x 5$ feet in length (concrete), six 18 inches in diameter $x$ about 23 feet in length (schedule 10 steel p1pe), and three 18 inches in diameter $x$ about 23 feet in length (schedule 10 steel pipe). About 21 feet of 14-inch $x$ 20-inch duct (galvanized) connects the nozzles to the exhaust header. The exhaust header has a volume of about $16,500 \mathrm{cu} f t$ and a surface area of 12,000 sq $f t$ between the reactor room and the filter compartments. 


\section{b. Dampers and Controls}

Figure II- 6 is a schematic diagram of the exhaust air system and shows the location of many of the dampers. Table II- 6 lists the dampers and their type and class of operation.

\section{TABLE II-6}

Schedule of Exhaust Air Dampers (a)

\begin{tabular}{|c|c|c|c|}
\hline Damper & Class (b) & Location & S1ze, Inches \\
\hline G & A & $\begin{array}{l}\text { Between purification area } \\
\text { and filter compartments }\end{array}$ & $84 \times 48$ \\
\hline $\mathrm{H}_{1}$ & A & $\begin{array}{l}\text { Upstream side of each filter } \\
\text { compartment }\end{array}$ & 54 Dia \\
\hline $\mathrm{H}_{2}$ & $\mathrm{~B}$ & $\begin{array}{l}\text { Downstream side of each } \\
\text { filter compartment }\end{array}$ & 54 Dia \\
\hline I & $G$ & $\begin{array}{l}\text { In exhaust fan (903) leak } \\
\text { collection system }\end{array}$ & $16 \times 16$ \\
\hline$J$ & D & $\begin{array}{l}\text { Upstream of each exhaust } \\
\text { fan (903) }\end{array}$ & $73 \frac{7}{8}$ D1a \\
\hline K & $\mathrm{C}_{1}$ & $\begin{array}{l}\text { Downstream of each exhaust } \\
\text { fan }(903)\end{array}$ & $78 \frac{1}{4} \times 56 \frac{1}{4}$ \\
\hline M & A & $\begin{array}{l}\text { Between }-20 \text { foot and }-40 \text { foot } \\
\text { levels and filter compartments }\end{array}$ & $138 \times 72$ \\
\hline $\mathrm{N}$ & B & $\begin{array}{l}\text { Between }-20 \text { foot, }-40 \text { foot } \\
\text { levels and stack }\end{array}$ & $138 \times 72$ \\
\hline$Q$ & $\mathrm{E}$ & $\begin{array}{l}\text { Between }-40 \text { foot level and } \\
\text { exhaust fans }(910)\end{array}$ & $9 i 1 \frac{3}{4} \mathrm{Dia}$ \\
\hline $\mathrm{R}$ & $G$ & $\begin{array}{l}\text { In exhaust fans ( } 910) \text { leak } \\
\text { collection system }\end{array}$ & $24 \times 24$ \\
\hline
\end{tabular}

(a) See FIgure II-6 for damper locations.

(b) Class of Dampers

A: Rubber-lined butterfly; modulating and quick closing operation.

B: Rubber-lined butterfly; two position, quick closing operation.

$\mathrm{C}_{1}$ : Conventional louver blade; modulating and closing operation interlocked with respective fan.

D: Variable inlet vane; fastened wlde open.

$\mathrm{E}$ : Variable inlet vane; automatic control.

G: Blast gate. 
Class $A$ and $B$ dampers, which are butterfly-type with a rubber-lined seat, effectively seal the ducts. Following is a brief description of the operation of various dampers.

Several groups of dampers are interlocked to provide automatic actions that take place under certain conditions. The controls of dampers in the exhaust from purification $(G)$ and in the exhaust from the below-grade process areas (M) are interlocked with the upper air plenum pressure (filter compartment inlet pressure). If this pressure should approach atmospheric (normally -1 inch to -2 inches $\mathrm{H}_{2} \mathrm{O}$ ), the dampers will close to prevent backflow of air to purification and -20 foot and -40 foot areas. Thus any contaminated material released from the reactor room, even if accompanied by a pressure surge, cannot reach other areas by the exhaust ventilation ducts.

The dampers adjacent to the filter compartments $\left(\mathrm{H}_{1}\right.$ inlet damper and $\mathrm{H}_{2}$ outlet damper) are interlocked with their respective compartments such that both dampers will be closed when the filter compartment is not in 1ts proper position and/or latched. Electrical switches attached to the filter compartment and latch provide the necessary control signals.

The dampers (K) Immediately downstream of each main exhaust fan (903) are interlocked with their respective fan to open or close as the fan starts or stops. However, if all three exhaust fans (903) are stopped, all three of the dampers will be opened.

The modulating dampers are used to adjust and balance the air flow from the process areas. All modulating dampers in reactor room supply header (C), in actuator tower ( $E$ ), in exhaust duct from purification area $(G)$, upstream of each filter compartment $\left(\mathrm{H}_{1}\right)$, and in exhaust duct from -20 foot and -40 foot levels are interlocked to be fail-safe (open fully) if the operating air pressure is lost. If air pressure is lost when the demper is being positioned by another interlock, the damper will remain in the position dictated by the first interlock signal.

\section{c. Filter Compartments}

\section{1) Description and Location}

The filter compartments contain the filtration-adsorption units. Five compartments are on the roof of the reactor bullding at the +55 foot elevation, and each contains three banks of filters or adsorbers in series, as shown in Figure II-7. The first bank has 20 molsture separators, the second has 32 particulate filters, 
and the third has 32 activated carbon beds. Each compartment is connected to the ventilation system between the exhaust air duct and the exhaust fans (903); hence, the compartments operate with a negative pressure. Each compartment is held in place by a latching mechanism attached to the plenum wall and the compartment. If the compartment is not in proper position and latched, It cannot be put on-line because the interlocked inlet and outlet compartment dampers $\left(\mathrm{H}_{1}\right.$ and $\left.\mathrm{H}_{2}\right)$ will not open. The air flow pattern is shown in Figure II-7.

The filter compartments can be remotely delatched from the ventilation system should they become highly contaminated. (a) All compartments are mounted on tracks and connected to cables for movement away from the plenums to the edge of the reactor building where they can be removed from the roof by a crane and shipped to the burial ground. Sufficlent area is also available on the roof to pull the compartments away from the plenum for service. The compartments contain drain lines to the reactor room to dispose of contaminated water, which could collect in the compartment at the molsture separators (described below) if an accident occurs with a release of steam and/or entrained water.

The three types of units in each compartment are described in the following paragraphs and are shown in Figure II-13. Operating experience of the compartment, fllters, and adsorbers is presented in Section V.

\section{2) Moisture Separators}

The molsture separators ("Demisters"*) are deslgned to remove about $99 \%$ of 1 - to $5-\mu$ entrained water particles to protect against significant rupture of the water-repellent particulate filters. (3) The separators consist of about 24 mats woven from "Teflon"** yarn (individual fibers about 0.001 -inch diameter) and stainless steel wire forming a pad 24 inches $x 24$ inches $\times 2$ inches thick. The number of mats in each pad is dictated by the desired removal efficlency which was correlated in terms of a flow resistance requirement of $0.95 \pm 0.05$ inch $\mathrm{H}_{2} \mathrm{O}$ at the rated air flow of 1600 cfm. The case, mat, and support mechanism are designed and tested to withstand flows equivalent to about 10 times the rated air flow through the separator.

Because no information was available in the literature on the performance of commercial separators for removal of water particles in steam-air mixtures ( $f \circ g)$, extensive tests were conducted at SRL on candidate units. These tests showed that the

* Registered trademark of Otto H. York Co.

* Registered trademark of E. I. du Pont de Nemours \& Co. 
specified "Demisters" were the only commercially avallable units that were satisfactory at the time of installation in the SRP facilities. The "Demisters" successfully withstood the test conditions (wet steam flow to about 10 times the normal air flow and exposure to fog for 10 days) and prevented damage of the particulate filters when exposed to these conditions. On the basis of calculated efficlencies and the observed test results, most of the water particles in the fog were removed by the "Demister" made of "Teflon". The calculated maximum water load on each "Demister" is about 1 pound of liquid $\mathrm{H}_{2} \mathrm{O}$ per minute, and the manufacturer's rating is 8 pounds per minute before flooding occurs.

Tests of standard type prefilters and conventional wire-mesh separators showed that they were practically useless in removing the entrained water particles. One type of prefilter was blown from its containing frame after 10 seconds exposure to wet steam at a maximum rate of 7 times the rated air flow.

The minimum temperature at which thermal degradation of the "Demisters" would be expected is about $150^{\circ} \mathrm{C}$. At this temperature the neoprene gasket would begin to deteriorate. The gasket is self extinguishing, however. At about $260^{\circ} \mathrm{C}$, the "Teflon" would begin to deteriorate, but the strength of the unit essentially would be unaffected because of the stainless steel wires on which the "TefIon" is woven. Radiation effects on "Teflon" have been measured. Calculations showed that at radiation levels associated with the maximum accumulation of fission products in the filter compartments, the reduced fiber tensile strength is far in excess of the actual stress on the flbers for several hours after an accident.

Complete speciflcations for the "Demisters" are presented in Appendix A. Operating experience is presented in Section $V$.

\section{3) Particulate Filters}

The particulate fliters are designed to remove $99+\%$ of all particles of $0.3 \mu$ diameter, or larger. The necessity for this high efficiency is explained in Section IV, B, I, b. Filter medium is made of 18-mil-thick glass-asbestos felt sheet which is fire resistant and water repellent with high wet strength characteristics. Under accident conditions the filters could be exposed to hot a1r, wet steam at $100^{\circ} \mathrm{C}$, or fog mixtures of steam, air, and entrained water particles. 
Commercially available particulate filters with a water repellent medium w1ll remove $99.9+\%$ of particulate matter from flowing air or other dry gases. Such fllters were known to be satisfactory for humid air, but were not designed for wet steam and/or fog. The wet strength characteristics of the various media were not known if the water load occurred after the filters accumulated dust from continuous service. To determine the maximum conditions of steam and fog filtration that newly developed filters could withstand with less than lo loss in efficiency, four types of tests were performed by $\operatorname{SRL}^{(3,4,5)}$ :

- Bench-scale tests with air, water, steam, and fos to screen candidate materials.

- Tests on clean filters with air-water spray, steam, and 10 days of fog.

- Tests on clean and dusty filters in series with "Demisters" with air-water spray, steam, and 10 days of fog.

- Dloctylphthalate (DOP) efficlency tests before and after the above tests on full-size units.

The most important tests were on full-size filters with and without "Demisters". The filters were exposed successively to:

- A burst of wet steam to about 10 times the normal air flow of $1000 \mathrm{cfm}$ for 30 seconds.

- A steam flow of twice the normal air flow for 5 minutes.

- Fog flow at about normal flow for 10 days.

The results of these tests showed:

- Filters with non-water-repellent media collapsed when exposed to steam and fog.

- Two types of commercially avallable filters with clean water-repellent media satisfactorily survived exposure to wet steam flow.

- Only one commercially available filter with clean water-repellent medium survived the entire sequence of tests.

- None of the filters survived the 10-day fog test when loaded with atmospheric dust and without a "Demister". 
Based on these tests, the best water-repellent filter was selected and extensively evaluated with clean and dusty media. with a "Demister" upstream. These tests demonstrated that the combination of "Demister" and particulate filter selected would withstand all the tests. These tests simulated the exposure conditions for any accident that would not significantly damage the reactor building. More severe conditions would be expected only when there is so much damage to the reactor bullding that no practical confinement system would work.

Significant design features and specifications for the waterrepellent particulate filters include:

- The filter is constructed by folding the felt sheet over corrugated aluminum inserts into closely separated pleats in a steel frame forming a unit 24 inches $\times 24$ inches $\times 11 \frac{1}{2}$ inches thick. The unit is deslgned for $1000 \mathrm{cfm}$ air at a pressure drop not exceeding 1.00 - inch $\mathrm{H}_{2} \mathrm{O}$ when clean.

- Each roll of medium must be qualified by the manufacturer by subjecting representative samples to tensile strength and elongation tests, both dry and wet, and with and without a flat fold in the medium.

- One full-size filter assembled from each roll of filter medium and selected randomly by a Du Pont inspector must pass the following sequence of tests:

a) $\Delta P$ across the filter must not exceed 4 times the normal when exposed to wet steam flow at twice normal flow and with water spray injected up. stream of filter for 15 minutes.

b) Flow resistance after drying must not exceed normal $\Delta \mathrm{P}$ at rated air flow.

c) The filter must not fail when exposed to a dust loading of 4 pounds at normal air flow.

d) The filter must not fail when subjected to a $\Delta P$ 6 times normal for 10 minutes.

e) Maximum penetration of DOP must not exceed $0.1 \%$ of 0.3- $\mu$ particles at rated air flow after completion of all sequence tests. 
- Each production unit is tested for pressure drop and DOP penetration by the manufacturer. DóP penetration shall not exceed $0.03 \%$ for $0.3-\mu$ diameter homogeneous particles at $20 \%$ and $100 \%$ of rated flow. Individual units are encapsulated during the test to permit detection of leaks in the gaskets and/or in the frame.

- After instaliation in the filter compartments, the units are tested with $0.6-\mu$ DOP prior to operation of the compartment. Any filter with a detectable leak (greater than 0.05\%) is replaced, because small holes may enlarge if the unit remains in service. The in-place DOP test is repeated annually to determine if leaks develop during service.

The gasket, adhesive, and binder in the particulate filter would begin to deterlorate at about $150^{\circ} \mathrm{C}$. However, the efficiency of the filters would not be affected because:

- Significant deterioration would not occur until after the fission products were confined.

- All components of the fllter are self-ext1nguishing.

- The strength of the filter is more than adequate to resist damage even without binder.

- Underwriters Laboratory tests showed that damage to the filter is negligible up to $370^{\circ} \mathrm{C}$.

Complete specifications for the water-repellenti particulate filters are presented in Appendix B. Operating experience is presented in Section $V$.

The in-place DOP test was modeled after the technique by the Naval Research Laboratory (NRL) ${ }^{(\theta)}$ and the Army Chemical Center. ${ }^{(7)}$ The DOP smoke generator was built to NRI specifications. The generator consists of a DOP container into which compressed air at $30 \mathrm{psig}$ is discharged through orlfices located in the liquid. The resulting DOP smoke (polydispersed aerosol with a mass mean diameter of approximately $0.6 \mu$ ) is discharged from the generator to the upstream face of the particulate filters. The air-DOP mixture is passed through the filters and then is analyzed for DOP by a Sinclair-Phoenix smoke penetrometer. Both the penetrometer and generator were calibrated at NRL. 


\section{4) Carbon Beds}

Activated carbon beds were designed to remove more than $99.9 \%$ of elemental lodine vapor that might be released from a reactor if an accident should occur. Numerous tests of small-scale carbon beds showed that more than $99.99 \%$ of elemental lodine vapor can be removed consistently with a l-inch-thick bed of new actlvated carbon of the type specified for SRP. (4,8) The tests were run under a wide range of conditions that included:

- Prefiltered fog mixtures (steam-air-entrained water particles) at $65^{\circ} \mathrm{C}$ and at face velocities to 80 feet per minute (normal face velocity is 65 feet per minute).

- Unfiltered fog mixtures with liquid water entrainment rates up to 5 times that expected downstream of the particulate filters, and with the carbon beds dry or saturated with liquid water.

- Steam at 70 feet per minute and from a wet condition at $100^{\circ} \mathrm{C}$ to superheated conditions at $130^{\circ} \mathrm{C}$.

- Air at 5 times the normal flow and at temperatures to $110^{\circ} \mathrm{C}$.

- Iodine loadings to 6 milligrams $I_{2}$ per gram of carbon.

Additionally, the tests demonstrated that mass transfer was the controlling mechanism for elemental iodine adsorption under SRP conditions. The results were correlated with the semiempirical equation for critical bed depth developed by Dole and $\mathrm{Klotz}^{(9)}$ and discussed in detail in Reference 8. As shown in Figure II-II, a bed depth of only 0.4 inch is required for an lodine removal efficiency of $99.99 \%$ at rated air flow. The design efficiency of $99.9+\%$ for the 1-inch-thick SRP bed is maintained at flows greater than 10 times the rated air flow, as shown in Figure 8 of Reference 8. A l-inch-thick bed was specified a.s an added measure of conservatism and to allow sufficient capacity for extended service life in the SRP confinement facilities.

No known commercial adsorber beds could satisfy the test requirements; hence, 1t was necessary for SRL to design and develop improved beds. The carbon beds developed by SRL and in use at SRP pass all of the above tests. The full-size unlt consists of a one-inch-thick bed of activated carbon enclosed between perforated metal sheets, as shown in Figure II-8. The carbon and frame 
are subjected to stringent tests by the manufacturer and SRI. Significant design features, shown in Figure II-12, and specifications of the unit currently specified include:

- Type 304L stainless steel construction to retard corrosion. (Beds currently in service are made with frames of cadmium-plated or painted mild steel. These have the same adsorption characteristics as those made of stainless steel, but they have a shorter life (see V,D). Beds made with stainless steel frames are now being installed in all filter compartments.)

- Rigid framing to prevent warping or buckling from mishandling and to withstand steam blasts to at least 10 times the normal air flow. No damage was sustained by either frame or carbon in an ll-day test w1th flowing steam-a1r mixtures.

- Spacing fingers external to the carbon bed to maintain the bed thickness at a minimum of 1 inch. Internal spacers are not used because flow channeling at the carbon-metal interface could occur, and spacers may interfere with obtaining a unfformly packed bed.

- 12 separate pleats to retard settling of the carbon during shipment or continuous exposure to flowing air for several years. The pleats are formed by 11 shielded baffles between two continuous sheets of perforated metal. Leaks are possible in units where each pleat is individually removable, but not where the unit is continuous. Shields direct the flow through a tortuous path in the curved portions of the units where minor settling may occur.

- Beds installed with pleats horizontal, to further minimize settling of carbon during service.

- A I-inch baffle at all sides of the bed formed by omitting perforations at the edge of metal sheet to prevent channeling at the carbon-gasket interface.

- Each carbon bed unit packed w1th about 57 pounds (minimum) of activated coconut shell carbon that is relatively dust free ( $97 \%$ hardness, (10) minimum). 
- The carbon packed with a gravity system in which the carbon falls a minimum distance of three feet before entering the bed. The bed is vibrated for $1-1 / 2$ minutes after the inftial loading operation. This method provides a high packing density and a more uniform distribution of the carbon particles.

- After packing, carbon fines and dust blown from each unit with compressed air at a mintmum nozzle velocity of 5000 feet per minute.

- A mesh distribution of $10 \times 14$, selected because tests showed that occasionally coarse particles could segregate with carbon containing a wider range of carbon particles, 1.e., mesh distribution of $6 \times 14$.

- A perforated face area of about 15 square feet that can pass 1000 scfm of air at a $\Delta P$ of about 0.8 -inch $\mathrm{H}_{2} \mathrm{O}$. The unit measures 24 inches $\times 24$ inches $\times 11 \frac{1}{2}$ inches.

- Physical and chemical tests of representative samples from each batch of carbon made and certified by the vendor.

- Carbon with an ignition temperature greater than $330^{\circ} \mathrm{C}$.

- Representative samples of the carbon submitted by the vendor to SRL for analysis. The carbon must remove 99.99\% of elemental lodine when exposed to fog at $65^{\circ} \mathrm{C}$ and flowing at a face velocity of 70 feet per minute and with an lodine loading of 1 milligram per gram of carbon.

- All units inspected by a Du Pont representative for quality construction and freedom from obvious and obscure flaws, before, during, and after charging with carbon. Particular attention is directed to construction details affecting quality of airtight seals and the carbon loading operation.

- Each unit tested for leaks with "Freon" by SRL prior to installation in the confinement sys.tem. Beds containing leaks greater than $0.1 \%$ of the total flow are unacceptable. Detalls of the preinstallation "Freon" test ${ }^{(I 1)}$ are given in section VI, A. 
- Carbon beds leak tested in place. The technique wa.s recently developed and demonstrated by SRL. "Freon$112 "$ is used as a tracer to determine if leaks exist in the carbon beds or at gasket surfaces. The test will be conducted on a routine basis. Additional details of the technique are given in section VI, A.

Activated carbon beds, as well as "Demlsters" and particulate filters, have neoprene gaskets which begin to deteriorate at about $150^{\circ} \mathrm{C}$. In the 1gnition test described in Section VI, D, 3 on a full-size prototype of the new SRP carbon bed, the neoprene gaskets were not significantly damaged by exposure to an air flow of $70 \mathrm{ft} / \mathrm{min}$ at $-280^{\circ} \mathrm{C}$ for 35 minutes.

Complete specifications for the activated carbon bed are presented in Appendix $C$. Operating experience is presented in Section V.

\section{d. Fans}

The exhaust fans (903) are belt-driven centrifugal fans with an electric motor drive. These fans remove the air from the reactor room, purification area, and -20 foot and -40 foot levels during normal operation and discharge it into the stack. During normal operation, two exhaust fans are on-line (in parallel) and one remalns on standby. The two operating fans can move the rated flow of $128,000 \mathrm{cfm}$ with a differentlal pressure of 5.9 inches $\mathrm{H}_{2} \mathrm{O}$. The fan suction pressure is normally -4 to -5 inches $\mathrm{H}_{2} \mathrm{O}$. The fan housings have a positive pressure rating of 10 inches $\mathrm{H}_{2} \mathrm{O}$ (about $0.4 \mathrm{psig}$ ), but gross fallure is unlikely at pressures below 1 psig.

Each exhaust fan has two separate power distribution systems; the electrical distribution systems for the reactor building and for the confinement substation. Either can be selected as a primary source. The systems are supplied by the area powerhouse (except for $C$ reactor) and outside area powerhouses ( $D_{2}$ O-Production Area and South Carolina Electric and Gas). Emergency AC power is also provided to the reactor bullding distribution system by diesels that start automatically if normal power falls. Automatic switching between normal and emergency power supplies provides a reliable power service to the fans.

\section{e. Stacks}

The exhaust air is discharged to a 200-foot-high stack. The stack is of concrete construction with a base I.D. of 17 feet $2 \frac{1}{4}$ inches and a top I.D. of 16 feet. 


\section{Flow-Pressure Drop Characteristics}

The design air flow for the exhaust ventilation system is $128,000 \mathrm{cfm}$. The total flow includes $37,700 \mathrm{cfm}$ from the reactor room, $26,300 \mathrm{cfm}$ from the purification area, and $64,000 \mathrm{cfm}$ from the -20 foot and -40 foot levels. Rated flow is achleved w1th two exhaust fans operating and four filter compartments containing clean filters on-line. Pressure losses in the system are summarized in Table II-7 for the design air flow.

Normally the reactor room is maintained at a negative pressure; however, if an accident should occur a positive pressure could persist for a few seconds. W1th positive pressure in the reactor room, considerably more air can be vented to the stack through the exhaust header. Figure II-9 shows the flow- $\Delta$ P characteristics of the exhaust ventilation system for the reactor room.

The discharge canal has a 12-inch water seal between the reactor room and the fuel disassembly area. If the reactor room pressure exceeds the value of the water seal, significant flow would be vented through the canal. Figure II-10 shows the calculated air flow through the canal for reactor room differentlal pressures to 5 psi.

\section{TABIE II-7}

\section{Pressure Losses in Exhaust Ventilation System at Rated Air Flow}

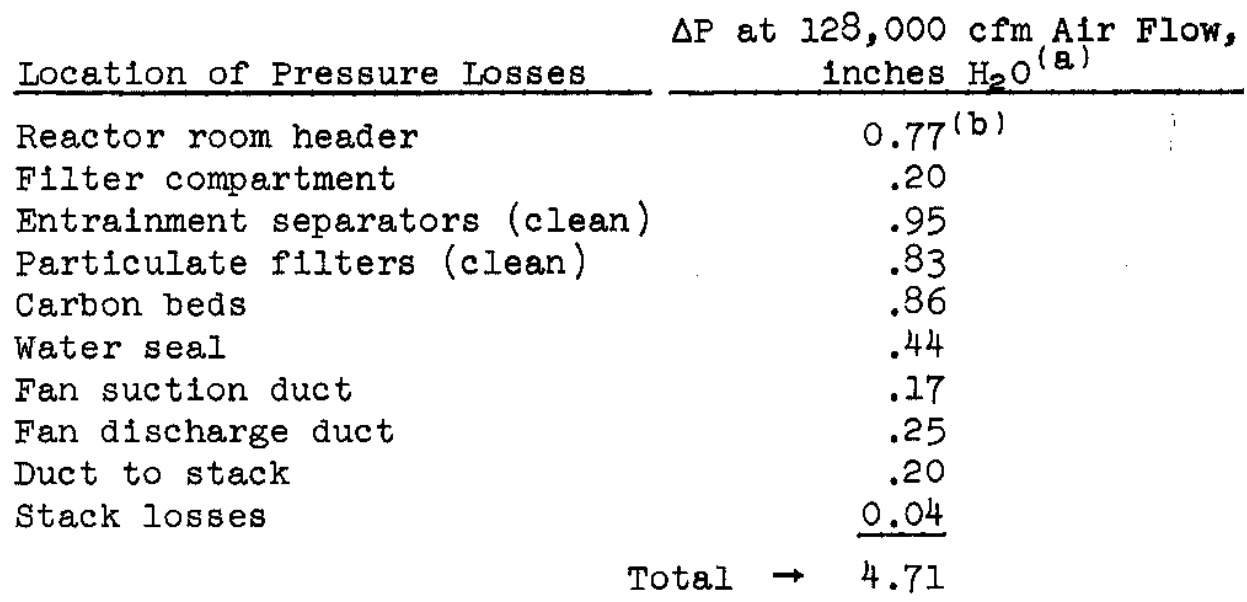

(a) For 4 filter comparments on-line with clean filters.

(b) For one reactor room header open with an air flow of $\sim 38,000 \mathrm{cfm}$, measured in R-Reactor Area and confirmed in C-Reactor Area test. 
For the worst postulated accident, the maximum pressure in the reactor room would be 1.9 psig. Air would be vented at a maximum rate of about $300,000 \mathrm{cfm}$ each through the exhaust header and the discharge canal. The analysis was based conservatively on air flow through all vent paths, 1.e., vent flow would be about 1.4 times greater for steam flow (no credit was taken for heat transfer to the building during the transient). As shown in Table II-2, no damage to the reactor bullding or activity confinement system would be expected. The exhaust fans would quickly reduce the reactor room pressure to a negative value and no release of activity would be expected, as discussed in section II, C.

Accumulation of dust on the molsture separators and particulate filters causes an increase in their $\Delta P$ and reduces the total ventilation system air flow. Total air flows of about 85,000 to 90,000 cfm have been experienced during normal operation. The increased resistance would not decrease significantly the vent flow during an accident. Reduced air flow during normal operation does not affect the ability to maintain a negative pressure in the process areas. A test in $C$ Reactor showed that a total exhaust system air flow of about $10,000 \mathrm{cfm}$ can maintain the process areas at a negative pressure.

Contaminated air leakage is negligible between the exhaust fans (903) and the base of the stack. Two heavy-duty, flanged joints per fan are located between the fan discharge and the heavy-walled, concrete duct to the stack. Each exhaust fan (903) is in a separate room and the flanges are within the rooms. An air flow of about $2000 \mathrm{cfm}$ is drawn from the room through the blast gates on the suction side of the fans. Alr also flows into the fan rooms from the adjacent bullding corridor. During normal operation, the differential pressure between the fan discharge and the surroundings is less than 0.5 inch $\mathrm{H}_{2} \mathrm{O}$. The reinforced concrete duct leading to the base of the stack is 12 inches thick; it is connected to the stack by steel plates embedded in both the stack and the duct and covered with aditional concrete.

\section{E. EQUIPMENT OPERATION}

The SRP filtration-adsorption system is continuously on-ilne during normal operation and requires no manual or automatic operating action when an emergency occurs. Exhaust a1r from process areas normally passes through the filters and adsorbers and w11l continue to do so after an accident. In addition, 
certain failures can occur but protection from a release of particulate or halogen activity will be maintained without action by the operator. These include:

- Failure of one exhaust fan. Two fans operate continuously, but only one is required to maintain a satisfactory exhaust rate.

- Failure of process room seals. The large exhaust air rate ensures that there will be inleakage of air even if a large number of seals fail.

- Failure of a source of electrical power. The exhaust fans can be operated by electrical power from any of two or three sources of power from outside the reactor building fed through either of two substations (normally each operating exhaust fan is fed from a different source of power and a different substation), or from an emergency, diesel-powered AC generator within the reactor bullding. Switching among the various sources of power is automatic.

Following an accident, it is planned to operate the exhaust ventilation system at full flow. Careful consideration was given to the possibility of reducing ventilation flow after an accident for the following reasons:

- To increase the decay time of noble gas activity before it is discharged from the stack.

- To increase the length of time during which noble gas activity is released so that if the winds are variable, the activity would be spread over a wider area.

It was decided not to reduce the flow for the following reasons :

- High flow provides more positive assurance of negative pressure in the process areas.

- More cooling is provided for the carbon beds.

- A shorter residence time will minimize deposition of lodine on surfaces and formation of methyl lodide. 
- There is additional margin for error at high flow (a fan fallure is not as serious).

- There is less likelihood of a mistake being made if no action has to be taken.

A large number of additional actions can be taken by an operator during an emergency to provide backup protection or to counteract additional failures. Control is possible either in the reactor building central-control room or in the remote control station located about 10 miles from the reactors. Some of the possible emergency actions are described below.

The operator has avaliable a large number of instruments and alarms to provide him with the data needed to follow the proper procedure. For the ventilation system some of these located both in the reactor building and in the remote control center are:

- Fan condition (on or off) - an alarm indicates fan failure

- Filter outlet damper position (open or shut)

- Stack total and Kanne activities

- Activity of the effluent from each filter compartment

- Activities on filters and adsorbers

- Various water activities

- Outlet temperature for each filter compartment.

Ventilation system actions that the operator can take in elther the reactor building or in the remote control station include:

- Starting or stopping any of the main exhaust (903) fans (one spare is normally avallable for starting if one of the two operating fans fails).

- Opening or closing the damper downstream of any of the five filter compartments. If a high compartment effluent act1vity indicates breakthrough or if high effluent temperature indicates fire, the downstream dampers can be closed to prevent loss of activity on the filter or carbon beds. 
In addition to the above control actions that can be taken in elther control location, any of the many system dampers, supply fans, or other exhaust fans can be controlled from the reactor building.

In addition to the specific controls listed above, a master incident switch in either the reactor central control room or in the remote control center can be manualiy activated when an emergency occurs. This switch does the following:

- Actuates the light water addition system to provide emergency cooling to the fuel if needed to reduce the likelihood of excessive heating of the ventilation air from fuel decay heat.

- Isolates purification water and gas systems to prevent a spread of activity from the main reactor piping complex. (This action also occurs automatically whenever there is an indication of high activity in the $\mathrm{D}_{2} \mathrm{O}$ or helium lines from purification.)

- Stops the supply a1r fans (902) to prevent an outleakage of air in case the exhaust fans should fall and to provide better assurance of negative pressure in the process areas. This function has not yet been added, but is planned.

- Actuates various other actions associated with disposition of contaminated water and sources of emergency light water.

\section{F. CONTAMINATED WATER RETENTION SYSTEM}

Contaminated water could be discharged into the reactor bullding from process line breaks, rupture of the reactor tank, or addition of emergency light water. Most of the water released above zero level in the reactor room flows through a floor drain directly to the 50-miliion galion basin. Other sources elther drain directly or indirectly to the -40 foot level. When sufficlent flooding of the reactor bullding has raised the water level to the -5 foot level (6-7 mililon gallons for $L, K$, and $C$ reactor bulldings and 15-16 million gallons for $P)$, the water flows by gravity into the retention basin. One basin is located at each reactor area and each basin covers about $4 \frac{1}{2}$ acres. The drain line is capable of handling $4000 \mathrm{gpm}$ when only half filled. 
The purpose of the retention basin 1s twofold:

- To retain part of the contaminants in the basin.

- To delay the release of fission products, so that measures can be taken to prevent their release to the ground water or river.

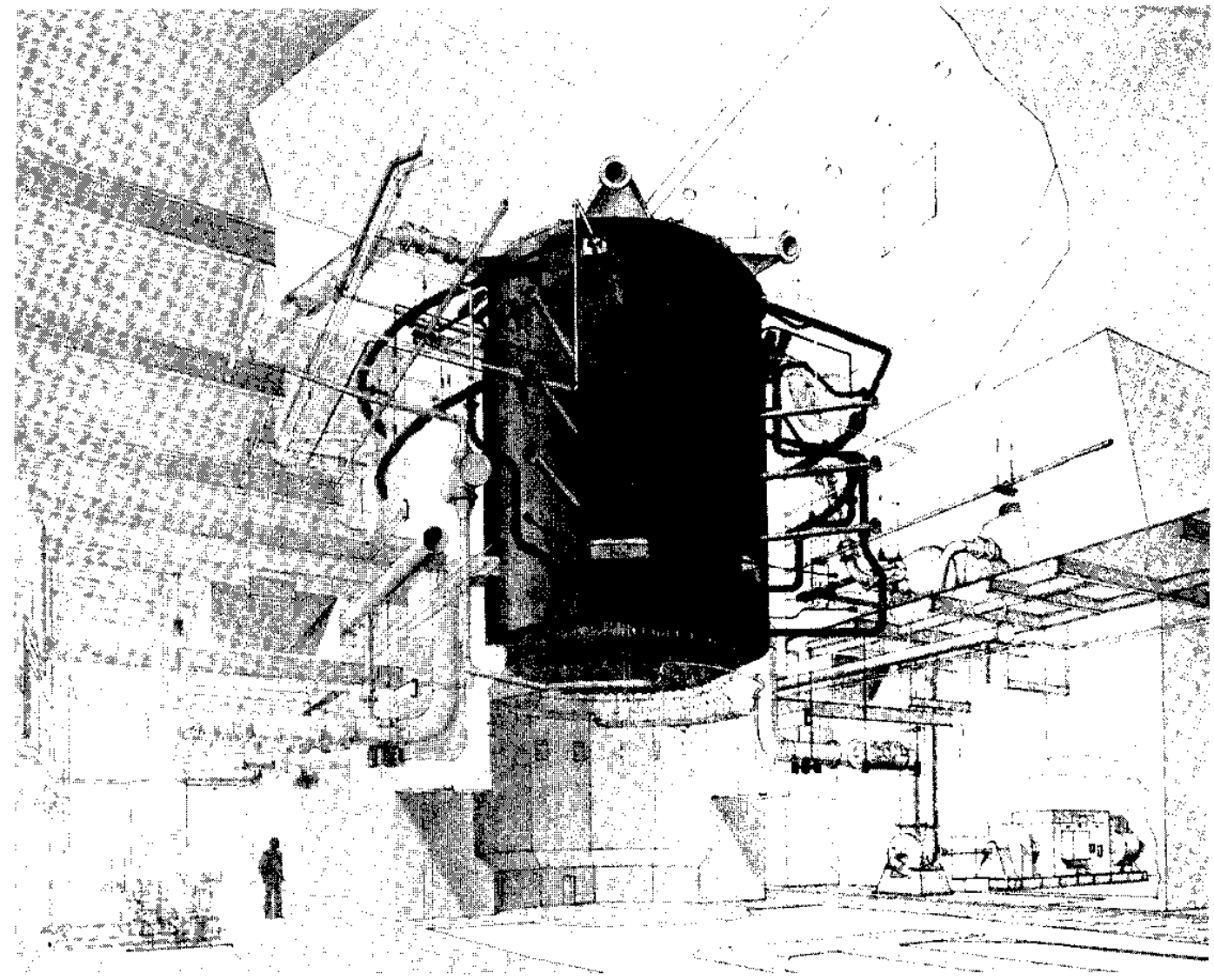

FIG. II.1. SAVANNAH RIVER REACTOR 


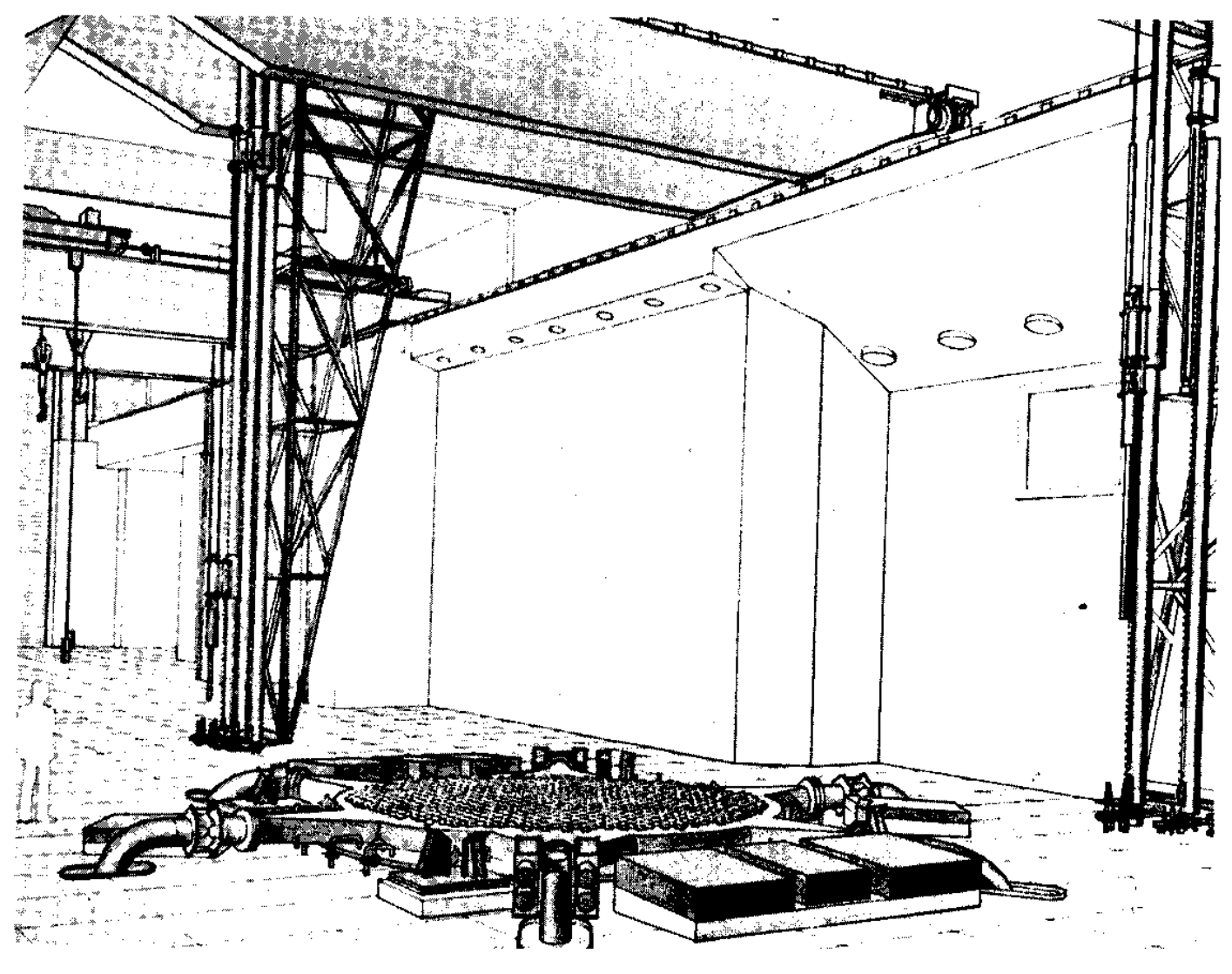

FIG. II-2 SAVANNAH RIVER REACTOR ROOM 


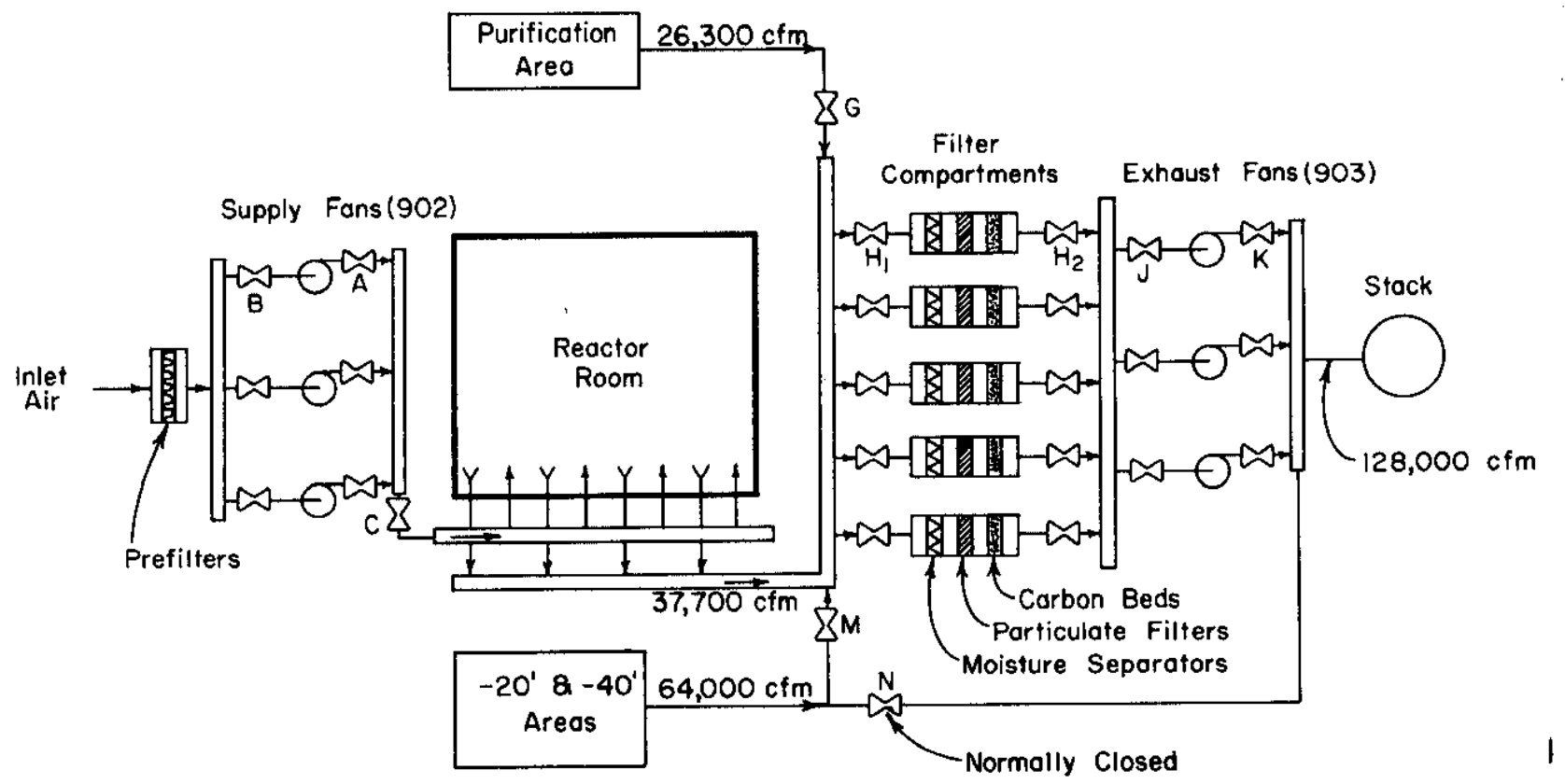

FIG. II-3 FLOW DIAGRAM OF REACTOR VENTILATION SYSTEM 


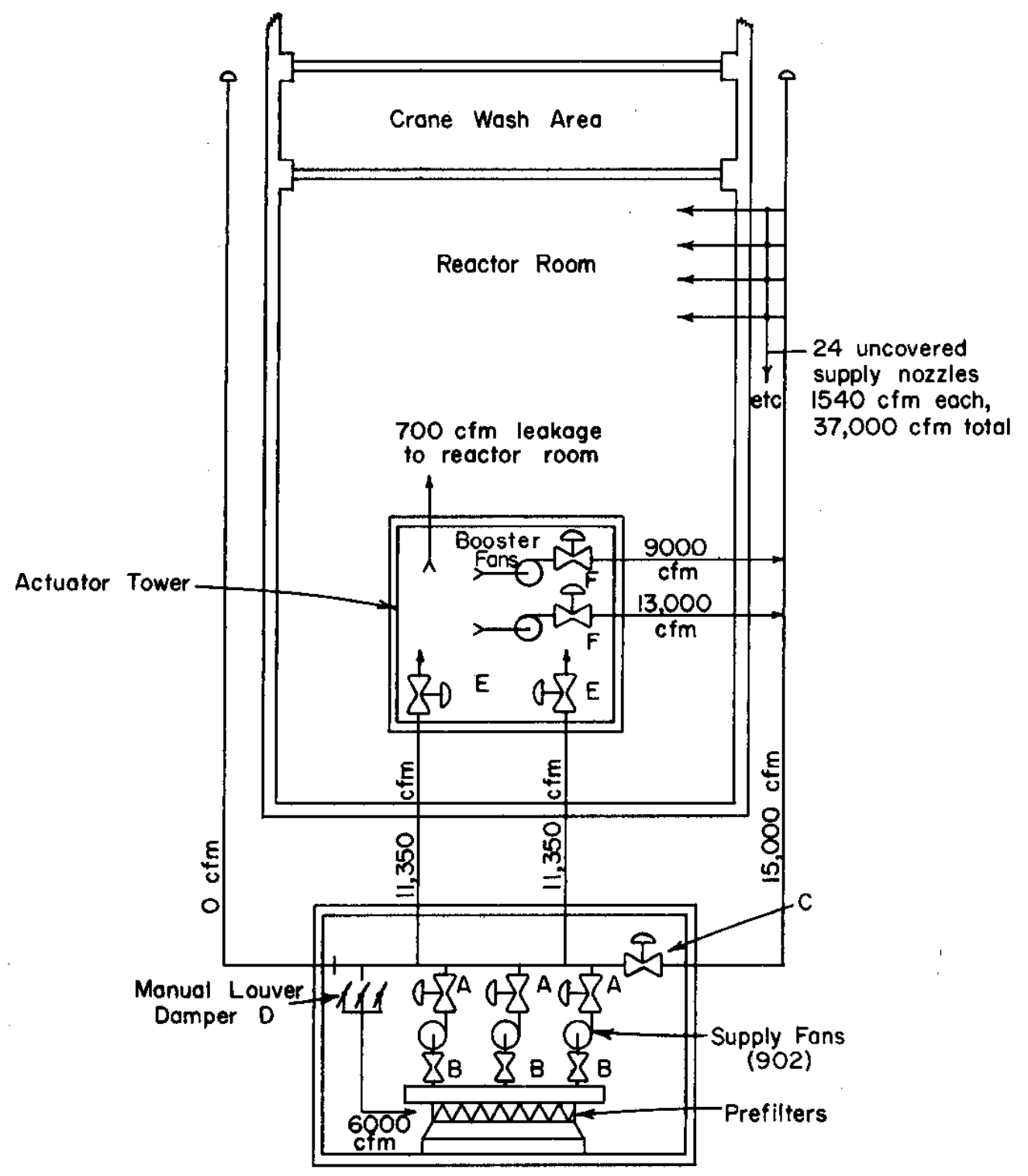

FIG. II-4 REACTOR ROOM SUPPLY AIR SYSTEM 


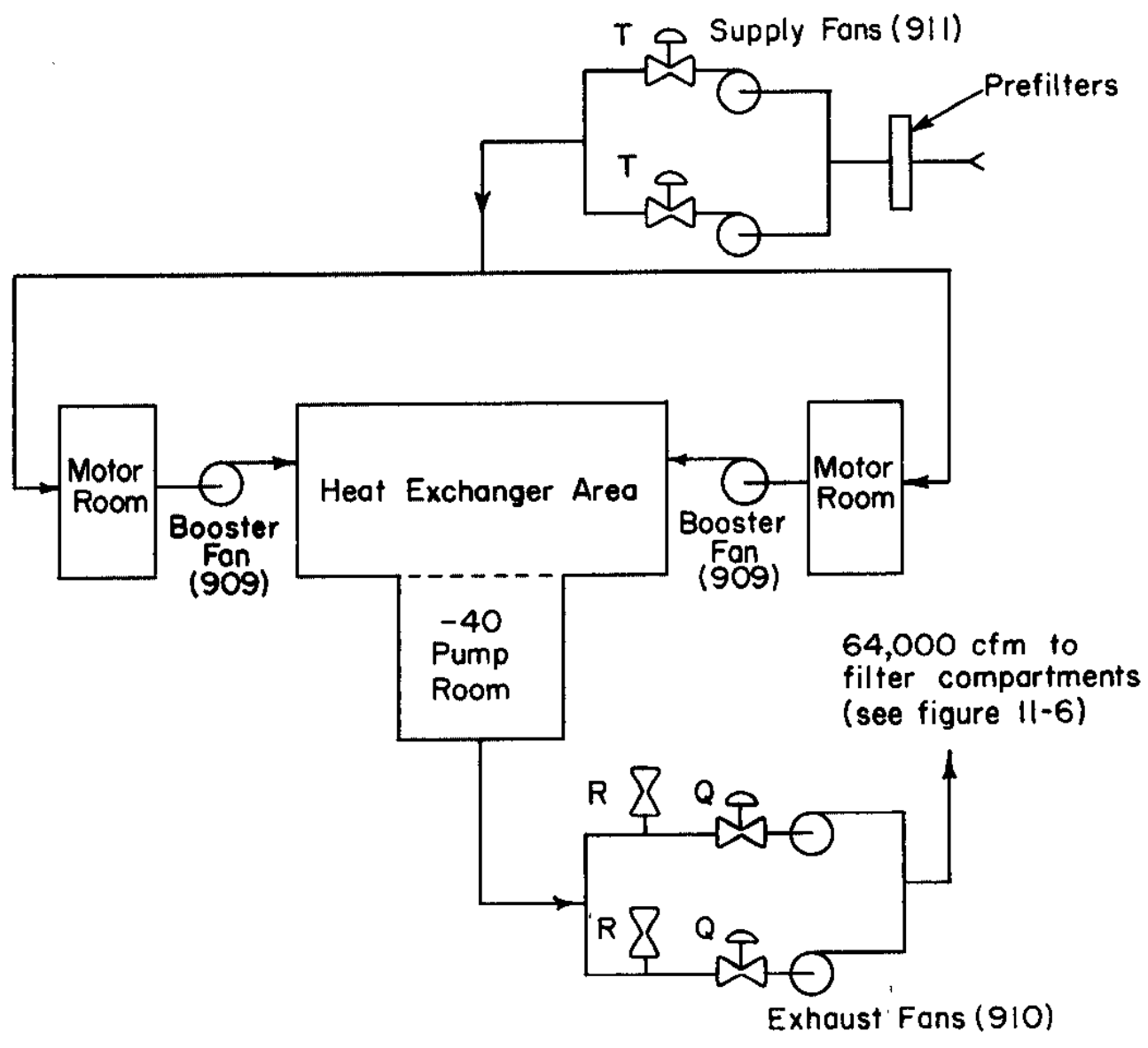

FIG. II-5 VENTILATION SYSTEM FOR -20 FT AND -40 FT LEVELS 


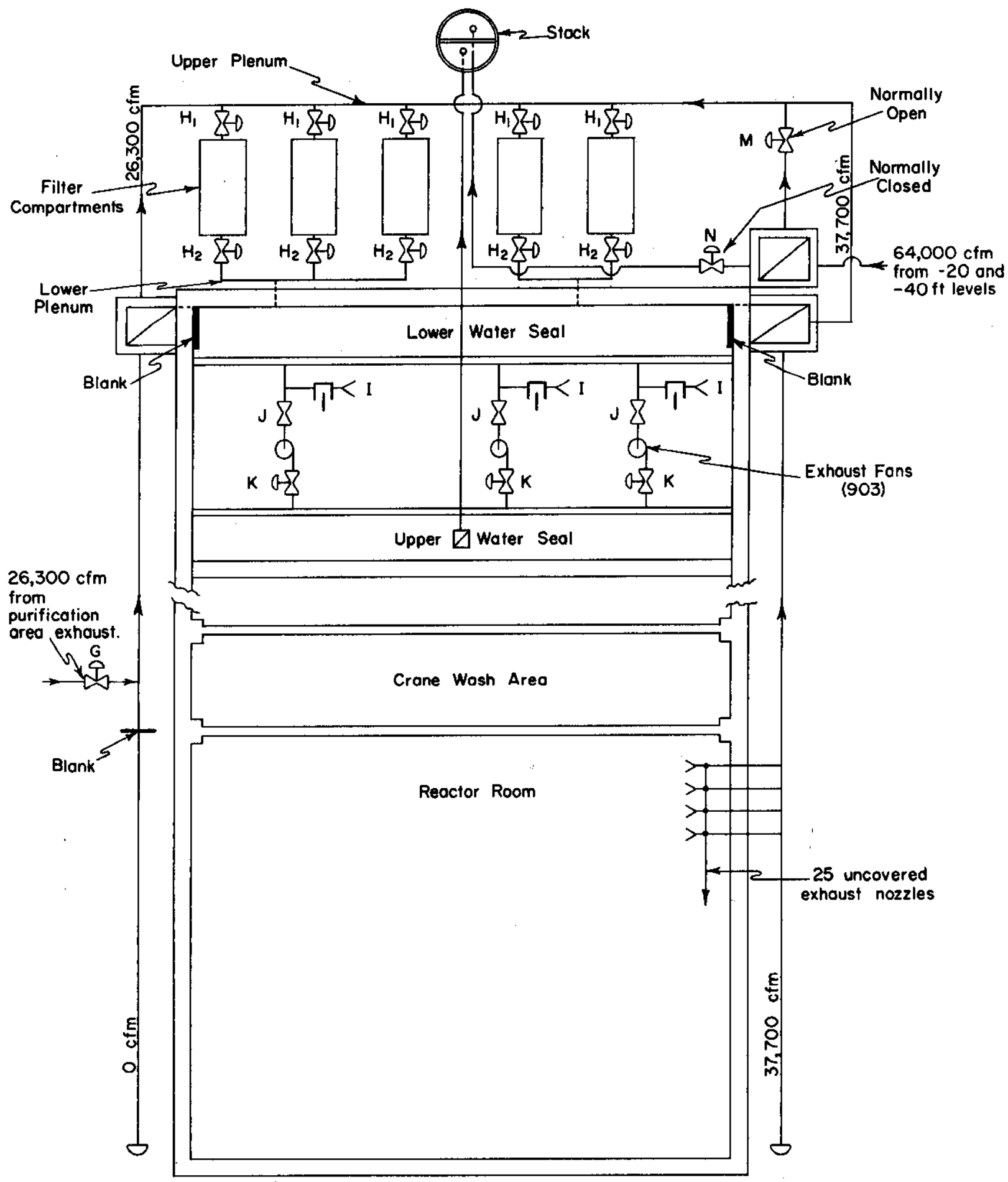

FIG. II.6 PROCESS AREA EXHAUST AIR SYSTEM 


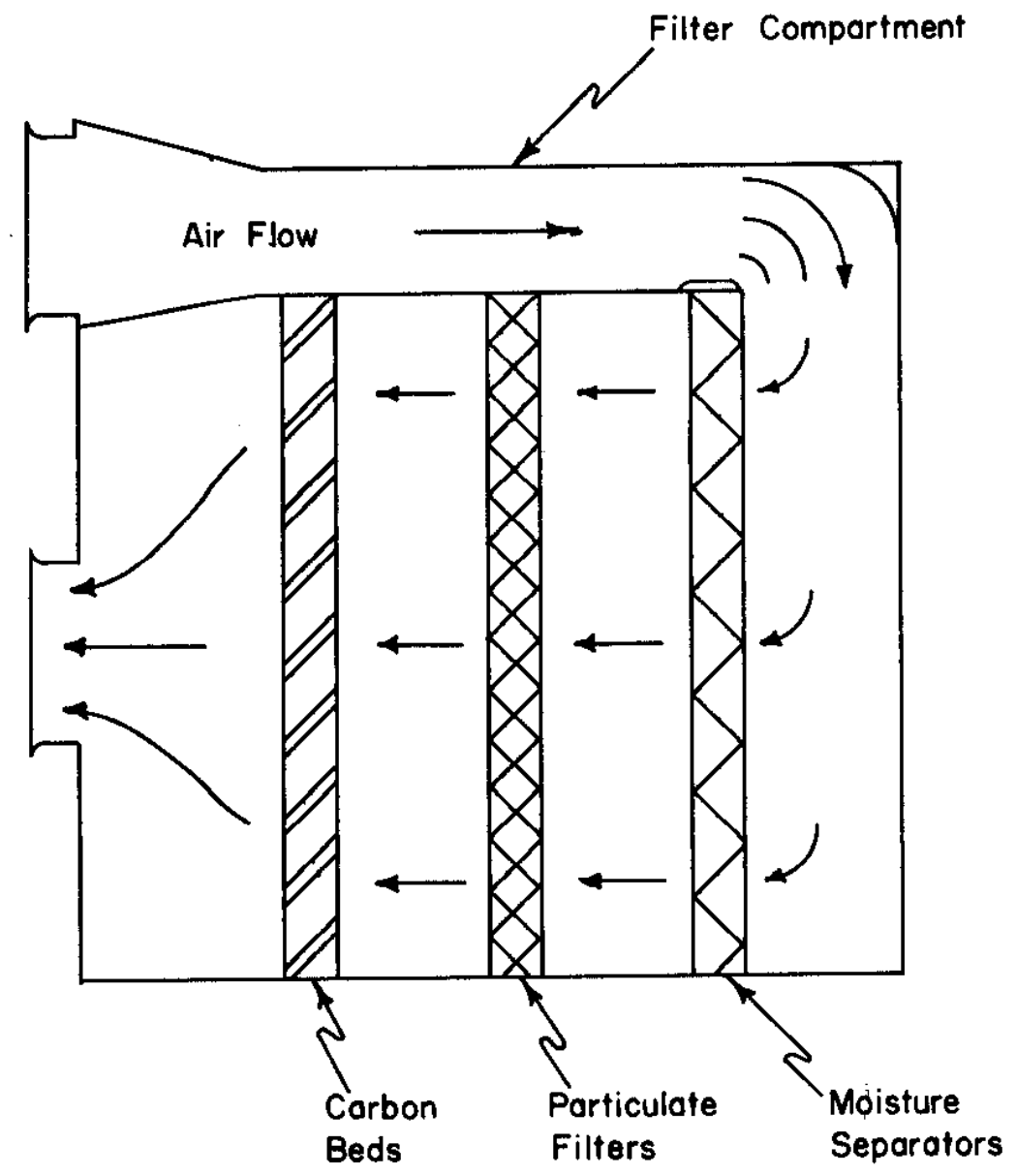

FIG. II-7 FILTER COMPARTMENT

(Elevation Cross Section) 


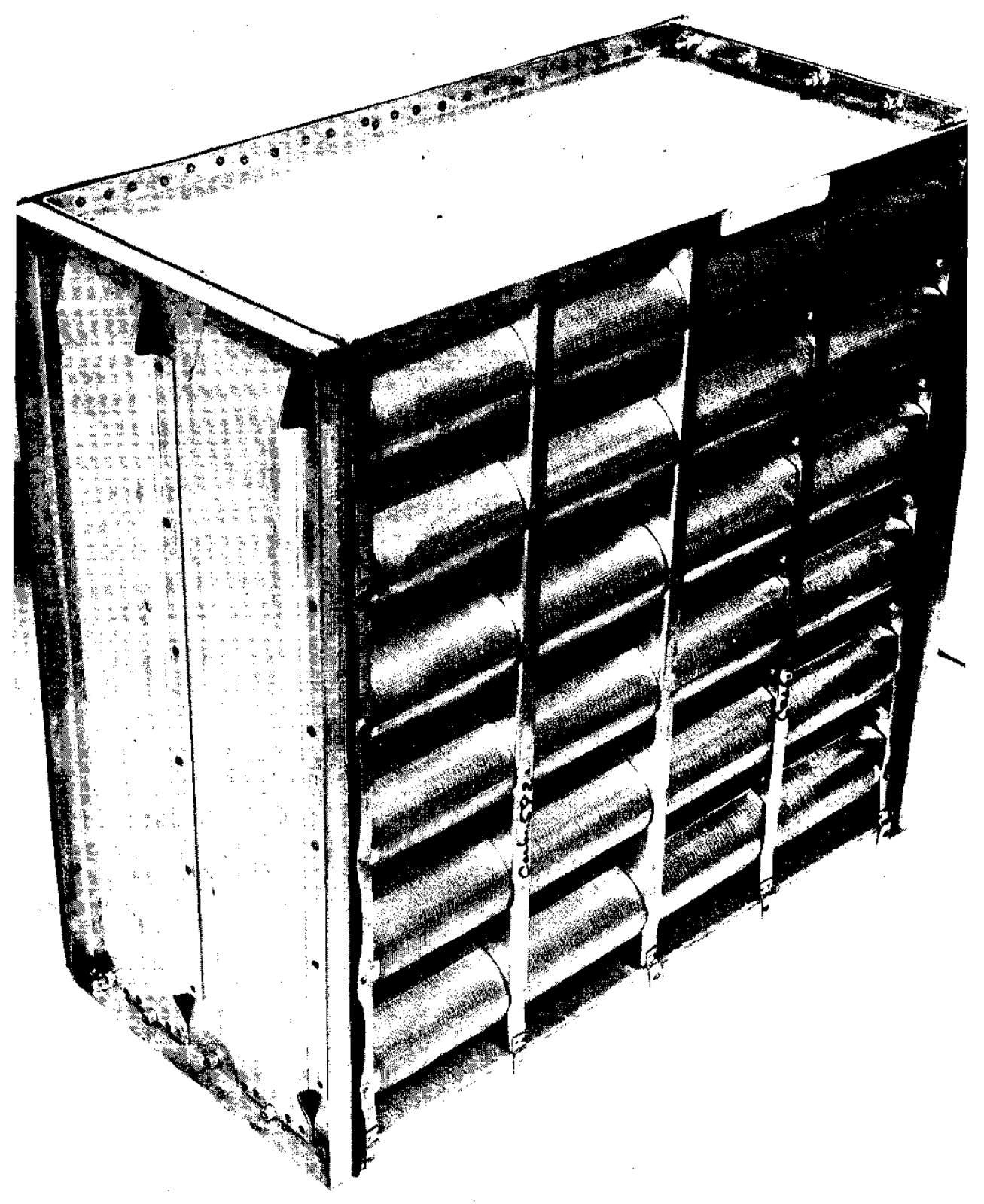

FIG. II-8 ACTIVATED CARBON BED FRAME 


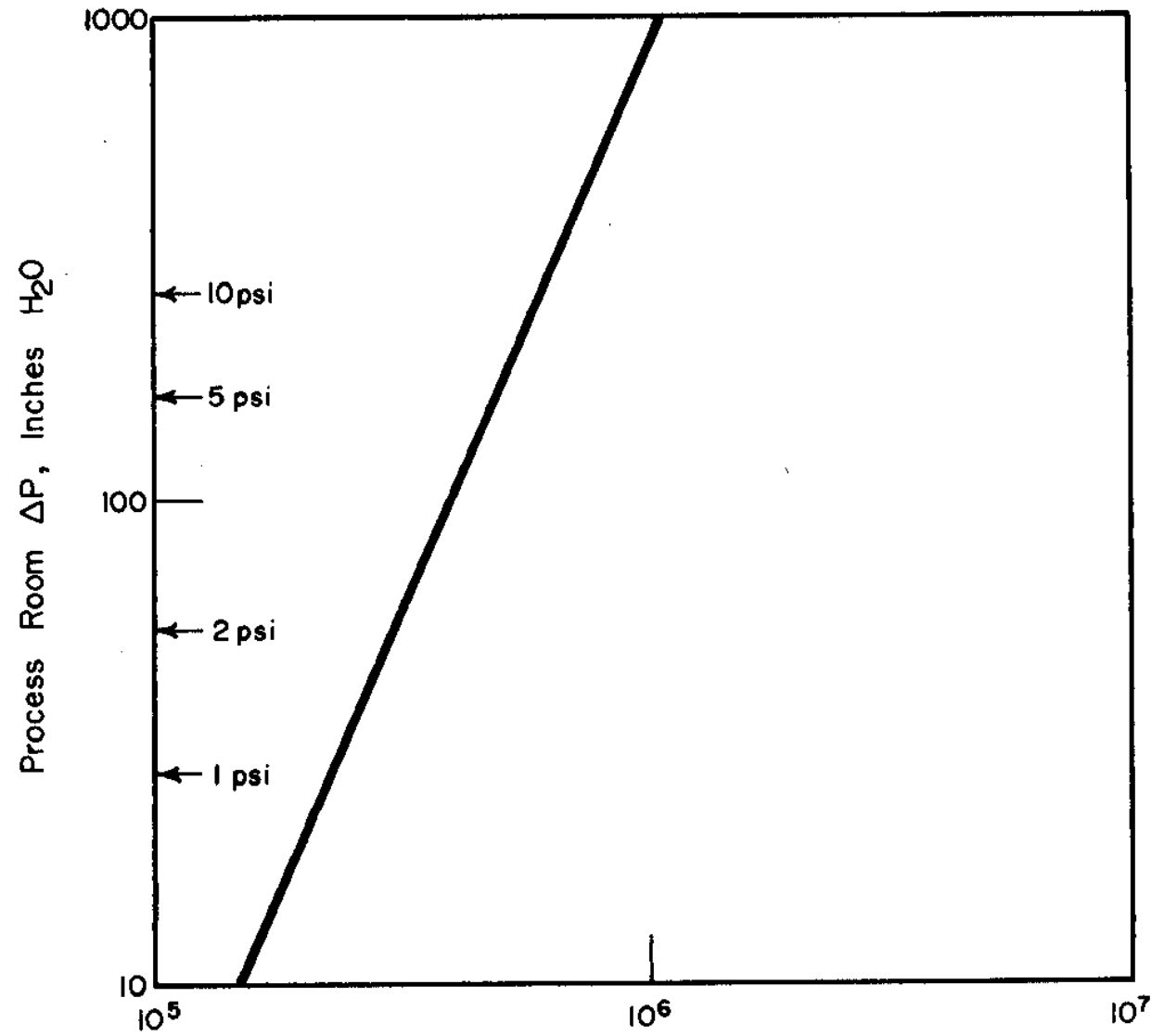

Process Room Exhoust Air Flow to Stacks, cfm (steody state)

\section{Bases:}

- Air flow at 15 $5^{\circ} \mathrm{C} \& 50 \% \mathrm{rh}$ and 14.7 psia

- Four filter compartments on line with clean filters

- One reactor room header on line

FIG. 11.9 EXHAUST RATE FROM REACTOR ROOM TO STACK 


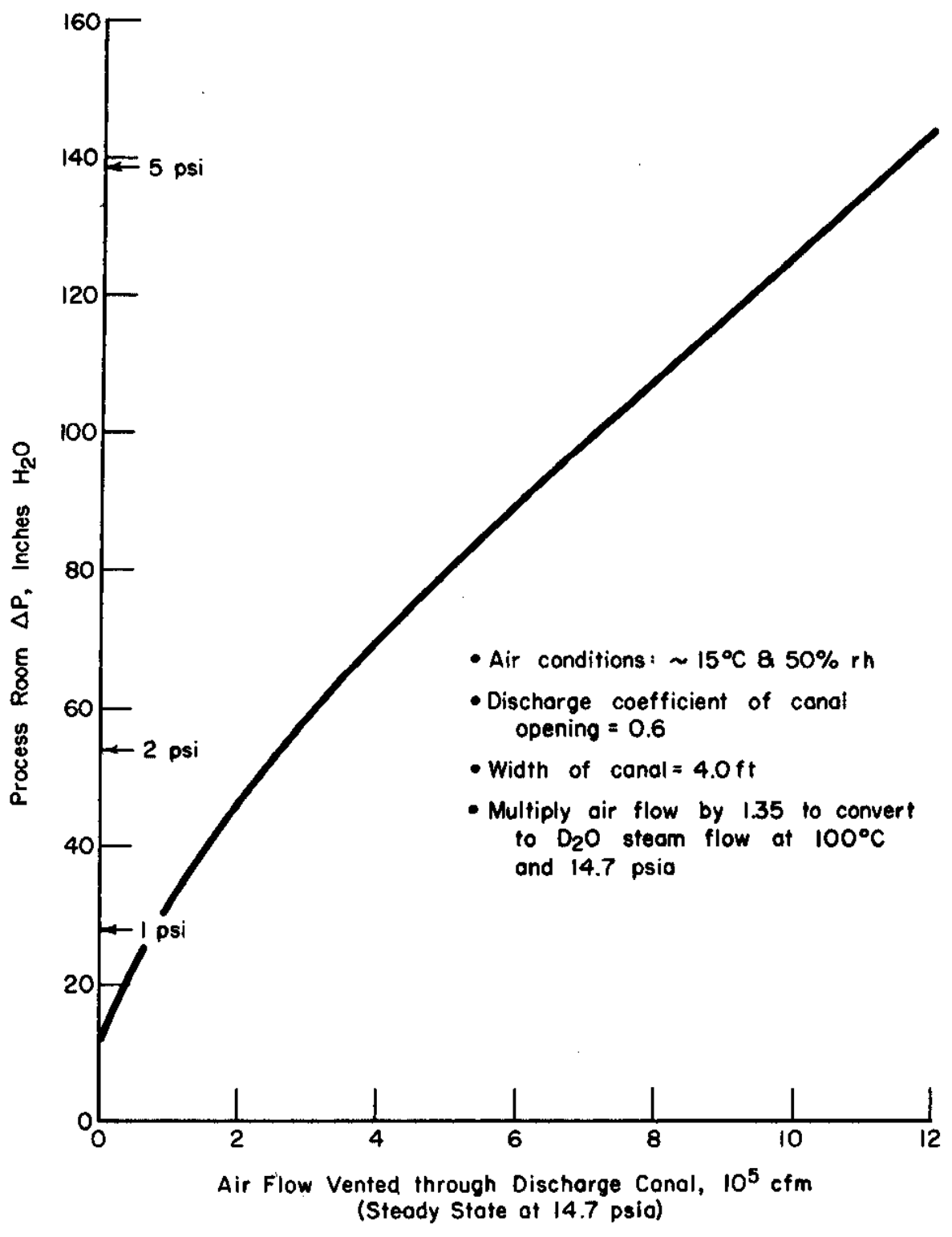

FIG. II-10 VENT RATE THROUGH DISCHARGE CANAL 


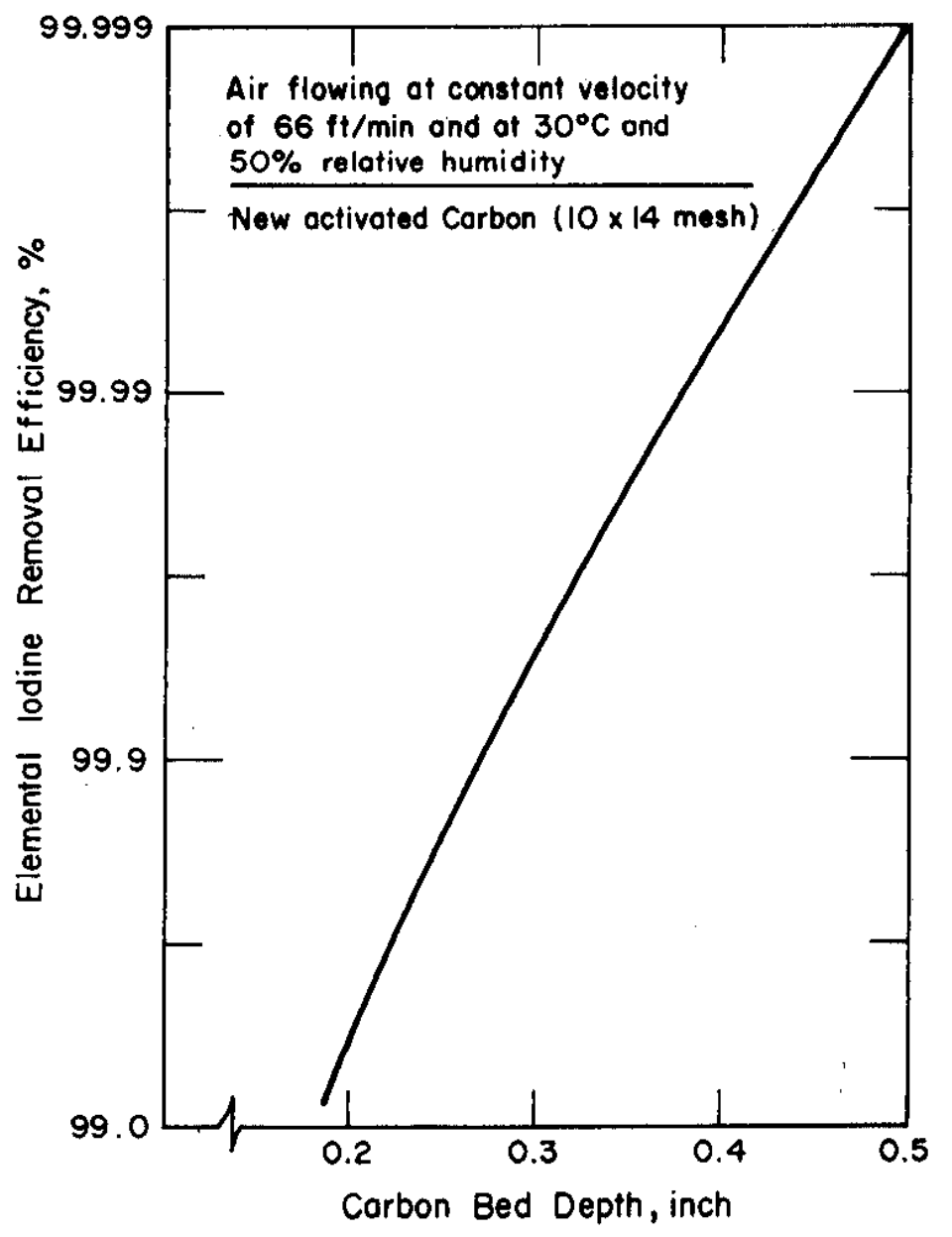

FIG. $11-11$ EFFECT OF BED DEPTH ON CALCULATED EFFICIENCY OF CARBON BEDS FOR REMOVING ELEMENTAL IODINE VAPOR (Reference 8 ) 


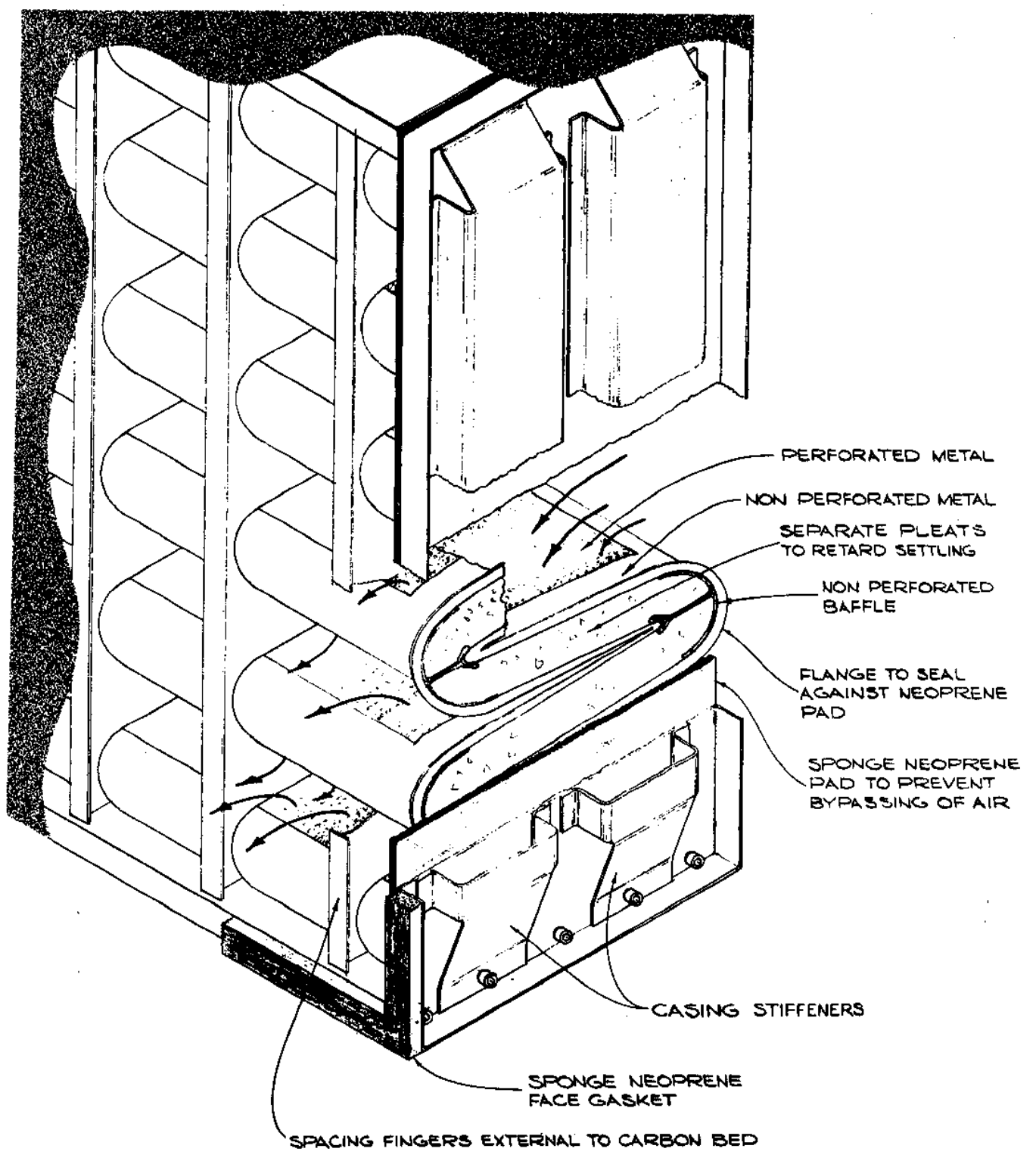

FIG. II-12 SECTIONAL SCHEMATIC OF SRP ACTIVATED CARBON BED 


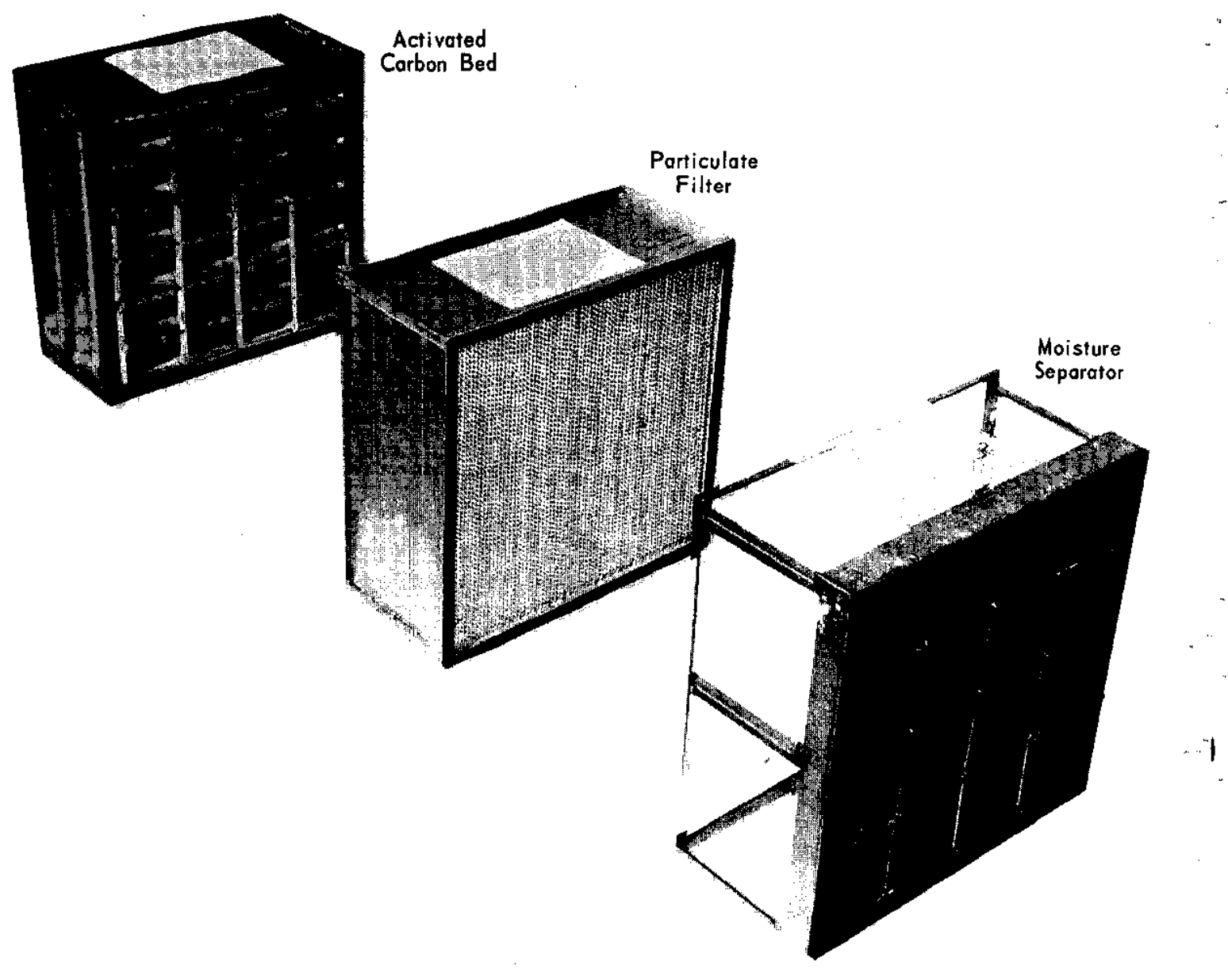

FIG. II-13 SAVANNAH RIVER PLANT FILTRATION-ADSORPTION UNITS

II-36 


\section{KINETICS OF IODINE COMPOUND FORMATION AND IODNNE TRANSPORT}

In tests at other sites several species of radiolodine were identified in experiments that were designed to determine the chemical form of radiolodine that is released from irradiated fuel under accident conditions. $(12,13,14)$ Radiolodine in exhaust gases and on surfaces of equipment was identifled $(12,13,15,16)$ as both inorganic compounds, such as elemental lodine $\left(I_{2}\right)$ and hydrogen lodide (HI), and as organic compounds. Several organic compounds were detected, but methyl lodlde was the chief organic constituent (about 90\%). The fraction of the lodine inventory that appeared as methyl iodide was usually very small, but varied widely under different conditions.

The inorganic species of radiolodine ( $I_{2}$ and $H I$ ) are very reactive and are removed and retained from alr streams by activated carbon with extremely high efficlency, even under adverse conditions. On the other hand methyl lodide, which is less reactlve than elemental lodine, is removed by activated carbon with less efficlency than lodine, especially from very humld air streams. No penetration of higher homologues of alkyl lodides has been reported in the literature. A knowledge of methyl iodide behavior is necessary therefore for evaluating its likelihood of formation.

The formation and decomposition of methyl lodide under reactor accident conditions are very complex problems. Four aspects of this problem will be treated in greater detall in section III, A, "Kinetics of Formation of Iodine Compounds":

- Formation of Iodine Compounds in Fue1

- Formation of Iodine Compounds Upon Meltdown

- Formation of Iodine Compounds in the Gas Phase Outside Reactor Vessel

- Formation of Iodine Compounds on Surfaces Outside Reactor Vessel

At present, the precise mechanism for the formation of methyl lodide has yet to be demonstrated, but some experimental evidence exists for the mechanism. This information was combined with thermodynamic and kinetic data in the literature to evaluate the formation of methyl iodide under different conditions. These rates of formation are calculated for ideal conditions. The rates probably would be significantly less under actual reactor conditions.

The information in Section III,A is a general presentation for water-cooled reactors, but the information also has general application for other types of reactors. 
Application to the SRP reactors of established theory, existing experimental data, and a correlation developed by SRL for surface reactions involving methane and lodine is presented in Section III,B. In Section III,C, analyses of fission product transport and deposition are presented.

\section{A. KINETICS OF FORMATION OF IODINE COMPOUNDS}

1. Formation of lodine Compounds in Fuel

Uranium metal (U), uranium-aluminum alloy (U-AI), and uranium oxide $\left(\mathrm{UO}_{2}\right)$ used as fuel in nuclear reactors contain trace amounts of impurities. Two of the impurities, uranium hydride and uranium carbide, produce some hydrogen gas and carbon during irradiation which can react to form small amounts of organic compounds, such as methane $\left(\mathrm{CH}_{4}\right)$, inside the fuel. These compounds can react with lodine, formed during fission, to produce compounds of iodine, such as methyl lodide $\left(\mathrm{CH}_{3} \mathrm{I}\right)$. In uranium metal used at SRP, the hydrogen content averaged about $1.3 \mathrm{ppm}$ by weight and the carbon averaged about $550 \mathrm{ppm}$. If all the hydrogen reacted with carbon, $5 \mathrm{ppm}$ methane would form. In uranium oxide evaluated at SRP, the hydrogen content averaged about $0.5 \mathrm{ppm}$ by weight and the carbon averaged $50 \mathrm{ppm}$. If all of the hydrogen $(0.5 \mathrm{ppm})$ reacted with carbon, 2 ppm methane would form, as follows:

$$
\mathrm{C}+2 \mathrm{H}_{2} \rightleftharpoons \mathrm{CH}_{4}
$$

Methane can exist thermodynamically at the conditions inside a fuel element during irradiation. Methane was measured in fission gases that were removed from $\mathrm{UO}_{2}$ fuel after irradiation at SRP. The methane averaged $0.02 \mathrm{cc}$ per $\mathrm{kg} \mathrm{UO} \mathrm{U}_{2}(0.014 \mathrm{ppm}$ by weight) and ranged up to $0.05 \mathrm{cc}$ per $\mathrm{kg} \mathrm{UO} \mathrm{UO}_{2}(0.035 \mathrm{ppm}$ by welght) depending upon the irradiation conditions. These experiments demonstrated that far less than 2 ppm methane would form as expected, because of the immobility of the reactants and because other reactants compete for the carbon and the hydrogen, for example:

$$
\begin{gathered}
\mathrm{C}+\mathrm{U} \rightleftharpoons \mathrm{UC} \\
3 \mathrm{H}_{2}+2 \mathrm{U} \rightleftharpoons 2 \mathrm{UH}_{3} \\
\mathrm{H}_{2}+2 \mathrm{I} \rightleftharpoons 2 \mathrm{HI}
\end{gathered}
$$

The amount of hydrogen and carbon avaliable to react to form methane can be calculated with the knowledge of the various equilibria and equilibrium constants. Methane was not measured in uranium metal nor uranium-aluminum alloy, so the amount of methane in these fuels was inferred from the $\mathrm{UO}_{2}$ data. Methane 
formation in metal fuel is probably lower than in oxide fuel because of reduced moblitity of carbon and hydrogen at the lower temperature of Irradiation.

Methane can react with radiolodine formed by fission to produce methyl lodide $\left(\mathrm{CH}_{3} \mathrm{I}\right)$ and hydrogen lodide (HI) inside the fuel.

$$
\mathrm{CH}_{4}+\mathrm{I}_{2} \stackrel{\mathrm{V}_{1}}{\longrightarrow} \mathrm{CH}_{3} \mathrm{I}+\mathrm{HI}
$$

The reaction will occur at a velocity $V_{1}$ which is equal to the product of the specific reaction rate constant $k_{1}$ (a function of temperature) and the concentrations of methane and lodine.

$$
\mathrm{v}_{1}=\mathrm{k}_{1}\left[\mathrm{CH}_{4}\right]\left[\mathrm{I}_{2}\right]
$$

Brackets symbolize concentrations of the reactants. Methyl lodide and the hydrogen lodide formed by reaction (5) also react to form methane and lodine,

$$
\mathrm{CH}_{\mathbf{3}} \mathrm{I}+\mathrm{HI} \stackrel{\mathrm{V}_{2}}{-} \mathrm{CH}_{4}+\mathrm{I}_{2}
$$

at a velocity $V_{2}$ that is equal to the product of the specific reaction rate constant, $k_{2}$ (a function of temperature), and the concentrations of methyl lodide and hydrogen lodide:

$$
\mathrm{V}_{2}=\mathrm{k}_{2}\left[\mathrm{CH}_{3} \mathrm{I}\right][\mathrm{HI}]
$$

At a flxed temperature and at equilibrium, the forward and reverse velocities will be equal,

$$
\mathrm{V}_{1}=\mathrm{V}_{2}
$$

and

$$
\mathrm{k}_{2}\left[\mathrm{CH}_{4}\right]\left[\mathrm{I}_{2}\right]=\mathrm{k}_{2}\left[\mathrm{CH}_{3} \mathrm{I}\right][\mathrm{HI}]
$$

so,

$$
\frac{\mathrm{k}_{1}}{\mathrm{k}_{2}}=\frac{\left[\mathrm{CH}_{3} \mathrm{I}\right][\mathrm{HI}]}{\left[\mathrm{CH}_{4}\right]\left[\mathrm{I}_{2}\right]}
$$

At a fixed temperature and at equilibrium, the concentration of each of the reactants and products will be constant, and the ratio of the product of concentrations of products to the concentrations of reactants will be a constant. The latter term is called the equilibrium constant, $\mathrm{K}$ : 


$$
\mathrm{K}=\frac{\left[\mathrm{CH}_{3} \mathrm{I}\right][\mathrm{HI}]}{\left[\mathrm{CH}_{4}\right]\left[\mathrm{I}_{2}\right]}
$$

Thus, with knowledge of the equilibrium constant over the temperature range of interest, one can calculate the concentration of methyl lodlde for various concentrations of reactants:

$$
\left[\mathrm{CH}_{3} \mathrm{I}\right]=\frac{\mathrm{K}\left[\mathrm{CH}_{4}\right]\left[\mathrm{I}_{2}\right]}{[\mathrm{HI}]}
$$

The equilibrium concentration of methyl 1odide was calculated as a function of the average bulk temperature of uranium fuel for a range of methane, lodine, and hydrogen lodide concentrations from measured equilibrium constants. (17) In this calculation, the effect of metals (uranium fuel and aluminum cladding) on the equilibrium was neglected. The effect of metals such as uranium would be to reduce the equilibrium concentration of methane, because uranium metal reacts with carbon to form uranium carbide which is a very stable compound at reactor fuel temperatures (uranium carbide is used for nuclear reactor fuel). Direct combination of carbon with hydrogen to form methane, and diffusion of methane throughout the fuel were assumed. The data are summarized in Figure III-1. The maximum amount of the lodine inventory that theoretically can be converted to methyl lodide based on total conversion of hydrogen to methane is summarized as follows:

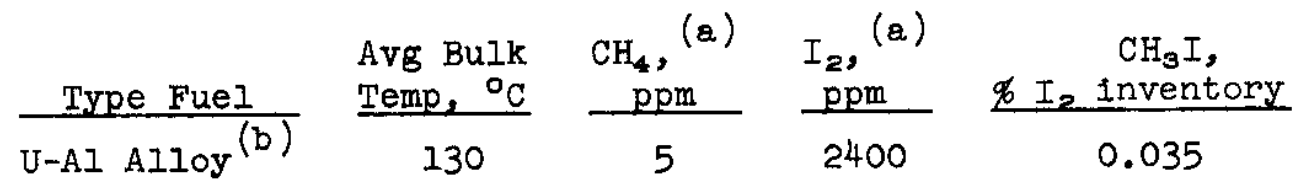

Because of competing reactions (Equations 2, 3, and 4 ) and the immobility of the reactants, a realistic estimate of methyl iodide

\begin{tabular}{|c|c|c|c|c|}
\hline Type Fuel & $\begin{array}{l}\text { Avg Bulk } \\
\text { Temp, }{ }^{\circ} \mathrm{C}\end{array}$ & $\begin{array}{l}\mathrm{CH}_{4,} \text { (a) } \\
\mathrm{ppm}\end{array}$ & $\begin{array}{l}I_{2},(a) \\
\text { ppm } \\
\end{array}$ & $\begin{array}{c}\mathrm{CH}_{3} \mathrm{I}, \\
\text { of } \mathrm{I}_{2} \text { inventory }\end{array}$ \\
\hline$U-A I$ AIloy ${ }^{(b)}$ & 130 & 0.035 & 2400 & 0.00067 \\
\hline
\end{tabular}
in SRP fuel, based on measurements at SRL, as discussed on page III-2, is as follows:

(a) ppm, based on welght of core material.

(b) For conditions applicable to the Savannah River high flux demonstration, as discussed in Reference 1.

The methyl lodide in fuel also will be reduced by pyrolysis and radiolysis. At high temperature and high radiation fields, methyl lodide decomposes to ethylene, methane, and elemental lodine. $(18,10)$ 


$$
4 \mathrm{CH}_{3} \mathrm{I}+\underset{\text { heat }}{\text { or }} \stackrel{\text { Radiation }}{\text { hea }}=\mathrm{C}_{2} \mathrm{H}_{4}+2 \mathrm{CH}_{4}+2 \mathrm{I}_{2}
$$

Upon recombination of these products, some of the lodine will react to form ethylene dilodide:

$$
\mathrm{I}_{2}+\mathrm{C}_{2} \mathrm{H}_{4} \rightleftharpoons \mathrm{C}_{2} \mathrm{H}_{4} \mathrm{I}_{2}
$$

This reaction not only reduces the methyl iodide concentration, but it has a product that is less volatile than methyl lodide and is more easily adsorbed on carbon.

\section{Formation of lodine Compounds upon Meltdown}

The average bulk temperature of uranium fuel would 1ncrease rapidly after coolant is lost in a nuclear accident, and melting would occur quickly. The aluminum sheath on the SRP fuel and aluminum-uranium alloy would melt at about $660^{\circ} \mathrm{C}$. For off-site dose calculations, it is customary to assume that about $50 \%$ of the lodine inventory will be released from the fuel; however, it was conservatively assumed in the analysis for methyl lodide formation that all of the lodine was released into the reactor vessel but only 50\% of the lodine inventory was released from the reactor vessel into the reactor building.

At the melting point of uranium, very reactive chemical species exist. These species, free radicals and atoms, ordinarily are only found at elevated temperatures, because a large amount of energy is required to form them. The free radical is frequently indicated as:

$$
\begin{aligned}
& \mathrm{CH}_{3^{*}}, \text { methyl free radical } \\
& \mathrm{C}_{2} \mathrm{H}_{5} \cdot \text {, ethyl free radical }
\end{aligned}
$$

The dot symbolizes the unpalred electron of a free radical.

The atom is indicated as:

$$
\begin{aligned}
& \mathrm{H} \text {, hydrogen atom } \\
& \mathrm{I} \text {, lodine atom }
\end{aligned}
$$

At elevated temperature, organic matter can be decomposed into free radicals and atoms. Intense light and radiation also produce free radicals. For example:

$$
\mathrm{CH}_{4}+\text { Energy } \rightarrow \mathrm{CH}_{3} \cdot+\mathrm{H}
$$

The lifetime of a free radical is very short, about $10^{-3}$ second, because it reacts so rapidly with its surroundings. 


$$
\begin{aligned}
\mathrm{CH}_{3} \cdot+\mathrm{H}_{2} & \rightleftharpoons \mathrm{CH}_{4}+\mathrm{H} \\
\mathrm{CH}_{3} \cdot+\mathrm{I}_{2} & \rightleftharpoons \mathrm{CH}_{3} \mathrm{I}+\mathrm{I} \\
\mathrm{H}+\mathrm{I}_{2} & \rightleftharpoons \mathrm{HI}+\mathrm{I} \\
\mathrm{I}+\mathrm{H}_{2} & \rightleftharpoons \mathrm{HI}+\mathrm{H}
\end{aligned}
$$

A free radical mechanism has been proposed by Atkins and Eggleton $(12,15)$ for the formation of organic compounds of lodine. Aals as well as lodine atoms can be produced in the vicintty of molten fuel. Although these species could lead to the formation of lodine compounds, the probabllity is most unlikely because of the low concentration of organic matter in the vicinity of molten fuel and the much greater probability for the reaction of a free radical or lodine atom with other materials (steam, nitrogen, oxygen, or hydrogen) that are present in much higher concentrations. In the presence of oxygen, oxidation of free predominant result of intense radiation. It is that oxygen be present in stolchiometric proportion; as long as any appreciable amount is present in the mixture, oxidation is certain $(20)$.

Attempts to prepare methyl lodide by the free radical mechanism were unsuccessful. (21) Irradiation at $200^{\circ} \mathrm{C}$ with a $10,000-$ curie cobalt source formed free radicals, but only trace quantities of methyl lodide were formed.

The equilibrium

$$
\mathrm{CH}_{4}+\mathrm{I}_{2} \rightleftharpoons \mathrm{CH}_{3} \mathrm{I}+\mathrm{HI}
$$

is strongly in favor of methane and elemental iodine. In fact, hydrogen lodide reacts rapidly with methyl lodide to form methane and elemental lodine. (22) To a lesser extent, hydrogen lodide reacts with metal which would shlft the equilibrium toward the right.

Upon meltdown, most (if not all) of any methyl lodide formed in the fuel would be decomposed by chemical reaction, radiolysis, and pyrolysis. In water-cooled reactors, the steam resulting from the contact of hot metal and water hydrolyses methyl lodide as follows:

$$
\mathrm{CH}_{3} \mathrm{I}+\mathrm{H}_{2} \mathrm{O} \text { (steam) } \Rightarrow \mathrm{CH}_{3} \mathrm{OH}+\mathrm{HI}
$$

Large excesses of steam will tend to force this equilibrium to the right. Hydrogen produced by the reaction of hot metal and water will also decompose methyl lodide:

$$
\mathrm{CH}_{\mathbf{3}} \mathrm{I}+\mathrm{H}_{2} \rightleftharpoons \mathrm{CH}_{4}+\mathrm{HI}
$$


A small amount of the molten fuel will react with water inside the reactor tank to produce hydrogen (deuterium) gas.

$$
\mathrm{U}+2 \mathrm{H}_{2} \mathrm{O}=\mathrm{UO}_{2}+2 \mathrm{H}_{2}
$$

Uranium oxide does not react with water to form hydrogen; however, aluminum, zirconium, or stainless steel cladding will produce hydrogen by reaction with water. The hydrogen reacts rapidiy with molecular lodine to form hydrogen 1odide. From published kinetic data(23), it is calculated that the entire inventory of lodine would react with an equivalent amount of hydrogen in about 0.1 second at the temperature of $700^{\circ} \mathrm{C}$ that is estimated for the atmosphere inside the reactor tank following a major accident with uranium-aluminum fuel. The intense radiation field inside the tank should accelerate Equation 25 so that equilibrium would be attalned in even less time than that required for the thermal reaction. Hydrogen, generated by the reaction of less than $0.01 \%$ of the metal with water, is sufficlent to convert almost all of the lodine inventory to hydrogen lodide.

$$
\mathrm{H}_{2}+\mathrm{I}_{2} \rightleftharpoons 2 \mathrm{HI}
$$

At conditions inside the reactor vessel this equilibrium is shifted far to the right so that the environment is rich in hydrogen lodide. About 95\% of the lodine was calculated to form hydrogen lodide. The equilibrium constant for Equation 25, shown in Flgure III-2, was calculated by:

$$
K=\frac{[\mathrm{HI}]^{2}}{\left[\mathrm{H}_{2}\right]\left[\mathrm{I}_{2}\right]}
$$

The hydrogen also reacts rapidly with atomic lodine to form $\mathrm{HI}$ :

$$
\begin{aligned}
\mathrm{I}_{2} & \rightleftharpoons 2 \mathrm{I} \\
\mathrm{H}_{2}+\mathrm{I} & \rightleftharpoons \mathrm{HI}+\mathrm{H}
\end{aligned}
$$

The rate of formation of methyl iodide by the reaction of methane with lodine in a reactor vessel is shown in Figure III-3. The methane concentration was chosen on the conservative assumption that $0.001 \%$ of. the carbon in the molten U-Al alloy and other components reacted with hydrogen formed by chemical reaction of water with fuel or cladding. The lodine concentration was based on conversion of $95 \%$ of the iodine inventory to hydrogen iodide by reaction with hydrogen. Only 5\% of the lodine inventory is avaliable to react with methane to form methyl lodide. Under SRP conditions, about $20 \%$ of the lodine inventory would be required to convert almost all of the methane in the reactor vessel to methyl lodide. However, as discussed later, the intense radiation 
fleld will decompose essentially all of the methyl 1odide. The specific rate constant for the methane-iodine reaction is shown in Figure III-4.

If the concentration of methyl lodide released from the fuel into the tank is greater than the equilibrium concentration, methyl lodide will decompose unt1l the equilibrium concentration is reached. On the other hand, if the methyl lodide concentration is less than the equilibrium concentration methyl lodide will form. These conditions are true provided that the reactants and reaction products (Equation 21) do not change, which would alter the equilibrium relationship, as discussed later.

Hydrogen lodide produced by the above reactions reacts very rapldiy and quantitatively with methyl lodide to form methane and elemental iodine. The overall rate constant for the reaction is $1.89 \times 10^{-2}$ Itter $/(\mathrm{mole})(\mathrm{sec}),(22)$ at $320^{\circ} \mathrm{C}$. This reaction is catalyzed by lodine atoms and involves a free radical. The rate of decomposition of methyl lodide by reaction with hydrogen lodlde is shown in Figure III-5.

The rates shown in F1gure III-5 were calculated from data reported in the literature. (24) The proposed mechan1sm 1s:

$$
\begin{gathered}
\mathrm{I}_{2} \\
\mathrm{I}+\mathrm{CH}_{3} \mathrm{II} \underset{2}{\stackrel{I}{\rightleftarrows}} \mathrm{CH}_{3} \cdot+\mathrm{I}_{2} \\
\mathrm{CH}_{\mathbf{3}} \cdot+\mathrm{HI} \underset{4}{\stackrel{3}{\rightleftarrows}} \mathrm{CH}_{4}+\mathrm{I}
\end{gathered}
$$

where, under most conditions step 4 of Equation 30 is negligible. The rate equation for this mechanism (neglecting the reverse of Equation 30) is:

$$
-\frac{d\left[\mathrm{CH}_{3} I\right]}{d t}=\frac{d\left[\mathrm{I}_{2}\right]}{d t}=\frac{k_{1} k_{3} \mathrm{~K}_{I_{2}}^{\frac{1}{2}}\left[\mathrm{CH}_{3} I\right][\mathrm{HI}]\left[\mathrm{I}_{2}\right]^{\frac{1}{2}}}{k_{2}\left[I_{2}\right]+k_{3}[\mathrm{HI}]}
$$

where:

$$
\begin{aligned}
& -\frac{d\left[\mathrm{CH}_{3} I\right]}{d t}=\text { rate of decomposition of methyl 1odide, moles } /(1)(\mathrm{sec}) \\
& \frac{d\left[I_{2}\right]}{d t}=\text { rate of formation of 1odine, moles } /(1)(\mathrm{sec})
\end{aligned}
$$




$$
\begin{aligned}
& \log k_{1}=11.20-\frac{20,000}{4.575 \mathrm{~T}} \text {, rate constant for step 1, Equation 29, } \\
& 1 /(\operatorname{mole})(\mathrm{sec}) \\
& \log k_{2}=10.00-\frac{1500}{4.575 T}, \begin{array}{l}
\text { rate constant for step 2, Equation 29, } \\
1 /(\text { mole })(\mathrm{sec})
\end{array}
\end{aligned}
$$

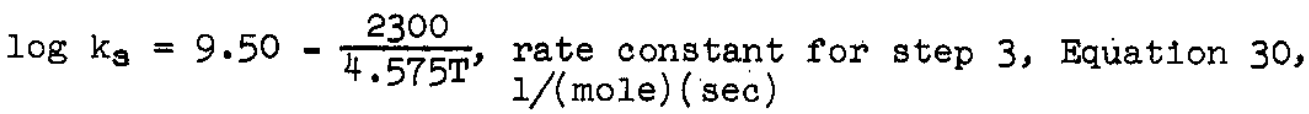

$$
\begin{aligned}
& \mathrm{K}_{\mathrm{I}_{2}}=\text { dissociation constant for lodine, moles/1. The } \\
& \text { terms enclosed by brackets are the concentrations } \\
& \text { of the compounds. } \\
& \mathrm{T}=\text { absolute temperature, }{ }^{\circ} \mathrm{K}
\end{aligned}
$$

The effect of a hydrogen atmosphere on the formation of methyl lodide has been demonstrated experimentally. $(13,14,25,26)$ In one group of experiments, steam was passed over an inductively heated sample of irradiated uranium metal or uranium dioxide. Released fission products and steam passed through a condenser and a series of liquid absorbents. The chemical state of lodine released was determined by chemical analysis of the different liquids. The methyl lodide released from uranium metal (where the metal-water reaction produces a hydrogen-rich atmosphere) was less than 0.3 of that (14) from uranium dioxide (hydrogen-deficient atmosphere).

Methyl lodide also is decomposed very rapidly by radiation. The course of radiolysis (18) is similar to that for pyrolysis that is discussed below.

$$
4 \mathrm{CH}_{3} \mathrm{I}+\text { Radiation }=\mathrm{C}_{2} \mathrm{H}_{4}+2 \mathrm{CH}_{4}+2 \mathrm{I}_{2}
$$

Because one of the products is ethylene, the usual equilibrium

$$
\mathrm{CH}_{4}+\mathrm{I}_{2} \rightleftharpoons \mathrm{CH}_{3} \mathrm{I}+\mathrm{HI}
$$

will be shifted toward greater decomposition of methyl 1odide. Methyl lodide decays exponentially in a combined oxidizing and radiation environment. The extent of decomposition is independent of the dose rate, but is proportional to the total absorbed dose. Experiments (27) with methyl lodide concentration of $10^{-8}$ to $10^{-8}$ moles/liter $\left(10^{3}-10^{5} \mathrm{\mu g} / \mathrm{m}^{3}\right)$ in dry air at $15^{\circ} \mathrm{C}$ showed that over $99 \%$ of the methyl lodide was decomposed at a total absorbed dose of $8 \times 10^{5}$ rads. The radiolysis products observed in these experiments were methyl nitrate and methyl nitrite. The formation of products such as methyl nitrate and nitrite will decrease the equilibrium concentration of methyl 1odide. At the high 
temperature inside the reactor tank these radiolysis products probably will react with each other and form other new products. These reactions $w 111$ also shift the equilibrium in the direction of lower methyl lodide concentrations. It is also possible that some materlals may slightly reduce the rate of decomposition of methyl lodide in a radiation fleld. The radiation fleld from fission products at shutdown is usually greater than $4 \times 10^{\circ} \mathrm{rads} / \mathrm{hr}$ per megawatt of thermal power at saturation. Hence, the radiation can be expected to decompose over $99 \%$ of the methyl iodide per second per $1000 \mathrm{MW}$ of thermal power.

Methyl lodide is also decomposed by heat. From $300-400^{\circ} \mathrm{C}$, saturated alkyl 1odides (such as $\mathrm{CH}_{3} I$ ) appear to pyrolyze with moderately rapid rates. (18) A study of literature data on the kinetics of the pyrolysis of $\mathrm{CH}_{\mathbf{s}} \mathrm{I}$ is underway at SRL.

Although no detailed study of the pyrolysis of methyl iodide has been reported, some predictions on this decomposition can be made from recent work by Benson. (18) The Important steps should be:

$$
\begin{aligned}
& \mathrm{I}+\mathrm{CH}_{3} \mathrm{I} \underset{2}{\stackrel{1}{\rightleftarrows}} \mathrm{CH}_{3} \cdot+\mathrm{I}_{2} \\
& \mathrm{CH}_{3} \cdot+\mathrm{CH}_{3} \mathrm{I} \stackrel{3}{\rightarrow} \mathrm{CH}_{4}+\mathrm{CH}_{2} \mathrm{I} \cdot \\
& \mathrm{CH}_{2} \mathrm{I} \cdot+\mathrm{I}_{2} \stackrel{4}{\frac{4}{7}} \mathrm{CH}_{2} \mathrm{I}_{2}+\mathrm{I} \\
& 2 \mathrm{CH}_{2} \mathrm{I} \cdot \underset{6}{\rightarrow}\left(\mathrm{C}_{2} \mathrm{H}_{4} \mathrm{I}_{2}\right) \rightarrow \mathrm{C}_{2} \mathrm{H}_{4}+\mathrm{I}_{2}
\end{aligned}
$$

The overall reaction would occur in two stages:

$$
\begin{aligned}
& 2 \mathrm{CH}_{3} \mathrm{I} \neq \mathrm{CH}_{2} \mathrm{I}_{2}+\mathrm{CH}_{4} \\
& 2 \mathrm{CH}_{2} \mathrm{I}_{2} \rightarrow \mathrm{C}_{2} \mathrm{H}_{4}+2 \mathrm{I}_{2}
\end{aligned}
$$

Reactions 36 and 37 will reduce the concentration of methyl 1odide. The inftial rate of production of $\mathrm{CH}_{2} \mathrm{I}_{2}$ would have a rate law:

$$
\frac{d\left[\mathrm{CH}_{2} I_{2}\right]}{d t}=\mathrm{K}_{2} \mathrm{I}_{2}^{\frac{1}{2}} \quad \mathrm{k}_{3} \mathrm{~K}_{1 \cdot 2} \frac{\left[\mathrm{U} \mathrm{K}_{3} I\right]^{2}}{\left[\mathrm{I}_{2}\right]^{\frac{1}{2}}}
$$


where, in consistent units:

$$
\begin{aligned}
\frac{\mathrm{d}\left[\mathrm{CH}_{2} \mathrm{I}_{2}\right]}{\mathrm{dt}}= & \text { the rate of formation of } \mathrm{CH}_{2} \mathrm{I}_{2} \\
\mathrm{~K}_{\mathrm{I}_{2}}= & \text { the equilibrium constant for the dissociation } \\
& \text { of lodine } \\
\mathrm{k}_{3}= & \text { the specific reaction rate constant for } \\
& \text { reaction Equation } 33
\end{aligned}
$$

At $400^{\circ} \mathrm{C}$, this reaction would have a half life of about 3 hours when the methyl lodide concentration is $5 \times 10^{-3}$ mole/liter

$\left(7 \times 10^{8} \mu \mathrm{g} / \mathrm{m}^{3}\right)$. The reaction is expected to be much faster at elevated temperatures, because the rate usually doubles for a $10^{\circ} \mathrm{C}$ rise in temperature. The activation energy would be about $44 \mathrm{kcal}$.

The second process would be about one-tenth as fast, and would have an activation energy of about $67 \mathrm{kcal}$. Its rate law would be of the form:

$$
-\frac{\mathrm{d}\left[\mathrm{CH}_{2} \mathrm{I}_{2}\right]}{\mathrm{dt}}=\frac{2 \mathrm{k}_{6} \mathrm{~K}_{5.4}{ }^{2} \mathrm{~K}_{I_{2}}\left[\mathrm{CH}_{2} \mathrm{I}_{2}\right]^{2}}{\left[\mathrm{I}_{2}\right]}
$$

and would have a half life of 3 hours at about $450^{\circ} \mathrm{C}$. Again, the rate would be much more rapid at higher temperatures.

The literature contains data that indicate much higher amounts of methyl lodide present (up to 10\%) either in the fuel or upon meltdown than would be expected from the above discussions. Some of these data are summarized in Table III- 1 .

The high yields of methyl lodide reported can be attributed to poor analytical techniques (discussed in Section III, A,4), impurities that are known to be present in $\mathrm{UO}_{2}$, and to impurities in the atmosphere of the test apparatus. In certain experiments, methane was added directly to the apparatus. In addition, some $\mathrm{UO}_{2}$ fuels may contain more than $0.014 \mathrm{ppm}$ methane (measured for high quality $\mathrm{UO}_{2}$ fuel irradiated at SRP) which can react with radlolodine to form methyl lodide. $\mathrm{UO}_{2}$ fuels also may contain more than $0.5 \mathrm{ppm}$ hydrogen, which upon release from the melted fuel could form methane by reaction with graphite that was used In the test apparatus to support the $\mathrm{UO}_{2}$ sample. A minor source 
of organic matter is the compressed atr used in the experiments. This air was dried with magnesium perchlorate and filtered through absolute filters before use, but removal of organic matter was omitted. Finally, the experiments were not conducted in an intense radiation field which is expected to decompose essentially all of the methyl lodide as discussed previously.

Experiments in the TREAT(28) facility to study the release of fission products from the fuel during a reactor accident in which the fuel melts rapidly as the result of a reactor transient add further confirmation to the insignificant amounts of $\mathrm{CH}_{3} I$ formed. "Stainless-steel and Zircaloy-clad $\mathrm{UO}_{2}$ fuel pellets were melted under water by transient fission-heat input of approximately $510 \mathrm{cal}$ per gram of $\mathrm{UO}_{2}$. Most of the water bolled out of the fuel-containing autoclave (about 1.5 inches in diameter by about 7.5 inches long) in 1 minute to simulate a ruptured reactor pressure vessel system, followed by slow bolling to dryness in 10 minutes. Approximately $60 \%$ of the ${ }^{131} \mathrm{I}$ was released from the melted fuel-cladding mixture. About 15\% of the total lodine was carried out of the fuel autoclave with the escaping steam. About $40 \%$ of the lodine was collected later in distilled-water rinses of the walls of the disassembled fuel autoclave. The following mechanism for transport of lodine was proposed. First, the portion ( $15 \%)$ that escaped from the fuel autoclave was carried only by steam which was formed at the heated fuel surface and moved out of the autoclave wlthout being condensed. Second, the lodine which entered the liquid water either directly or by entrainment in condensing steam was essentially permanently trapped by chemical reactions to form mostly nonvolatile water soluble compounds such as metal lodides. Less than $0.01 \%$ of the total ${ }^{131} I$ was found in penetrating forms such as $\mathrm{CH}_{3} \mathrm{I}$."

3. Formation of lodine Compounds in the Gas Phase Outside Reactor Vessel

Most of the lodine escapes from the reactor tank as hydrogen lodide, because of the rapid reaction of hydrogen and iodine, Equation 25, and the large equilibrium constant as mentioned previously. As hydrogen lodide escapes, it should react rapidly with oxygen in the air to form elemental iodine.

$$
4 \mathrm{HI}+\mathrm{O}_{2} \rightleftharpoons 2 \mathrm{I}_{2}+\mathrm{H}_{2} \mathrm{O}
$$

The literature does not contain sufficient information to calculate rates or equilibrium data for this reaction. In the following discussion, it was assumed conservatively that elemental iodine exists in the gas phase outside the reactor vessel. 
Although it appears in some experiments (30) that radiolodine has reacted directly in some way with alrborne organic matter, the kinetics of the reaction of lodine with hydrocarbons are not favorable because the carbon-hydrogen bond strength ( $102 \mathrm{kcal} / \mathrm{mole}$ ) is greater than the carbon-iodine bond strength ( $54 \mathrm{kcal} / \mathrm{mole})$. However, at trace concentrations $\left(<1 \mu \mathrm{g} / \mathrm{m}^{3}\right)$ lodine may exist in a form that reacts differently from lodine at macroconcentrations.

The reaction between methane and lodide was studied quantitatively by Benson. (31) The following mechanism was confirmed by extensive kinetic measurements for the gaseous system $\mathrm{CH}_{4}+\mathrm{I}_{2} \vec{F}$ $\mathrm{CH}_{3} \mathrm{I}+\mathrm{HI}$ (Equation 2I).

$$
\begin{gathered}
\mathrm{I}_{2} \rightleftarrows 2 \mathrm{I} \\
\mathrm{I}+\mathrm{CH}_{4} \underset{3}{\stackrel{4}{\rightleftarrows}} \mathrm{CH}_{3} \cdot+\mathrm{HI} \\
\mathrm{CH}_{3} \cdot+\mathrm{I}_{2} \underset{\mathrm{I}}{\stackrel{2}{\rightleftarrows}} \mathrm{CH}_{3} \mathrm{I}+\mathrm{I}
\end{gathered}
$$

The rate equation for this mechanism is:

$\frac{\mathrm{d}[\mathrm{HI}]}{\mathrm{dt}}=\frac{\mathrm{d}\left[\mathrm{CH}_{3} I\right]}{\mathrm{dt}}=\mathrm{k}_{4} \mathrm{~K}_{\mathrm{I}_{2}}^{\frac{1}{2}}\left[\mathrm{I}_{2}\right]^{\frac{1}{2}}\left[\mathrm{CH}_{4}\right]\left\{1-\frac{[\mathrm{HI}]\left[\mathrm{CH}_{3} \mathrm{I}\right]}{[\mathrm{HI}]_{\mathrm{eq}}\left[\mathrm{CH}_{3} \mathrm{I}\right]_{\mathrm{eq}}}\right\}$

where, in consistent units:

$$
\begin{aligned}
\frac{d\left[\mathrm{CH}_{3} I\right]}{\mathrm{dt}}= & \text { the rate of formation of methyl iodide } \\
\mathrm{k}_{4}= & \text { the specific rate constant for the forward } \\
& \text { reaction } 4 \mathrm{l} \text {, shown in Figure III-4 } \\
\mathrm{K}_{\mathrm{I}_{2}}= & \text { the equilibrium constant for the dissociation of } \\
& \text { iodine in Figure III-2 } \\
{\left[\mathrm{I}_{2}\right]=} & \text { the concentration of iodine } \\
{\left[\mathrm{CH}_{4}\right]=} & \text { the concentration of methane } \\
{[\mathrm{HI}]=} & \text { the concentration of hydrogen iodide } \\
{\left[\mathrm{CH}_{3} \mathrm{I}\right]=} & \text { the concentration of methyl iodide }
\end{aligned}
$$


The righthand term inside the braces can be neglected when calculating the maximum rate of formation of methyl lodide. The rate constant $\left(\mathrm{k}_{\mathbf{4}}\right)$ and the equilibrium constant $\left(\mathrm{K}_{\mathrm{T}}\right)$ vary exponentially with temperature; the effect of temperature on ${ }^{2}$ these constants can be calculated by the Arrhenius equation:

$\log \mathrm{K}_{I_{2}}=15.06-\frac{37,600}{4.575 \mathrm{~T}}$, equ1librium constant for Equation 27 , $\log \mathrm{k}_{4}=11.70-\frac{3400}{4.575 \mathrm{~T}}, \begin{aligned} & \text { rate constant for step 4, Equation } 41 \text {, } \\ & 1 /(\mathrm{mole})(\mathrm{sec})\end{aligned}$

The maximum rate of formation of methyl lodide by the above mechanism in the gas phase was calculated for the following concentrations :

$$
\begin{gathered}
\mathrm{I}_{2}: 1 \text { and } 10 \mathrm{ppm} \text { (vol) } \\
\mathrm{CH}_{4}: 2 \text { and } 20 \mathrm{ppm} \text { ( } \mathrm{vol} \text { ) }
\end{gathered}
$$

The kinetic data(31) showed a slow rate of reaction between $I_{2}$ and simple hydrocarbons to form methyl iodide. Calculated rates of formation are summarized in Figure III-6. These extremely low rates of reaction limit the formation of organic compounds to insignificant concentrations. At a temperature of $100^{\circ} \mathrm{C}$, $20 \mathrm{ppm}$ methane, and $10 \mathrm{ppm}$ lodine, the rate of formation of methyl lodide would be negligible, <I $\times 10^{-14} \mu \mathrm{g} /\left(\mathrm{m}^{3}\right)(\mathrm{min})$. A temperature of about $400^{\circ} \mathrm{C}$ in the gas phase and at the same concentrations would be required to form about $1 \%$ methyl iodide per day. The equilibrium concentration of methyl lodide in the gas phase, shown in Flgure III-7, would limit the maximum possible amount of methyl lodide to less than $0.005 \%$ of the lodine inventory for the above concentrations and at $100^{\circ} \mathrm{C}$. The equilibrium concentration was calculated from the following equation:

$$
K=\frac{\left[\mathrm{CH}_{3} I\right][\mathrm{HI}]}{\left[\mathrm{CH}_{4}\right]\left[\mathrm{I}_{2}\right]}
$$

\section{Formation of lodine Compounds on Surfaces Outside Reactor Vessel}

The preceding discussions show that it is very unlikely that a significant quantity of methyl lodide will be released from the reactor vessel of most water cooled reactors. Other investigators have reported that the indicated formation of methyl iodide involves an adsorption-desorption activation or local reaction of 
lodine with organic materials on surfaces. $(30,32)$ For such a reaction to occur, the lodine vapor must be transferred from the bulk gas to surfaces of the containment structure. The rate of deposition, which is discussed in section III,C, is a function of the aerodynamic conditions. Once the lodine vapor reaches the surface it may a) chemically react with the surface or with materials on the surface, or b) it may be physically adsorbed. If the first mechanism controls, a layer of reaction product accumulates on the surface; thus, the concentration of iodine on the surface may become much greater than that in the gas phase. If the chemical reaction product of the sorbed molecule has sufficient vapor pressure, the lodine compound (such as methyl lodide) may be desorbed. If the second mechanism controls, physical adsorption of lodine can also lead to concentrations on the surface that exceed that in the gas phase.

The deposition of lodine is rapid on metals such as copper and silver because metal lodides are formed by chemical reaction. Deposition on bare ferrous metals is enhanced by corrosive oxidation especially in a humid atmosphere. Iodine deposition on painted surfaces is generally much slower than on metals, because the protective coating is much less reactive than the bare metal surface.

Unfortunately, there is no information in the literature on the catalytic effect of a given surface on methyl lodide formation. SRL therefore undertook a comprehensive review and analysis of the data in the literature on methyl lodide formation in reactor containment test facilities. The pertinent data from this review are summarized in Table III-2.

As shown in Table III-2, the amount of methyl lodide formed in the test facilities varied significantly. Consideration of the differences in the conditions of the tests and the kinetics of the methyl lodide reaction show that the following conditions promote the fraction of lodine that may be converted to methyl lodide:

- Bare ferrous metal surfaces

- H1gh deposition rates

- Long aging periods

- High surface to volume ratios

- Low gas-phase lodine concentration

- Moderately high temperatures 
- Organic 1mpurities

- $\mathrm{CO} / \mathrm{CO}_{2}$ atmospheres

In order to determine more quantitatively the effects of the above conditions on methyl fodlde formation, the avallable data were correlated. Analysis of the data indicated that the methyl lodide formation varled as the square root of the lodine concentration on the surface, as would be predicted from the gas-phase kinetics. By analogy with the gas phase equation of Benson, discussed in Section III, A, 3, a similar expression was developed for the overall reaction on a surface

$$
\mathrm{CH}_{4}+\mathrm{I}_{2} \stackrel{\text { surface }}{\longleftarrow} \mathrm{CH}_{3} \mathrm{I}+\mathrm{HI}
$$

for the mechanism:

$$
\begin{aligned}
& I_{2} \stackrel{\text { surface }}{\rightleftarrows} 2 I \\
& \mathrm{I}+\mathrm{CH}_{4} \stackrel{\text { surface }}{\rightleftharpoons} \mathrm{CH}_{3} \cdot+\mathrm{HI} \\
& \mathrm{CH}_{3} \cdot+\mathrm{I}_{2} \stackrel{\text { surface }}{\longleftarrow} \mathrm{CH}_{3} \mathrm{I}+\mathrm{I}
\end{aligned}
$$

and the rate equation for this mechanism is

$$
\frac{\mathrm{d}\left[\mathrm{CH}_{3} I\right]_{S}}{\mathrm{dt}}=\mathrm{k}_{\mathrm{S}}\left(\mathrm{K}_{\mathrm{I}_{2}}\right)_{\mathrm{s}}^{\frac{1}{2}}\left[\mathrm{I}_{2}\right]_{\mathrm{s}}^{\frac{1}{2}}[\mathrm{M}]_{s}\left\{I-\frac{[\mathrm{HI}]_{\mathrm{S}}\left[\mathrm{CH}_{3} I\right]_{\mathrm{S}}}{[\mathrm{HI}]_{\mathrm{s}}\left[\mathrm{CH}_{3} I\right]_{\mathrm{s}}}\right\}
$$

An approximate expression of Equation 48 when conversion to $\mathrm{CH}_{3} I$ is relatively small (less than $30 \%$ ) is:

$$
\frac{\left[\Delta \mathrm{CH}_{3} I\right]_{s}}{\Delta t}=k_{s}\left(K_{I_{2}}\right)_{s}^{\frac{1}{2}}\left[I_{2}\right]_{s}^{\frac{1}{2}}[M]_{s}\left\{1-\frac{\left[\Delta \mathrm{CH}_{3} I\right]_{s}^{2}}{\left[\Delta \mathrm{CH}_{3} I\right]_{s}^{2}}\right\}
$$


where

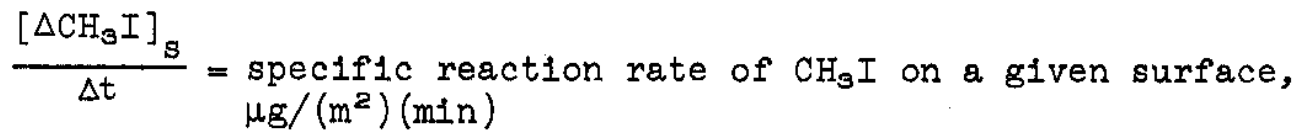

$$
\begin{aligned}
& \mathrm{k}_{\mathrm{s}}=\text { specific reaction rate constant for a given } \\
& \text { surface at a given temperature, } \mathrm{m}^{2} /(\mu \mathrm{g})(\mathrm{min}) \\
& \left(\mathrm{K}_{I_{2}}\right)_{\mathrm{S}}=\begin{array}{l}
\text { equilibrium constant for Equation } 45 \text { at a given } \\
\text { temperature, } \mu \mathrm{g} / \mathrm{m}^{2} \text {. }
\end{array} \\
& {\left[I_{2}\right]_{s}=\text { concentration of } I_{2} \text { on surface, } \mu \mathrm{g} / \mathrm{m}^{2} \text {. }} \\
& {[\mathrm{M}]_{\mathrm{S}}=\text { concentration of } \mathrm{CH}_{4} \text { on surface, } \mu \mathrm{g} / \mathrm{m}^{2} \text {. }} \\
& {\left[\Delta \mathrm{CH}_{3} I\right]_{\text {eq }}=\underset{\text { equilibrium concentration of } \mathrm{CH}_{3} I \text { on a given }}{\text { surface, } \mu \mathrm{g} /\left(\mathrm{m}^{2}\right)} .}
\end{aligned}
$$

Unfortunately, sufficient information is not available from the 11terature and from the data summarized in Table III-2 to derive accurate values for the specific reaction rate constant ( $k_{f}$ ) of Equation 49 for various surfaces. Most data give only the final quantity of methyl lodide formed and lodine deposition on the surface after many hours of aging. In addition, information was not avaliable on the methane concentration [M] on the surfaces (although no significant differences between tests facilities are expected) or on the effect of a given surface on the equilibrium constant $\left(\mathrm{K}_{I_{2}}\right)_{\mathrm{s}}$ for Equation 45. Consequently, the three parameters $k_{s},\left(K_{I_{2}}\right)_{s}$, and $[M]_{s}$, which are constants for any given system at a given temperature, were combined into a single constant, and Equation 49 reduces to the following equation for calculating the average rate of formation of methyl lodide:

$$
\frac{\left[\Delta \mathrm{CH}_{3} I\right]_{S}}{\Delta t}=K_{S}\left[I_{2}\right]_{S}^{\frac{1}{2}}
$$

where,

$$
\mathrm{K}_{\mathrm{S}}=\operatorname{overall} \text { rate constant }\left[\mathrm{k}_{\mathrm{s}} \times\left(\mathrm{K}_{I_{2}}\right)_{\mathrm{s}}^{\frac{1}{2}} \times[\mathrm{M}]_{\mathrm{s}}\right], \frac{(\mu \mathrm{g})^{\frac{1}{2}}}{(\mathrm{~m})(\mathrm{mIn})}
$$

The terms within the braces in Equation 49 were deleted from Equation 50 because of lack of sufficient data. This does not have a significant effect on the overali rate constant for the experimental data. 
All data on methyl iodide formation summarized in Table III-2 were reduced and analyzed in terms of the parameters in Equation 50. This information is shown in Table III-3. In Table III-4, average overall rate constants $\left(\mathrm{K}_{\mathrm{S}}\right)$ are shown for each surface, atmosphere, aging time, and temperature.

The rate constants $\left(\mathrm{K}_{\mathrm{S}}\right)$, and therefore the rate of formation of methyl lodide, are one to two decades lower for painted surfaces than for bare stainless steel [paint equivalent to that used in the Battelle Northwest Laboratory (BNWL) Aerosol Development Facility and the United Kingdom Atomic Energy Authority (UKAEA) Zenith Reactor]. However, the combination of a surface with a

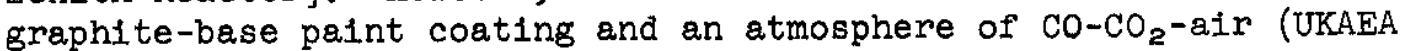
data) produced the highest rate constant, and therefore the maximum rate of formation of methyl lodide, of any surface and environment studied. The rates of formation of methyl lodide in air at 20 to $25^{\circ} \mathrm{C}$ versus the square root of lodine concentration on painted (nonreactive type) concrete, painted (nonreactive type) steel, and bare stainless steel surfaces are shown in Figure III-8.

The rate constants $\left(\mathrm{K}_{\mathrm{S}}\right)$ for steam-air mixtures were also about two decades lower for painted surfaces than for bare stainless steel. The rate constants are not slgnificantly different for painted surfaces (BNWL data) in air at $20^{\circ} \mathrm{C}$ or steam-air at $80^{\circ} \mathrm{C}$. However, the rate constant for bare stainless steel [Oak Ridge National Laboratory (ORNL) data] in a steam-air mixture at an average temperature of $50^{\circ} \mathrm{C}$ is about 5 times higher than in air at about $25^{\circ} \mathrm{C}$. As discussed previously, information is not available in the literature for determining the equilibrium constant for dissociation of lodine on a surface. Hence, the data cannot be normalized for temperature. However, the equilibrium constant $\left(\mathrm{K}_{\mathrm{I}_{2}}\right)_{\mathrm{s}}$ and the specific rate constant $\left(\mathrm{k}_{\mathrm{s}}\right)$ would be expected to increase exponentially with temperature in accordance with the Arrhenius equation for gas phase reactions. (31)

The ORNL data for bare stainless steel in a steam-air mixture indicate that the average rate constant $\left(K_{S}\right)$ increases by a factor of about five for an increase of about $20^{\circ} \mathrm{C}$ (Table III-3). These results indicate that the rate of formation of methyl lodide in steam would be significantly less than in air at the same temperature.

Although appreclable hydrolysis of methyl lodide in the gas phase would not be expected, hydrolysis of methyl lodide in the Ilquid film on surfaces may be a significant factor in decreasing the rate of formation of methyl lodide in steam-air mixtures. In the BNWL steam-air tests, the quantity of methyl lodide (fraction of lodine inventory) in the gas phase increased to a maximum value 
In about one hour, and after five hours decreased to $40-85 \%$ of the maximum value. The BNWL tests provide further evidence that the methyl lodide is hydrolyzed in the liquid film from condensing steam on surfaces. The liquid film also probably depletes the surface of methane and iodine which would further reduce formation of methyl lodide. The rates of formation of methyl lodide in steam-air mixtures at 50 to $80^{\circ} \mathrm{C}$ versus the square root of lodine concentration on painted steel and bare stainless steel surfaces are shown in Figure III-9.

Data were only available from the BNWL(ADF) and ORNL(NSPP) tests throughout the entire test period. Only the BNWL data have been analyzed to date. The rate constants $\left(K_{s}\right)$ for formation of methyl lodide during the first 20 minutes of these tests are shown in Table III-3, and the average rate for all the tests is shown in Table III-4. A comparison of these figures shows that the rate constants for the first 20 minutes was about one decade

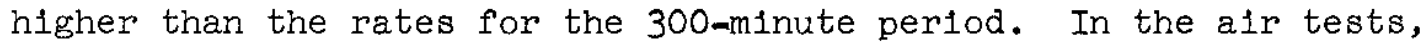
formation of methyl lodide was 50 to $95 \%$ completed in one hour and almost $100 \%$ completed in five hours. As discussed above, the methyl iodide fraction decreased after one hour in steam-air mixtures.

The data and correlation demonstrate that formation of methyl iodide by active surfaces is negligible for most reactor confinement systems in which fresh air flow continuously replenishes the confined air space in structures with a nonreactive-type paint coating. Application of this analysis to the SRP confinement system, discussed in section III, B, shows that methyl lodide formation on the building surfaces is about $10^{-6} \%$ of the lodine inventory in the fuel.

Care must be taken when applying the rate constants to reactors with containment dome structures in which the fission products are confined for relatively long periods of time. For painted (nonreactive-type) surfaces and for ambient air, the average rate constant derived from the first 20 minutes of exposure in the BNWL tests should be substituted in Equations 48 or 49 and the equation integrated as a function of time. For steam-air mixtures, the rate constant for 20 minutes should be applied over a time interval of one hour. Appropriate rate constants for use in Equations 48 or 49 for bare ferrous metal surfaces are not available as yet, and the rate constants in Table III-4 should not be applied for perlods longer than indicated in the table. The rate constants glve only the rate of formation of methyl lodide and not the final amount formed when equilibrium conditions are reached. Significantly greater concentrations of methyl iodide can form on surfaces than in the gas phase. Because methyl iodide rapidly desorbs from surfaces 
and because the rate of decomposition of methyl lodide to satisfy the equilibrium gas phase relationship is very slow, the gas phase concentration of methyl lodide can exceed the final equilibrlum value from one to several hours, depending upon the actual gas phase conditions. However, no significant formation of methyl lodide would be expected in containment domes in which the air is at relatively low temperature and is rapidly recirculated through particulate filters and carbon beds.

Of interest are the data from the UKAEA test facility (Highly Active Test Rig) in $\mathrm{CO} / \mathrm{CO}_{2}$ at $400^{\circ} \mathrm{C}$ for a period of 30 minutes (Table III-3). At such high temperatures, one would expect that the rate of methyl lodide formation would be controlled by the gas phase reaction. The agreement is good between the indicated rate of formation of methyl iodide in the experiment (about $0.2 \mu \mathrm{g} /\left(\mathrm{m}^{3}\right)(\mathrm{min})$ and $\mathrm{with}$ an initial iodine concentration in the gas phase of $4 \mathrm{ppm}$ ( $\mathrm{vol}$ ), $4 \times 10^{4} \mu \mathrm{g} / \mathrm{m}^{3}$ ) with that predicted from Figure III- 6 for a methane concentration of 2 ppm (vol).

It was assumed conservatively in this analysis that all of the indicated methyl iodide was formed on surfaces of the containment test facilities and subsequently released to the gas phase. Some fraction of the compounds could have been released from the cooled 1rradiated fuel used in some of the experiments and/or formed on surfaces in the test furnaces or in the gas phase within the furnaces during the melting operation. Rate constants were based on reported values of iodine deposited on surfaces of the test facilities. Application of Equation 50, including mechanisms that control mass transfer of lodine to surfaces, is discussed in Sections III, B and C.

Additionally, all of the data in Table III-3 on methyl lodide formation involved the use of a May Pack sampling device. Some of the ambiguities that could arise from the use of this device were discussed by Collins, $(32,33)$ et al. In general, analyses involving May Pack sampling devices are more likely to show higher methyl lodide formation than probably exists. Recent experiments by Collins $(32)$ showed that methyl lodide formation indicated from May Pack data was about 6 times greater on the average than measured by sensitive gas chromatographic techniques (Table III-1). Consequently, the rate constants $\left(\mathrm{K}_{\mathrm{S}}\right)$ in Tables III-3 and III-4 are probably very conservative (higher than actually exists). 
UKAEA Estimates of Methyl Iodide

Released from Cooled Irradiated $\mathrm{UO}_{2}$

\begin{tabular}{|c|c|c|c|c|c|c|}
\hline \multirow{2}{*}{\multicolumn{2}{|c|}{ Experiment }} & \multirow[b]{2}{*}{ Gas Composition } & \multirow{2}{*}{$\begin{array}{r}\mathrm{UO}_{2} \\
\mathrm{Fuel} \\
\mathrm{MWD} / \mathrm{T} \\
\end{array}$} & \multirow{2}{*}{$\begin{array}{l}\text { Percent } \\
\text { of Iodine } \\
\text { Released } \\
\text { from Fuel }\end{array}$} & \multicolumn{2}{|c|}{$\begin{array}{l}\text { Inventory Released } \\
\text { as Methyl Iodide }\end{array}$} \\
\hline & & & & & May Pack & $\begin{array}{c}\text { Ga.s } \\
\text { Chromatograph }\end{array}$ \\
\hline & No. 21 & $\begin{array}{l}54 \% \mathrm{CO}_{2}, 35 \% \mathrm{CO} \\
\text { plus air, } \mathrm{H}_{2}, \mathrm{H}_{2} \mathrm{O}, \\
200 \mathrm{ppm} \mathrm{CH}_{4}\end{array}$ & 150 & $2.8-3$ & 1 & 0.2 \\
\hline & No. 22 & $\mathrm{CO}_{2} / \mathrm{CO}$ & 150 & $4-9$ & 2 & 0.5 \\
\hline & No. 23 & $\begin{array}{l}\mathrm{CO}_{2} / \mathrm{CO} \\
\text { Sat. } \mathrm{H}_{2} \mathrm{O}\end{array}$ & 150 & 40 & 4 & 5.0 \\
\hline a & No. 24 & $\begin{array}{l}\mathrm{CO}_{2} / \mathrm{CO} \\
\text { plus } \mathrm{CH}_{4}(1000 \mathrm{ppm})\end{array}$ & 150 & 33 & 20 & 1.0 \\
\hline & No. 25 & $\mathrm{CO}_{2} / \mathrm{CO}$ & 150 & $27-35$ & 10 & Not done \\
\hline & No. 26 & $\mathrm{CO}_{2} / \mathrm{air}$ & 100 & $25-47$ & 2 & 0.7 \\
\hline & No. 27 & $\mathrm{CO}_{2} / 5 \% \mathrm{CH}_{4}$ & 150 & $13-27$ & 0.7 & 0.1 \\
\hline & Table 3 & Steam-air & 0.5 & 6.2 & 0.02 & - \\
\hline & Table 3 & steam-air & 0.5 & 6.8 & 0.02 & - \\
\hline & Table 3 & Steam-a1r & 1.0 & 2.4 & 0.01 & - \\
\hline & Table 3 & Steam-air & 2.0 & 2.4 & 0.02 & - \\
\hline & Table 3 & Steam-a.1r & 5.0 & 2.9 & 0.001 & - \\
\hline & Table 3 & Steam-a1r & 1.0 & 13.7 & 0.1 & - \\
\hline & Table 3 & Steam-air & 2.0 & 15.4 & 0.003 & - \\
\hline & Table 3 & Steam-air & 7.0 & 40.5 & 0.03 & - \\
\hline & Table 4 & Steam & 100 & 28 & 0.04 & - \\
\hline & Table 4 & Steam & 100 & 35 & 0.5 & - \\
\hline & Table 4 & Steam & 100 & 34 & 3 & - \\
\hline & Table 4 & Steam & 100 & 9 & 2 & - \\
\hline & Table 4 & Steam & 100 & 27 & 0.08 & - \\
\hline & Table 4 & Steam-air & 100 & 60 & 0.2 & - \\
\hline
\end{tabular}




\section{Summary of Literature Data on Methyl Iodide Formation}

\begin{tabular}{|c|c|c|c|c|c|c|c|c|}
\hline $\begin{array}{l}\text { Test }(a) \\
\text { Fac1l1ty }\end{array}$ & Surface & $\begin{array}{c}I_{2}^{(b)} \\
\text { Deposition, } \% \\
\end{array}$ & $\begin{array}{l}\text { Aglng } \\
\text { T1me, } \mathrm{hr} .\end{array}$ & $\begin{array}{c}\text { Surface } \\
\text { to Volume } \\
\mathrm{Rat10} \\
\mathrm{m}^{2} / \mathrm{m}^{3} \\
\end{array}$ & $\begin{array}{r}\mathrm{I}_{2}(\mathrm{c}) \\
\text { Conc, } \\
\mu \mathrm{g} / \mathrm{m}^{3} \\
\end{array}$ & $\begin{array}{l}\text { Temp., } \\
\text { oc } \\
\end{array}$ & Atmosphere & $\begin{array}{l}\mathrm{CH}_{3} \mathrm{I},(\mathrm{b}) \\
\end{array}$ \\
\hline $\begin{array}{l}\mathrm{ADF} \\
\mathrm{ADF}\end{array}$ & $\left\{\begin{array}{l}\text { Painted } \\
\text { Steel }\end{array}\right\}$ & $\begin{array}{l}20-95 \\
50\end{array}$ & $\begin{array}{l}5 \\
5\end{array}$ & 5.2 & $\begin{array}{l}0.03-630 \\
0.2-640\end{array}$ & $\begin{array}{l}20 \\
80\end{array}$ & $\begin{array}{l}\text { A1r } \\
\text { Steam-A1r }\end{array}$ & $\begin{array}{l}0.05-0.7 \\
0.1-6.0\end{array}$ \\
\hline $\begin{array}{l}\text { CMF } \\
\text { CMF }\end{array}$ & \multirow{3}{*}{$\begin{array}{l}\text { Bare } \\
\text { Stainless } \\
\text { Steel }\end{array}$} & $\begin{array}{r}25-90 \\
8-60\end{array}$ & $\begin{array}{l}3-4 \\
4-18\end{array}$ & 9.1 & $\begin{array}{l}5-2200 \\
2000- \\
8000\end{array}$ & $\begin{array}{l}25 \\
30- \\
110\end{array}$ & $\begin{array}{l}\text { A1r } \\
\text { Steam-A1r }\end{array}$ & $\begin{array}{l}0.3-3.7 \\
0.5-1.3\end{array}$ \\
\hline CMF & & \multirow[t]{2}{*}{20} & $5-16$ & & 2000 & $30-$ & \multirow{2}{*}{$\begin{array}{l}\text { Steam-A1r- } \\
0.3 \% \mathrm{CH}_{4} \\
\text { Air }\end{array}$} & $2 \cdot 5-21$ \\
\hline NSPP & & & $36-48$ & 1.4 & $2600-25000$ & 30 & & $6-10$ \\
\hline Zenith & \multirow{2}{*}{$\begin{array}{l}\text { Painted } \\
\text { Concrete } \\
\text { \& Steel }\end{array}$} & 90 & 5 & $|1.4|$ & $0.4-0.8$ & 25 & Alr & $0.09-0.6$ \\
\hline Zenth & & 1 & Vent1lated & & 0.8 & 25 & A1r & $<0.003^{(\alpha)}$ \\
\hline HATR & \multirow{2}{*}{$\begin{array}{l}\text { Painted } \\
\text { Steel }\end{array}$} & 10 & 0.5 & 11 & 40,000 & 400 & $\mathrm{CO}-\mathrm{CO}_{2}$ & 0.25 \\
\hline HATR & & 95 & 20 & 7.8 & 1300 & 25 & $\mathrm{CO}-\mathrm{CO}_{2}-\mathrm{A} 1 \mathrm{r}$ & 5 \\
\hline
\end{tabular}

NOTES:

(a) ADF - Aerosol Development Fac1lity, Battelle - Northwest (ax)

CMF - Containment Mockup Facility, Oak Rldge National Lab. (\$1, se,s7)

NSPP - Nuclear Safety Pilot Plant, Oak Ridge National Lab. (21)

Zenith - Reactor Facility, United Kingdom Atomic Energy Authority(10)

HATR - Highly Active Test Facllity, United Kingdom Atom1c Energy Authority (sa)

(b) Values shown are maximur reported for test in terms of starting lodine inventory and are not necessarily the final equilibrium value.

(c) Maximum lodine concentration in gas phase at start of test.

(d) Limit of experimental measurement. 
Average Rate Constants for Methyl Iodide Formation on Surfaces of Containment Test Facilities

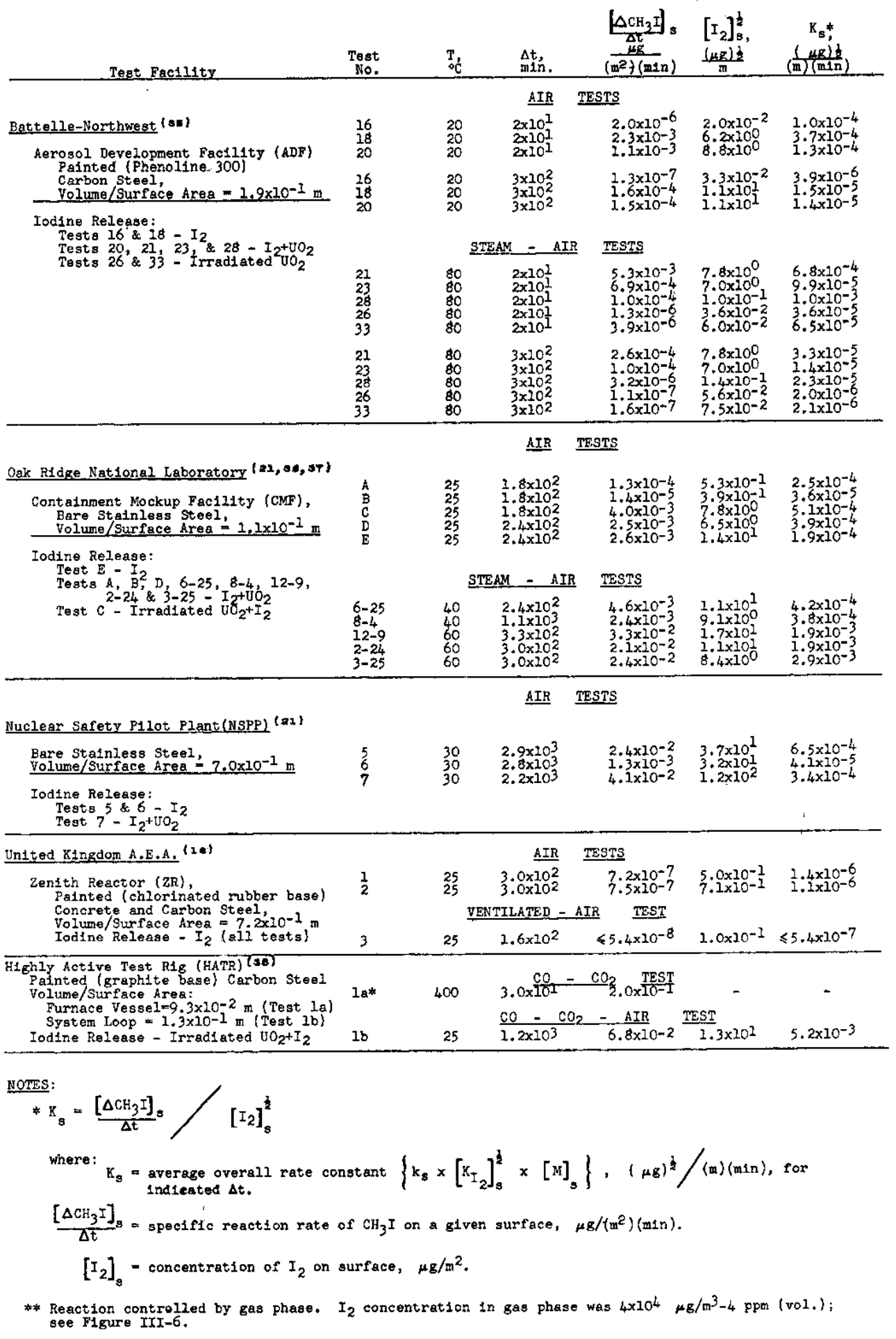




\section{TABLE III-4}

Summary of Average Rate Constants for Methyl Iodide Formation on Surfaces

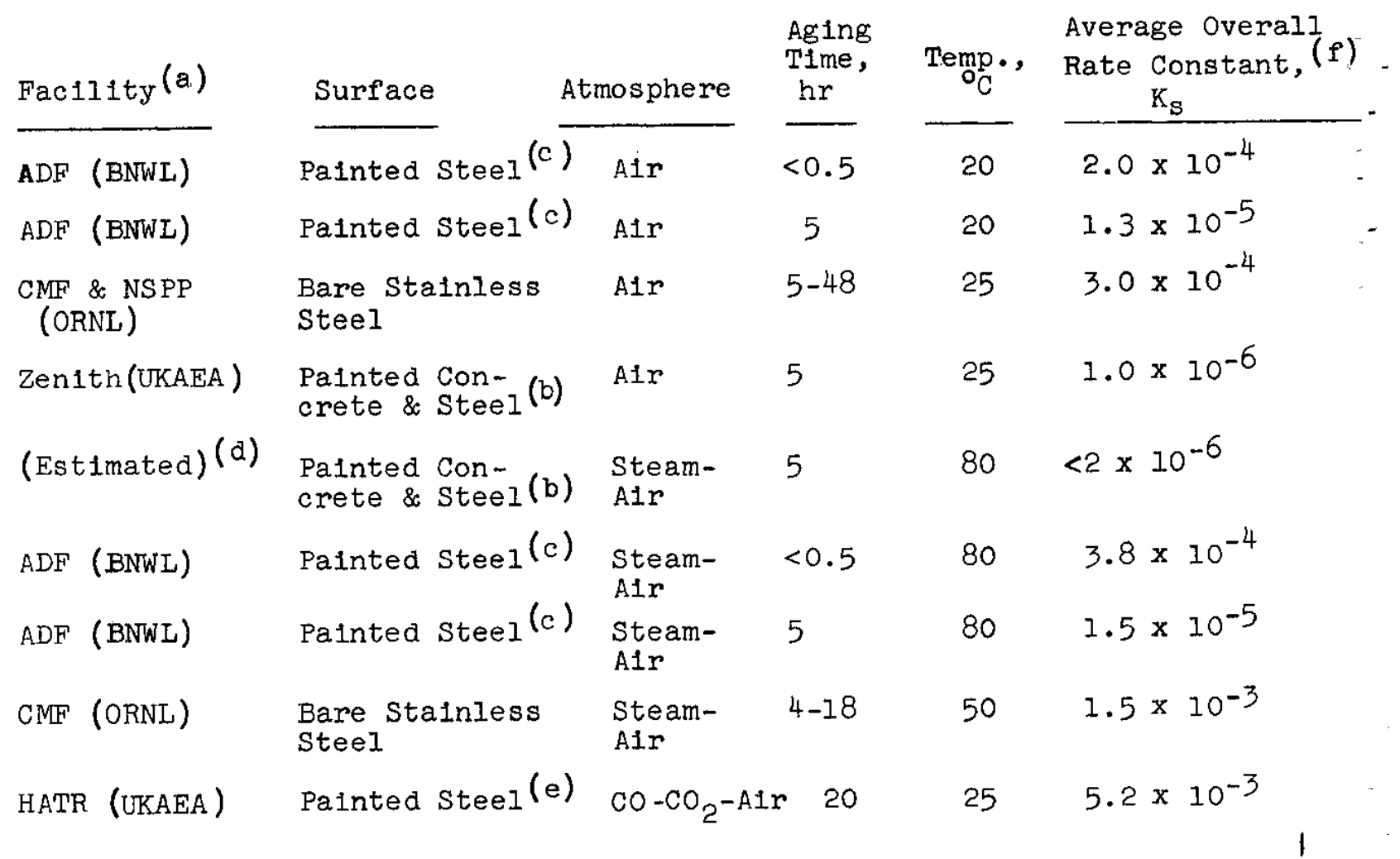

(a) Description of test facilities is given in Table III-3.

(b) Chlorinated rubber base paint. (16)

(c) Vinyl base paint (Phenoline 300 - Carboline Co.)

(d) Rate constant estimated from Zenith air tests and steam air tests in ADF facility.

(e) Graphite-loaded primer (Strathclyde PA-2I)

(f) $\mathrm{K}_{\mathrm{S}}=\left[\mathrm{k}, \frac{\mathrm{m}^{2}}{\mu \mathrm{g}-\mathrm{min}}\right]\left[\mathrm{K}_{\mathrm{I}_{2}}, \frac{\mu \mathrm{g}}{\mathrm{m}^{2}}\right]_{\mathrm{S}}^{1 / 2}\left[\mathrm{M}, \frac{\mu \mathrm{g}}{\mathrm{m}^{2}}\right]_{\mathrm{S}}$ 


\section{B. SRP CONDITIONS WITH RESPECT TO IODINE COMPOUNDS}

Discussed in section III, A are factors which contribute to the formation of lodine compounds. The factors are treated both qualitatively and quantitatively for general application to many reactor confinement applications. In this section, the same information is applied specifically to SRP conditions. Calculations are based on methyl lodide rather than lodine compounds in general, because methyl lodide was reported as being the chief constituent (about 90\%) of the compounds associated with radiolodine releases and because other lodine compounds are adsorbed readily by activated carbon even under moist conditions.

Shown in Table III-5 is a qualitative comparison of conditions that promote the fraction of lodine converted to methyl iodide and SRP conditions.

\section{TABLE III-5}

Qualitative Comparison of Conditions Affecting Fraction of Iodine Converted to Methyl Iodide

Conditions that Promote Fraction of Iodine Converted to Iodine Compounds

\section{In the fuel}

- Organic impurities

- High temperatures

- H1gh hydrogen content

Upon meitdown

- Low radiation field

- H1gh temperatures

- $\mathrm{CO} / \mathrm{CO}_{2}$ atmosphere

In the reactor room (gas phase)

- Long residence time

- High temperatures

- Organic impurities

- Low gas phase lodine concentration

On reactor room surfaces

- Bare ferrous metal surfaces

- High surface to volume rat1o

- Dry surfaces
SRP Conditions

In the fue 1

- High purity fuel

- Low temperatures

- Low hydrogen content

Upon meItdown

- High radiation field

- High temperatures

- Steam and/or oxidizing atmosphere

In the reactor room (gas phase)

- Short residence time

- Low temperatures

- Relatively clean air

- High gas phase lodine concentration

On reactor room surfaces

- Primarily painted concrete surfaces

- Low surface to volume ratio

- Condensing steam on surfaces and/or dry 
The information in Table III-5 is now treated quantitatively in light of the discussion in Section III, A. Each of the factors affecting the overall kinetic relationship is combined into a single equation; then the individual factors are evaluated and combined to yield the effective reaction rate for converting elemental lodine to methyl 1odide. Based on residence time, the conversion rate 1 s expressed as the fraction of initial reactor lodine inventory escaping the activity confinement system as methyl lodide.

Equation (5I) is a generalized reaction rate expression for the factors relevant to the SRP system.

$$
\left[\frac{\Delta \mathrm{CH}_{3} \mathrm{I}}{\Delta \mathrm{t}}\right]_{\text {overall }}=\left[\frac{\Delta \mathrm{CH}_{3} \mathrm{I}}{\Delta \mathrm{t}}\right]_{\begin{array}{c}
\text { absorbed } \\
\text { radiation }
\end{array}}\left[\frac{\begin{array}{l}
\text { Prior to } \\
\text { Incident }
\end{array}}{\left\{\left[\frac{\Delta \mathrm{CH}_{3} I}{\Delta t}\right]_{\text {fuel }}\right.}\right\}
$$

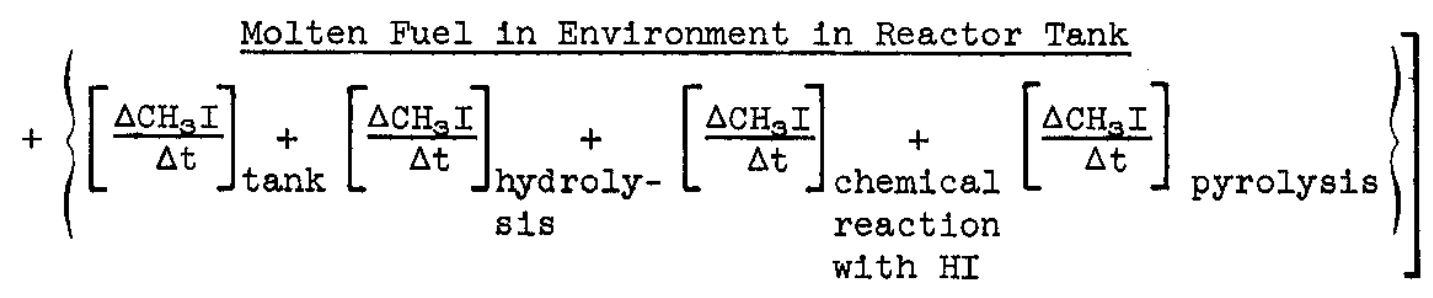

Outside Reactor Tank

$+\left\{\left[\frac{\Delta \mathrm{CH}_{3} I}{\Delta t}\right]_{\substack{\text { gas } \\ \text { phase }}}+\left[\frac{\Delta \mathrm{CH}_{3} I}{\Delta \mathrm{t}}\right]_{\text {surface }}\right\}\left[\frac{\Delta \mathrm{CH}_{3} \mathrm{I}}{\Delta \mathrm{t}}\right]_{\begin{array}{c}\text { absorbed } \\ \text { radiation }\end{array}}$ 


\section{Formation of Methyl lodide in Fuel}

High purity fuel used at SRP and low metal temperatures do not favor conversion of elemental lodine to methyl lodide. The average impurity level for hydrogen and methane in uranium-aluminum a.1loy is $1.2 \mathrm{ppm} \mathrm{H}_{2}$ and $0.035 \mathrm{ppm} \mathrm{CH}_{4}$. These values are inferred from measured values on uranium oxide fuel. From Figure III-1 and the above methane concentrations, the following amounts of methyl iodide in SRP fuel were determined:

\begin{tabular}{|c|c|c|c|c|c|}
\hline \multirow[b]{2}{*}{ Type Fuel } & \multirow[b]{2}{*}{$\begin{array}{l}\text { Avg Bulk } \\
\text { Temp, }{ }^{\circ} \mathrm{C}\end{array}$} & \multirow[b]{2}{*}{$\begin{array}{c}\mathrm{CH}_{4}{ }^{(\mathrm{a})} \\
\mathrm{ppm} \\
\end{array}$} & \multirow[b]{2}{*}{$\begin{array}{l}I_{2}{ }^{(a)} \\
\mathrm{ppm} \\
\end{array}$} & \multicolumn{2}{|r|}{$\mathrm{CH}_{3} \mathrm{I}$} \\
\hline & & & & Mass, g. & $\begin{array}{r}\text { \% of Total } \\
\text { Iodine Inventory }\end{array}$ \\
\hline U-A1 Alloy (b) & 130 & 0.035 & 2400 & 8400 & 0.00067 \\
\hline
\end{tabular}

(a) ppm, based on weight of core material.

(b) For conditions applicable to the Savannah River high flux demonstration, as discussed in Reference 1 .

\section{Formation of Methyl lodide Upon Meltdown}

The following factors relating to formation and decomposition were considered in calculating the net methyl lodide that could be released from the reactor tank following a full-core meltdown:

- methyl iodide release from the fuel

- gas-phase formation in tank

- surface reaction

- chemical reaction with hydrogen iodide

- hydrolysis

- pyrolysis

- radiolysis

Those factors which contribute to methyl lodide formation include the material released from the fuel, gas-phase reaction with impurities in the tank, and reaction catalyzed by metal surfaces. Should an accident occur involving a full-core meltdown, most of the liquid water would be rapidly drained or efected from the tank. The remaining coolant would be vaporized, and molten fuel would collect in the bottom of the tank. 
As discussed in Section III,A,4, analysis of UKAEA tests ${ }^{(38)}$ at $400^{\circ} \mathrm{C}$ for 30 minutes showed that surface reaction 1 , the quential compared to the gas-phase react but not included because of mechanism for reaction is recosults compared to the gas-phase the relative magnitude of the gas-phase equilibrium concentration reaction in the tank. The gas 43 to be $400 \mu \mathrm{g} / \mathrm{m}^{3}(0.004 \%$ of total was determined from Equation $18 \times 10^{7} \mu \mathrm{g} / \mathrm{m}^{3}$ (100\% of lodine invenIodine concentration: 1.8 tory released into reactor vessel). Methane concentration: $50 \mu \mathrm{g} / \mathrm{m}^{3}(0.001 \%$ of carbon in fuel and other components conserven at assumed to react with mass to form methane).

Temperature:

$$
700^{\circ} \mathrm{C}
$$

Because the equilibrium concentration of methyl iodide in the reactor vessel $\left(400 \mu \mathrm{g} / \mathrm{m}^{3}\right)$ is more than that which would be by release from the fuel ( $120 \mu g / m$, Equation the very rapid formation of methyl lodide would apply. value would be obtained reaction rate at $700^{\circ} \mathrm{C}$,
in less than one second.

The remaining factors - hydrolysis, pyrolysis, and radiolysis favor decomposition of methyl iodide. Radiolysis is consid is quantitatively, but because of insufficlent dysis. Pyrolysis, taken for the effectudied further.

For conditions applicable to the savann to decompose $99 \%$ of methyl demonstration, (1) radiolysis is expected tection III,A,2. The quantilodide per 1.2 secondiolysis are considered independently of tative effects of radiolysis are conside Table III-6. 


\section{TABLE III-6}

Decomposition of Methyl Iodide in the Reactor Vessel by Rad1olysis

\begin{tabular}{|c|c|c|c|}
\hline $\begin{array}{l}\text { Residence } \\
\text { Time, sec }\end{array}$ & $\begin{array}{c}\text { Maximum Initial } \\
\mathrm{CH}_{3} I \text { Concentration } \\
\text { In Reactor Vessel, } \mu \mathrm{g} / \mathrm{m}^{3} \\
\end{array}$ & $\begin{array}{c}\text { Remaining } \mathrm{CH}_{\mathrm{s}} \mathrm{I} \\
\text { Concentration In } \\
\text { Reactor Vessel, } \mu \mathrm{g} / \mathrm{m}^{3} \\
\end{array}$ & $\begin{array}{r}\mathrm{Net} \\
\mathrm{CH}_{3} \mathrm{I} \\
\mu \mathrm{g}\end{array}$ \\
\hline$I$ & 400 & $9.4 \times 10^{0}$ & $6.6 \times 10^{2}$ \\
\hline 2 & 400 & $2.2 \times 10^{-1}$ & $1.5 \times 10^{1}$ \\
\hline 3 & 400 & $5.4 \times 10^{-3}$ & $3.8 \times 10^{-1}$ \\
\hline 4 & 400 & $1.3 \times 10^{-4}$ & $9.1 \times 10^{-3}$ \\
\hline 5 & 400 & $3.2 \times 10^{-6}$ & $2.2 \times 10^{-4}$ \\
\hline
\end{tabular}

The net amount of methyl lodide that could escape the tank after the effects of radiolysis is less than $10^{-3} \mu \mathrm{g}$ (10-12\% of reactor lodine inventory) for a residence time of about 5 seconds. Because there is little driving force to rapldiy remove vapor from the tank prior to the addition of light water, most of the lodine would remain in the tank unt1l water was added.

Radiolysis alone is adequate to reduce the concentration of methyl lodide to an inconsequential value in the reactor vessel. Because of the effectiveness of the decomposition mechanisms, the initial concentration of methyl lodide in the tank would have no bearing on the off-site ingestion dose.

3. Formation of Methyl lodide in Reactor Room

Formation of methyl lodide in the reactor room was calculated for two cases: (1) formation in the gas phase, and (2) formation on surfaces.

The gas phase reaction is controlled by the temperature in the reactor room. Because the reactor room pressure is essentially atmospheric, the highest temperature that might be expected would be $100^{\circ} \mathrm{C}$ or less in the immediate vicinity of the reactor tank during the inftial phase of a major accident. After light water addition has begun and steam generation has stopped, the room temperature would drop to about $25^{\circ} \mathrm{C}$. During the first 30 minutes of an accident, an average temperature of about $40^{\circ} \mathrm{C}$ was calculated. As shown in Figure III-6, at a temperature of about $40^{\circ} \mathrm{C}$, the rate of formation of methyl lodide in the gas phase would be about $10^{-20} \mathrm{\mu g} /\left(\mathrm{m}^{3}\right)(\mathrm{min})$, which is inconsequential. 
The controlling mechanism for formation in the reactor room would be reaction on surfaces. The reaction rate for surfaces is expressed by Equation 49. In the SRP ventilated system, however, the lodine concentration is continuously diminishing, as expressed by Equation 52 in Section III,C,1. Therefore a precise determination of the reaction rate would be calculated by integrating a combined form of Equations 49 and 52. In the interest of time, the reaction rate is estimated conservatively (Equation 50) from the maximum lodine concentration as determined by the procedure described in Section III,A,4. This maximum concentration corresponds to a reaction rate of $5 \times 10^{-5} \mathrm{\mu g} /\left(\mathrm{m}^{2}\right)(\mathrm{min})$. If it is assumed that methyl lodide desorbs upon formation, the total amount reaching the adsorption beds is negligible, about $10^{-6} \%$ of total reactor lodine inventory in the first hour. Inconsequential formation of methyl lodide on the surfaces would occur after one hour because of desorption of elemental lodine as demonstrated by the Zentth reactor tests.

4. Decomposition of Methyl lodide Release to the Atmosphere

Although a radiation field in the order of $10^{\circ} \mathrm{R} /$ hour could exist on the beds, no credit was taken in the analysis for decomposition of methyl lodide on the beds, because the retention time of methyl iodlde on SRP carbon is unknown. Tests are planned to determine this value.

\section{Summary of Methyl lodide Release to the Atmosphere}

The net amount of methyl lodide that could be formed in the SRP system if an accident should occur is inconsequential; it would contribute less than 1 Rem to the off-site ingestion dose. Although the lodine compound formation was calculated to be about $10^{-6} \%$ of total reactor lodine inventory, a value of $10^{-4}$ is used. Th1s conservatism allows for possible differences between methane concentration on surfaces at SRP, variation in results from tests from which $K_{\mathrm{S}}$ was derived, precision of factors used in deposition calculations, and conditions on the surfaces, $1 . e .$, dry or condensing steam.

\section{TRANSPORT AND DEPOSITION OF FISSION PRODUCTS IN THE SRP SYSTEM}

Transport and deposition of fission products within the reactor building must be determined to permit calculation of the disposition of the fission products, methyl iodide formation, and heat loads on the filters and adsorbers. Transport of fission products was considered from two aspects: removal of material from the reactor room through the exhaust ventilation system and removal in water solution or suspension to the 50-milition-galion emergency basin. 
1. Transport and Deposition through Exhaust Ventilation System

In a once-through, high-volume ventilation system such as the SRP system, removal of fission products from the proximity of the reactor to the activity confinement system was designed to be very rapid. Most of the materlal is carried through the exhaust ducts to the filter compartments; only a small part is deposited on the surfaces of the reactor room and ventilation ducts. The reduction in lodine vapor activity in the reactor room and the amount of material deposited on surfaces was calculated from an exponential equation and deposition constants developed primarily by the British. $(16,39)$

$$
C=C_{\circ} \exp -\left[\left(\frac{\mathrm{VA}}{\mathrm{V}}+\frac{F}{\mathrm{~V}}\right) \mathrm{t}\right]
$$

where:

$$
\begin{aligned}
C= & \text { quantity of fission products in reactor room at time } t \\
C_{0}= & \text { inftial quantity of fission products in reactor room at } \\
& \text { time zero } \\
\mathrm{V}= & \text { deposition velocity } \\
\mathrm{A}= & \text { surface area } \\
\mathrm{V}= & \text { room volume } \\
\mathrm{F}= & \text { exhaust air flow } \\
t= & \text { time after incident }
\end{aligned}
$$

The amount of material deposited on surfaces of the reactor room and ventilation ducts was calculated with use of the IBM 704 computer as the difference between Equation 52 when the deposition velocity was equal to zero, and when the deposition velocity was equal to the experimentally determined value. Instantaneous release of fission products into the reactor room was assumed. An air flow of $38,000 \mathrm{cfm}$ through the reactor room and an effective deposition velocity of $4.7 \times 10^{-3} \mathrm{~cm} / \mathrm{sec}$ were used in the calculation. ( 38 )

For SRP application, maximum lodine deposition of $1 \%$ of the airborne inventory was calculated to occur on surfaces of the reactor room and exhaust ducts. Compared to unventilated facilities $1 \%$ deposition is low, but the SRP surface to volume ratio and the residence time for deposition are very low. Also, 
"Amercoat" 33HB, which is the paint used on concrete at SRP, had the lowest deposition of several paints tested at ORNL (21). TID-14844(40) suggests a deposition of 50\%, but for application to reactors with containment shells this value may be low, and higher deposition factors may be applicable. Although the inftial mass of lodine calculated to reach the carbon beds was almost doubled when $1 \%$ deposition was used rather than the suggested $50 \%$, the potential for lodine compound formation is greatly reduced, as discussed in Section III,B. The results of the transport and deposition calculations are shown in Figures III-10 and III-II. About $99 \%$ of the material would be removed from the process room in 40 minutes at normal exhaust ventilation flow.

For practical purposes, lodine is the only fission product of concern in the deposition determination. Noble gases deposit on reactor room surfaces in negligible quantities and then are retained only temporarily. The amount of noble gas that dissolves in the full reactor inventory of $\mathrm{D}_{2} \mathrm{O}$ plus emergency light water that might be added to the system is negligible. Likewise the SRP activated carbon beds detaln noble gases for only a few seconds. Therefore, no deposition is assumed, and 100\% of the noble gases leaving the reactor escape to the atmosphere.

Only one percent of the nonvolatile fission product activity was assumed to escape the reactor ${ }^{(41)}$. Half of this amount was estimated to settle out in the reactor room or deposit on surfaces. Because of the small fraction released and the $99 \%$ efficiency of the particulate filters, the off-site radiation and ingestion doses are negligible.

\section{Transport to Emergency Storage Bosin}

As discussed in Section II-F, any waterborne' fission products would be transported to the 50-mililon-galion storage basin. With regard to rapid off-site contamination, the only group of fission products of concern would be the halogens, some of which could enter the basin and escape into the atmosphere. All noble gases would be released to the ventilation system because of their high volatility and low solubllity. Nonvolatile particulate matter would either remain in the water, settle to the bottom of the basin, or soak into the soll. If the reactor iodine inventory were transported to the storage basin, less than half the 300 rem stated in the $10 \mathrm{CFR} 100$ guidelines could be released to the atmosphere. 


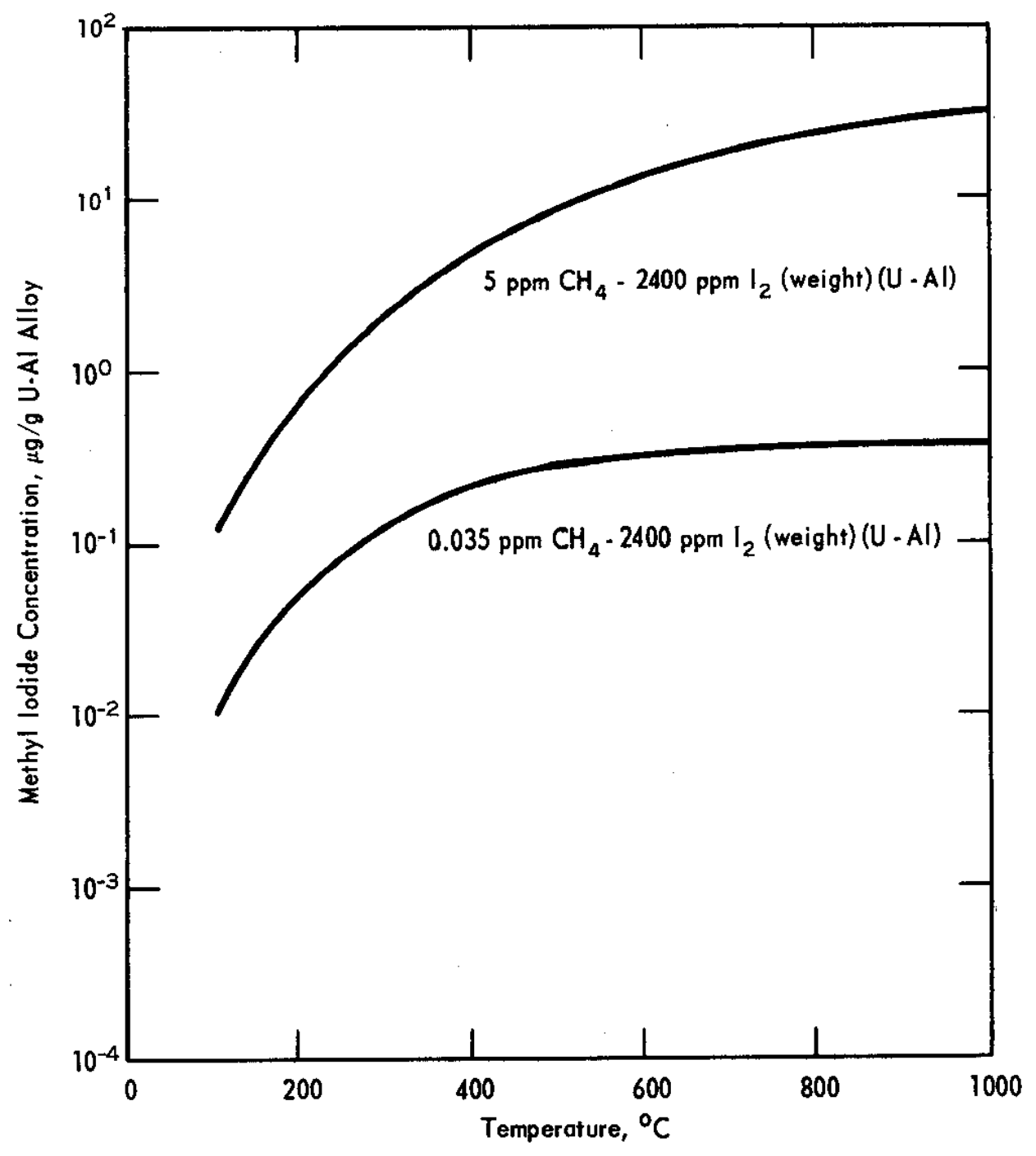

FIG. III-1 MAXIMUM POSSIBLE EQUILIBRIUM AMOUNT OF METHYL IODIDE IN IRRADIATED URANIUM-ALUMINUM ALLOY 


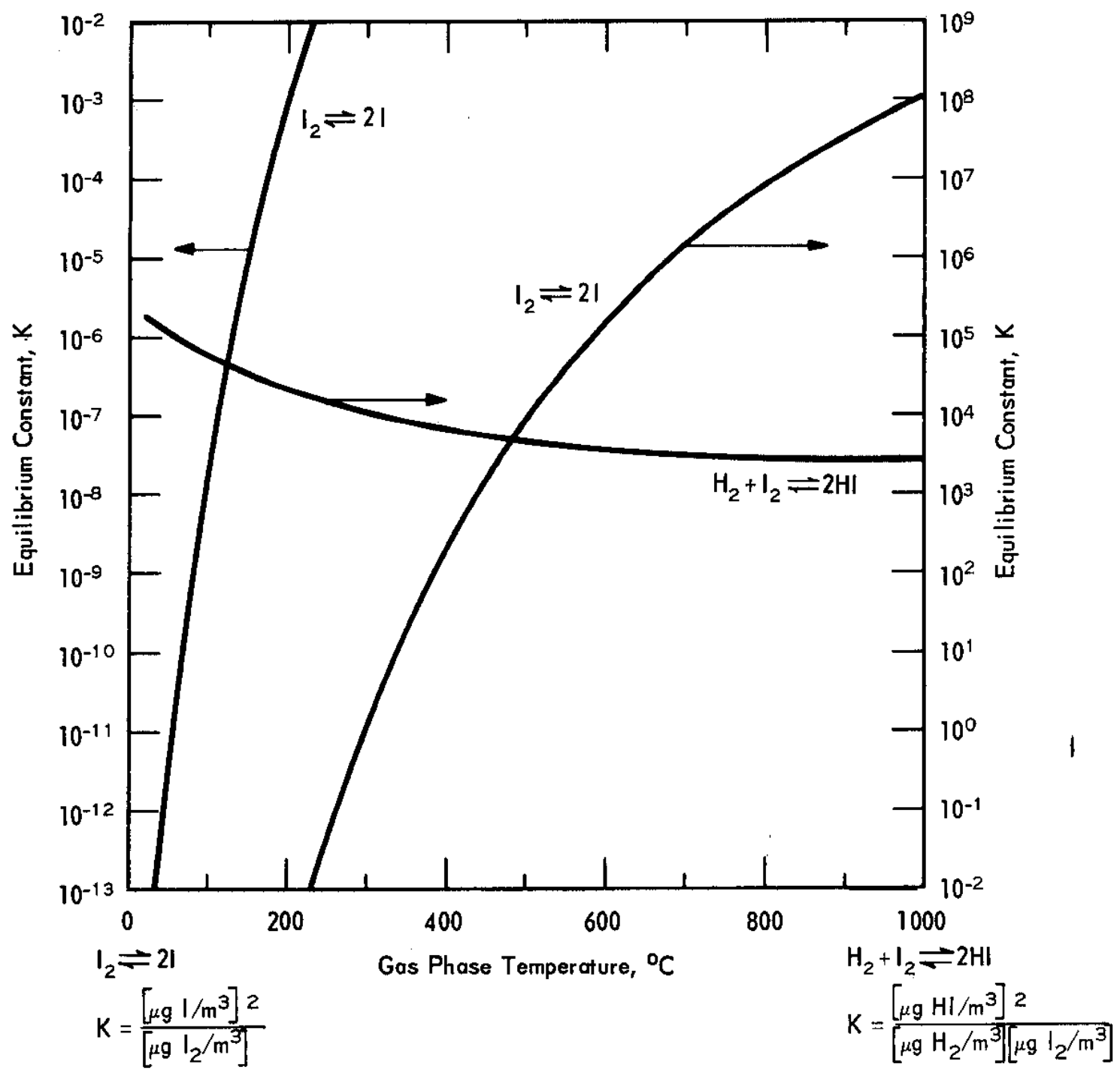

FIG. III.2 EQUILIBRIUM CONSTANTS FOR IODINE AND HYDROGEN IODIDE 


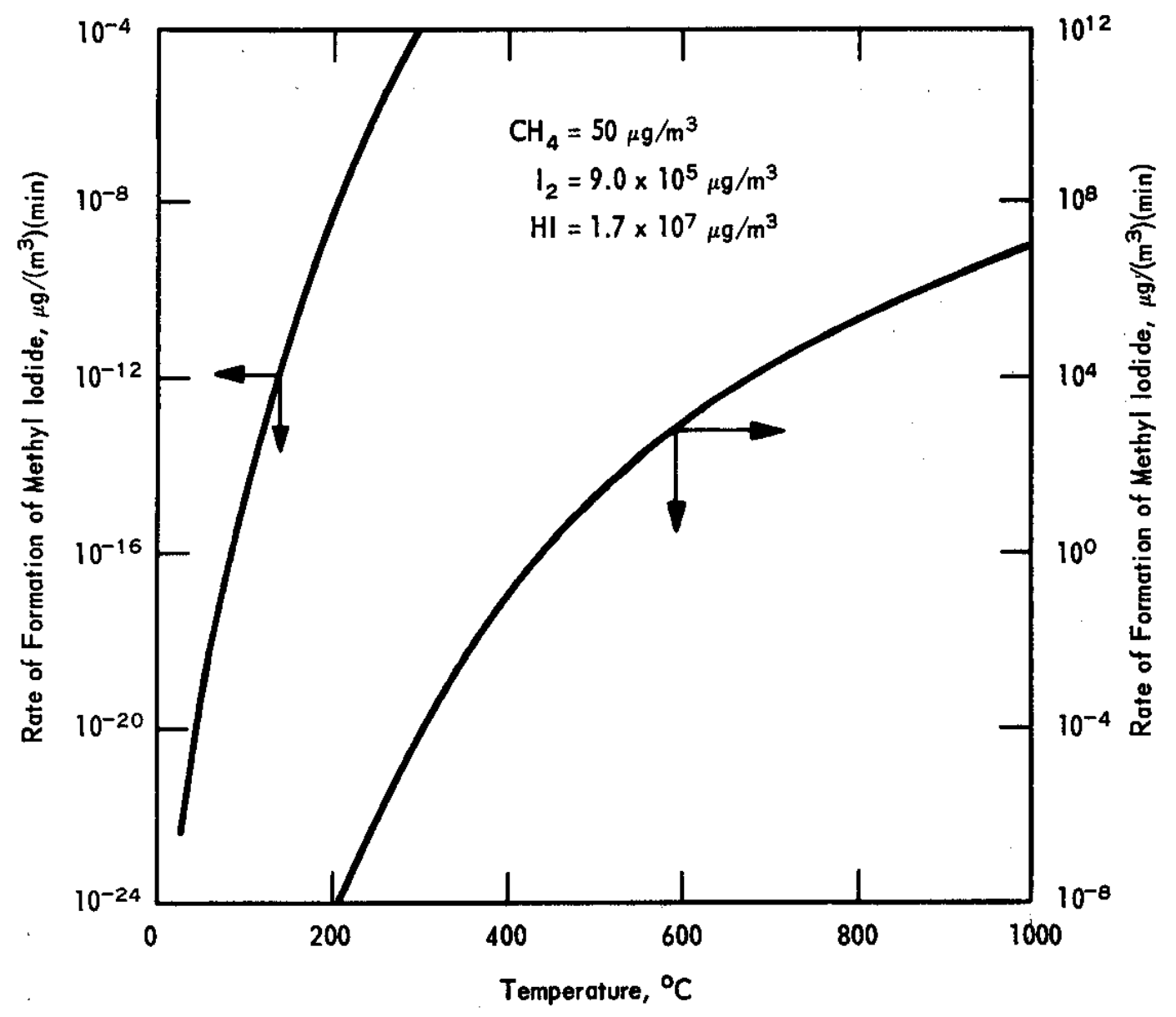

FIG. III.3 RATE OF FORMATION OF METHYL IODIDE IN HYDROGEN IODIDE - RICH ATMOSPHERE 


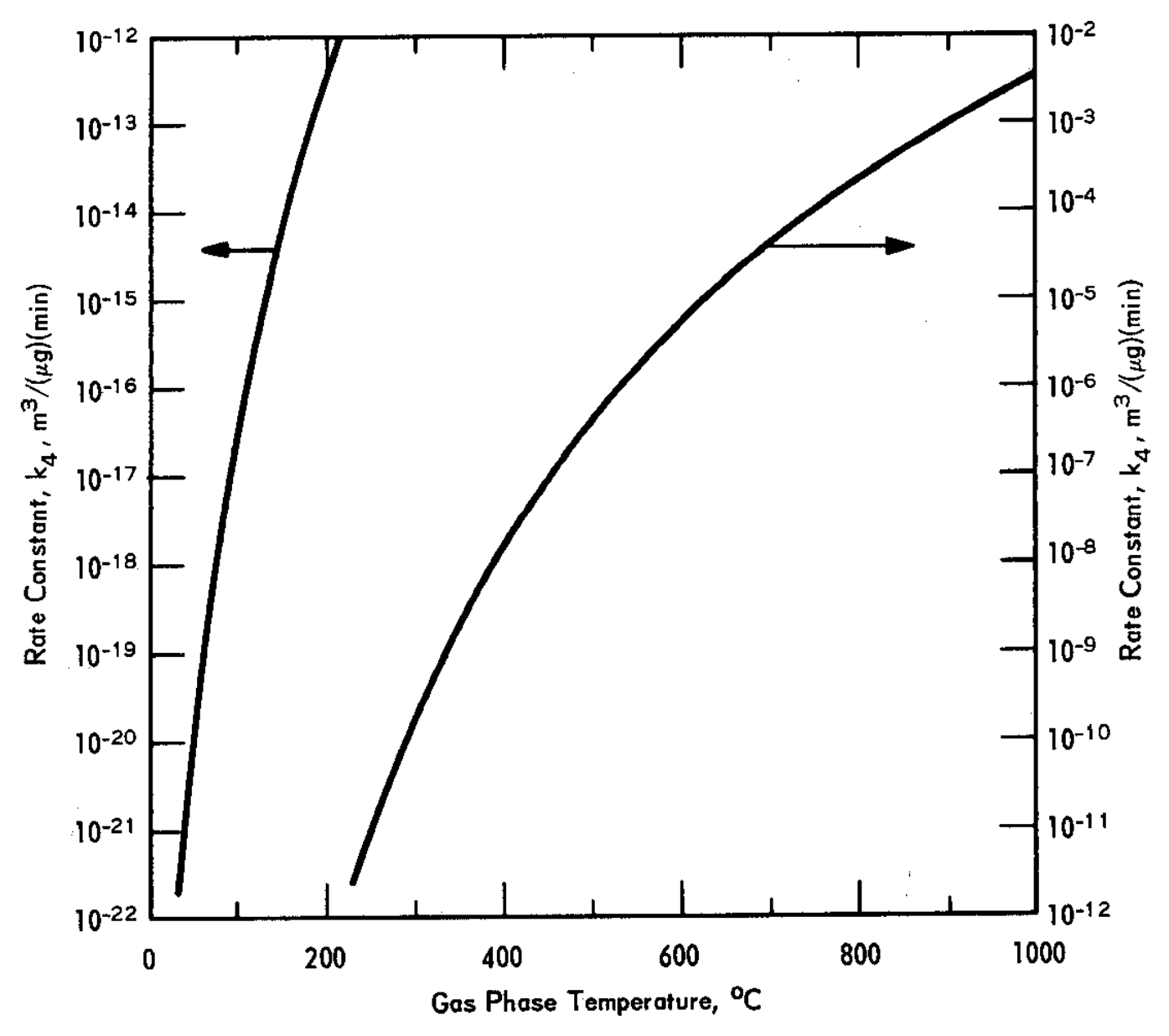

FIG. III-4 SPECIFIC RATE CONSTANT FOR METHANE - IODINE REACTION 


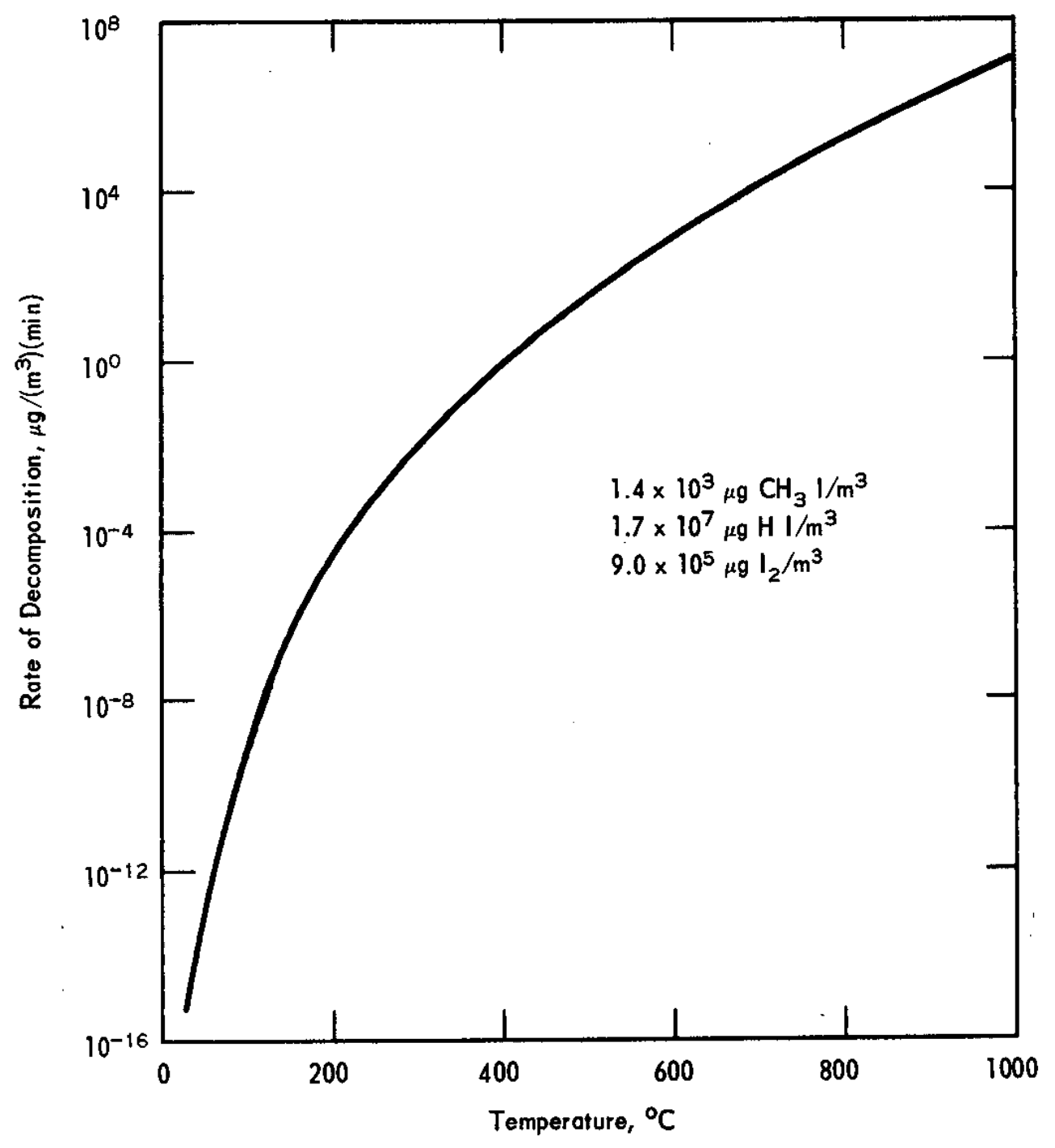

FIG. III-5 RATE OF DECOMPOSITION OF METHYL IODIDE BY REACTION WITH HYDROGEN IODIDE 


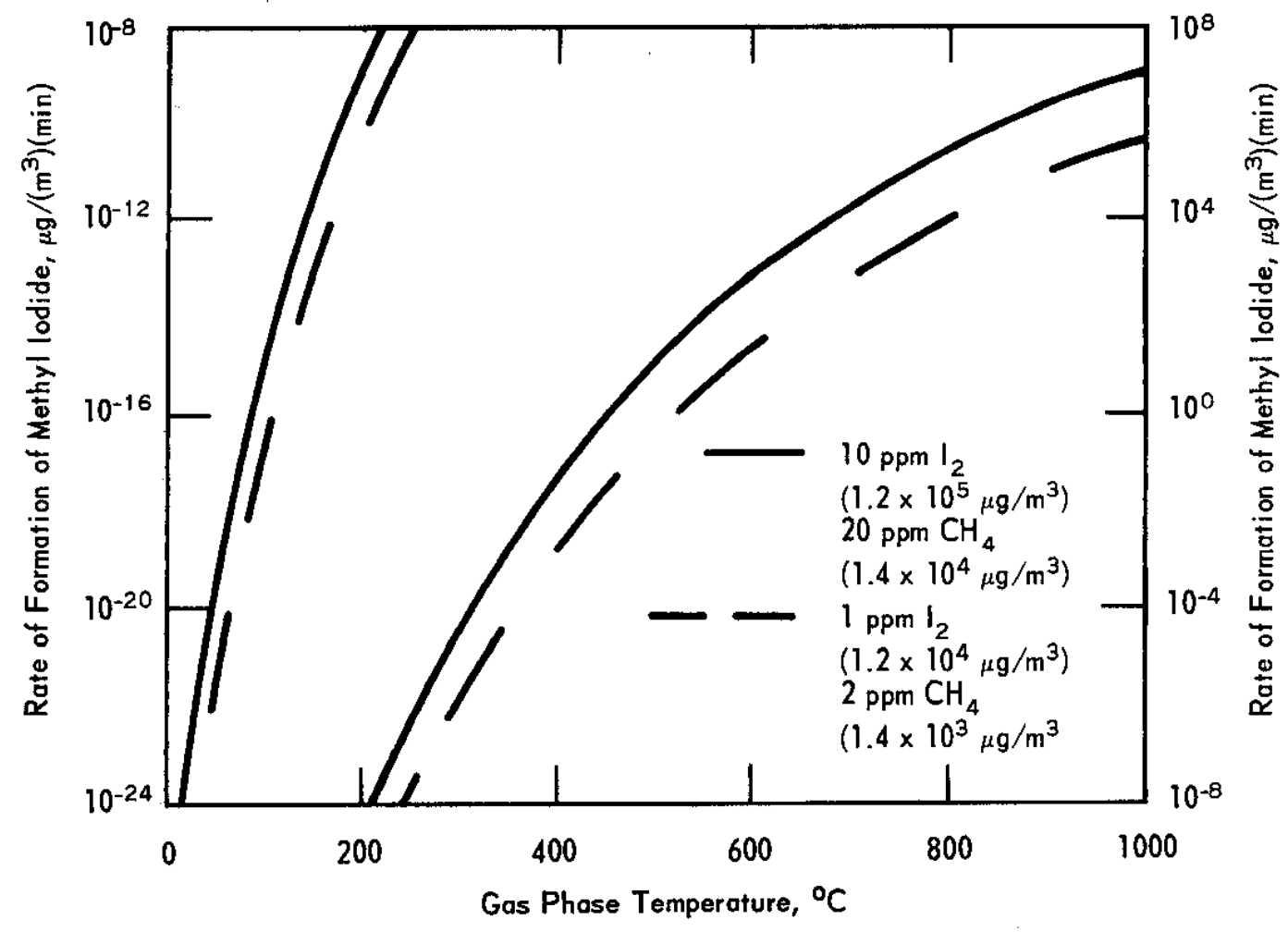

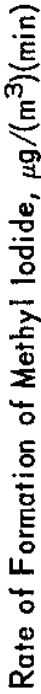

FIG. III.6 RATE OF FORMATION IN GAS PHASE OF

METHYL IODIDE IN CONTAINMENT BUILDINGS 


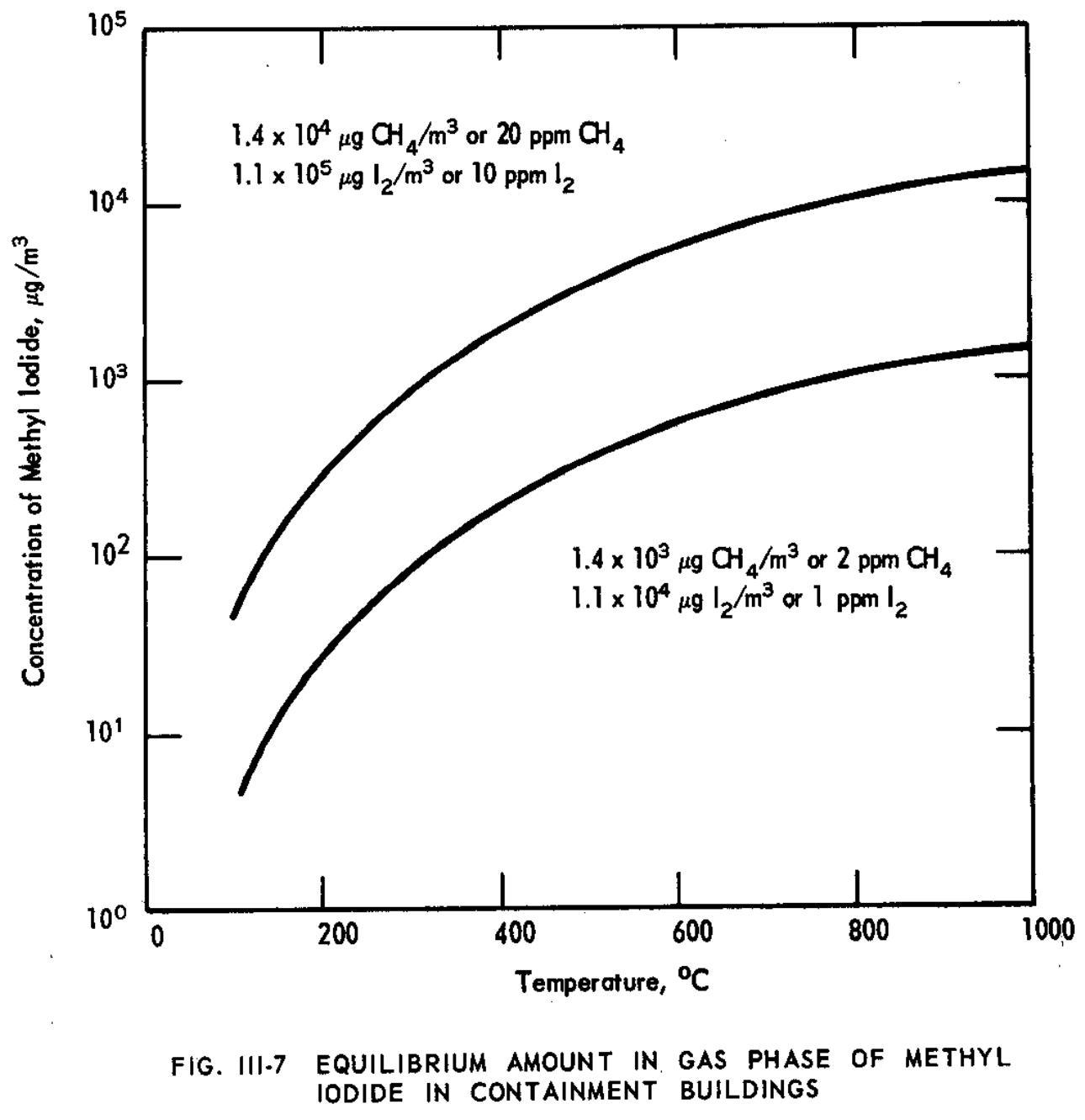




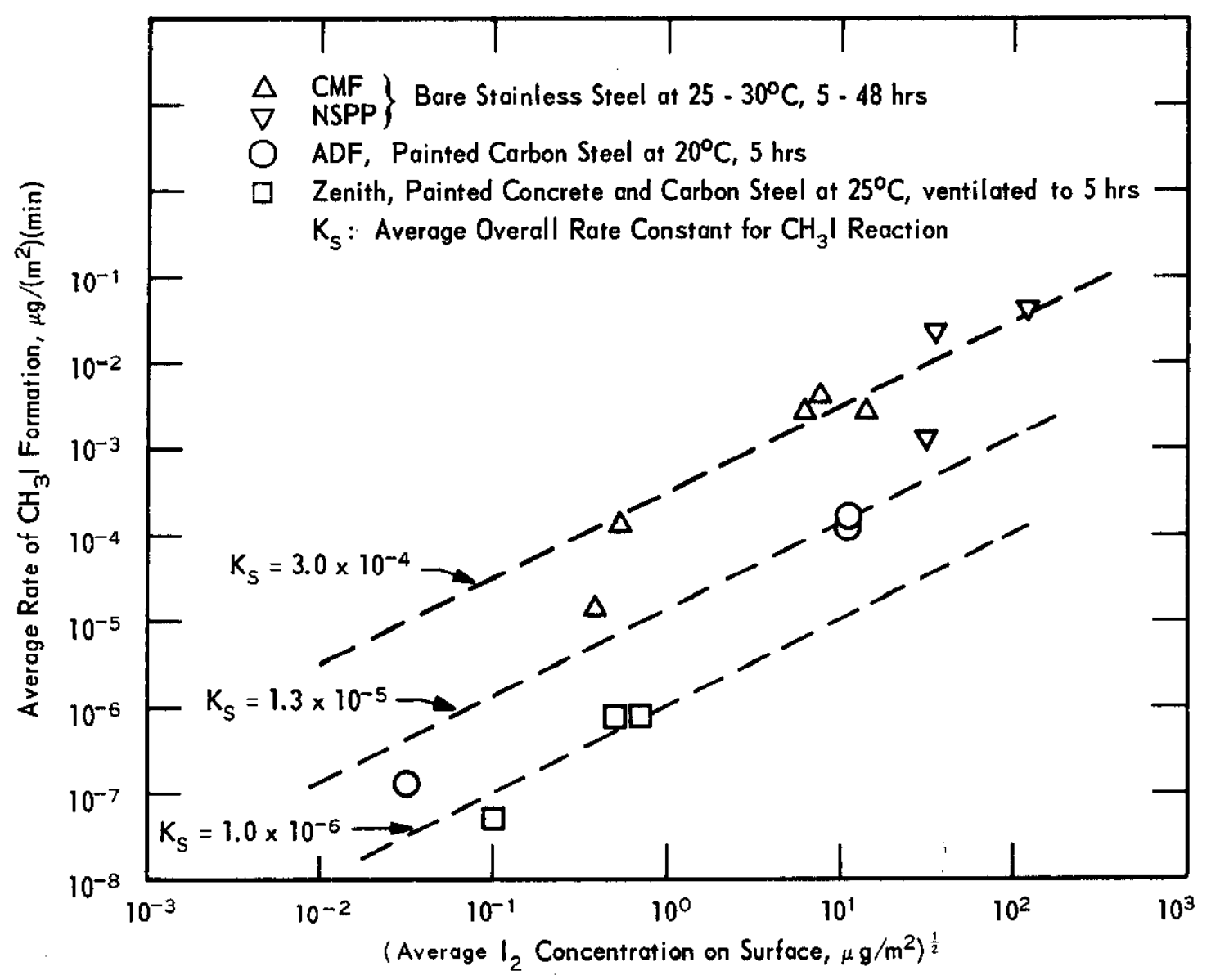

FIG. III.8 METHYL IODIDE FORMATION ON SURFACES IN AIR ENVIRONMENT 


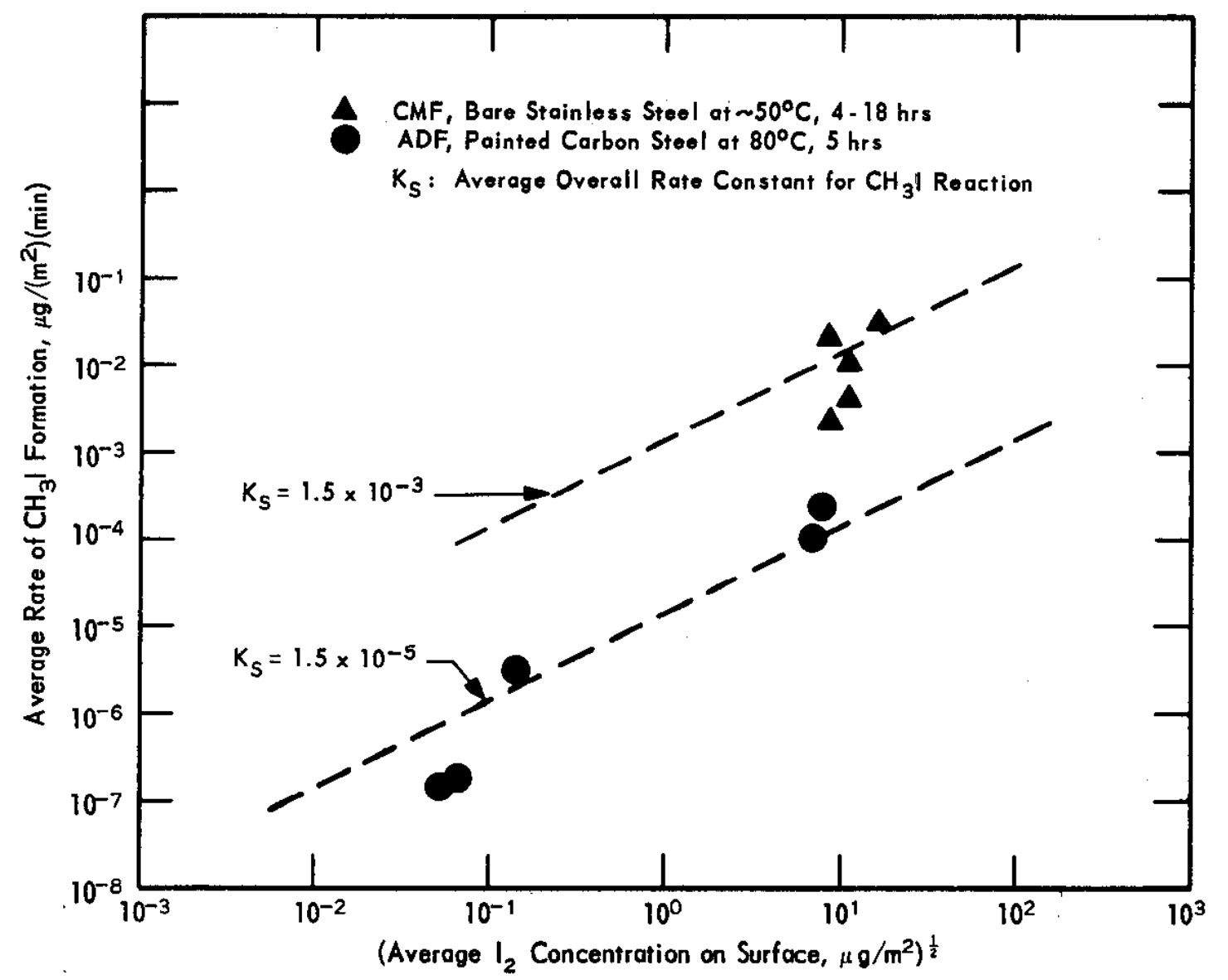

FIG. III-9 METHYL IODIDE FORMATION ON SURFACES IN STEAM - AIR ENVIRONMENT 


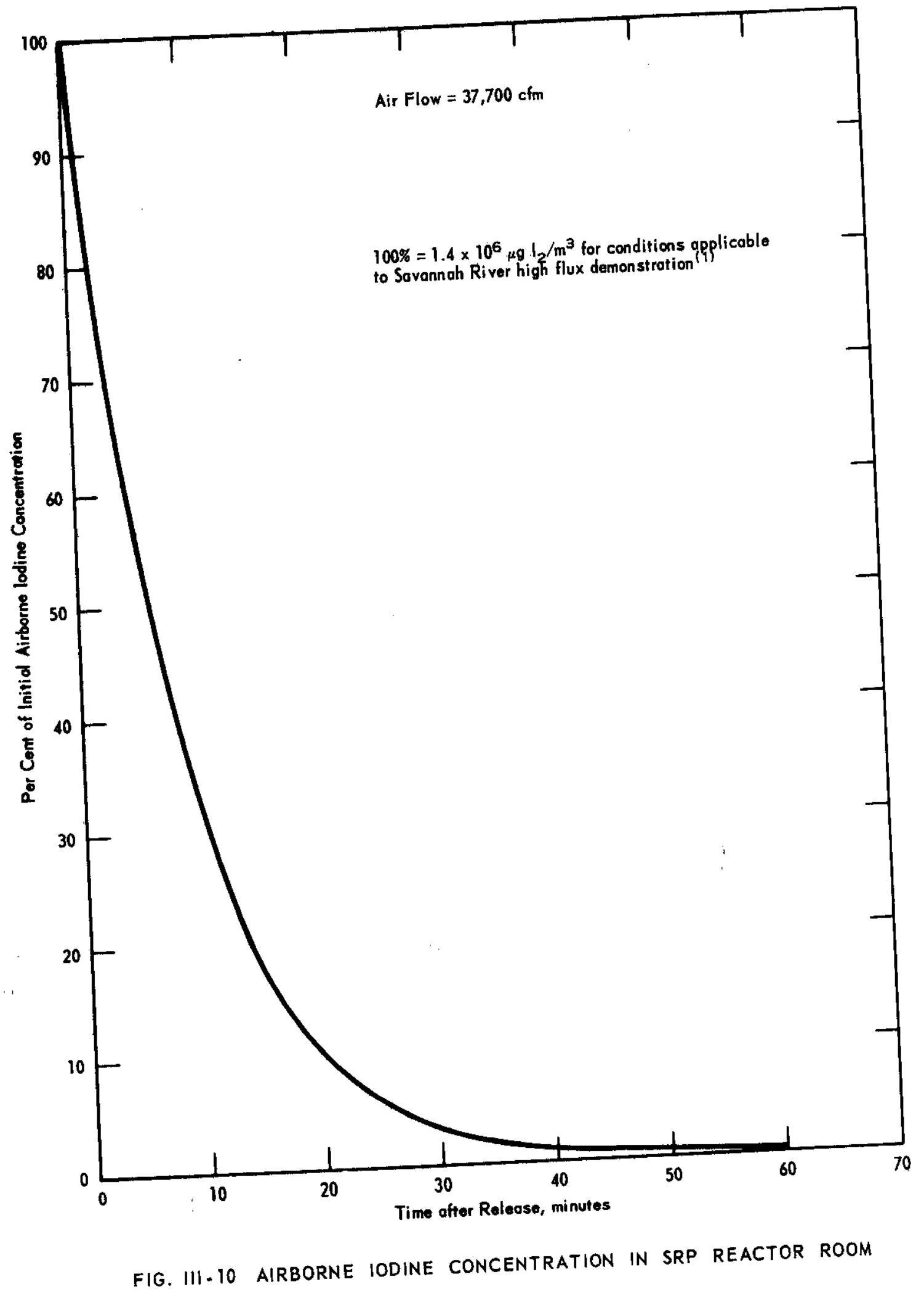

III-42 


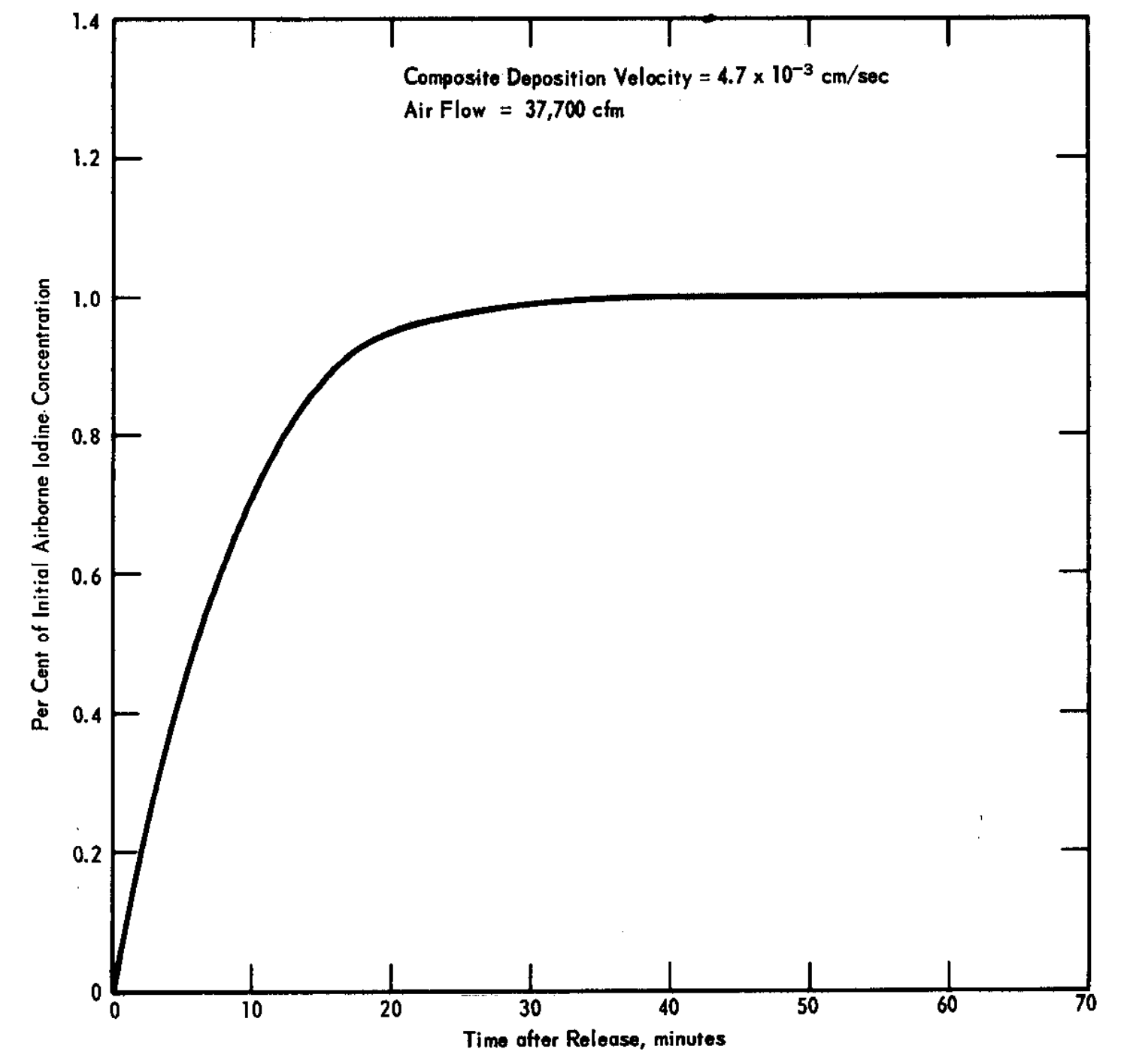

FIG. III. 11 AMOUNT OF IODINE DEPOSITING ON SRP REACTOR BUILDING SURFACES 


\section{FISSION PRODUCT COLLECTION}

This section is concerned primarily with the relationship of the efficiency of the SRP activity collection system to the guidelines in $10 \mathrm{CFR} 100^{(42)}$. Information presented is based on operating conditions in the Savannah River high flux demonstration (1) and is summarized with respect to the type of fission products released; particulate matter, halogens, and noble gases.

\section{A. PARTICULATE MATTER}

Although the gamma radiation from particulate matter (the relatively nonvolatile fission products) is approximately equal to that from noble gases, the effect of particulate matter is of small concern in relation to ingestion and whole body dose because of the relatively small amount of material that would reach the plant boundary. SL-1,(41) Brit1sh, (43) and ORNL $(21,28,36,44)$ experience indicated that an assumption of $1 \%$ released from the reactor is reasonable. About 50\% of the material released was estimated to deposit on building or containment surfaces prior to reaching the particulate filters. Based on a design efficiency of $99 \%$ (inplace DOP tests demonstrated an efficiency of $99.9+\%$, Sections II,D, 2 and $V, C)$, the fraction of particulate matter which would escape the reactor building even for the highly unlikely case of full core meltdown would be less than 0.00005 , which is inconsequential compared to noble gas release.

\section{B. HALOGENS}

The primary concern with halogen activity is thyroid ingestion. The criterion in $10 \mathrm{CFR} 100$ is a dose of 300 rem at the plant boundary integrated over the time of passage of the cloud. In the highly unlikely event of a full core meltdown with a full inventory of fission products and under adverse meteorological conditions using conservative calculational methods, the average efficiency of the adsorbers must be equal to or greater than $99.42 \%$ (maximum penetration of $0.58 \%$ of the material reaching the banks) to remain within the $10 \mathrm{CFR} 100$ guidelines.

\section{Factors in Evaluating Adsorber Units}

Four factors were considered in evaluating the effectiveness of the iodine adsorption system.

- The efficiency of used carbon for removing elemental iodine vapor.

- Penetration of iodine in particulate matter not retained by particulate filters. 
- Leak paths through the bed or gaskets.

- Iodine compound formation and retention.

The maximum and average penetrations that were measured or calculated to occur by the above mechanisms are summarized in

Table IV-l.

TABLE IV -1

Iodine Penetration of Activated Carbon Beds (a)

$\begin{aligned} I_{2}(\mathrm{~b}) & \begin{array}{l}\text { Gasket Methyl } \\ \text { Mechanism } \rightarrow \text { Vapor }\end{array} \text { Particulates Leaks Iodide } \text { Total }\end{aligned}$

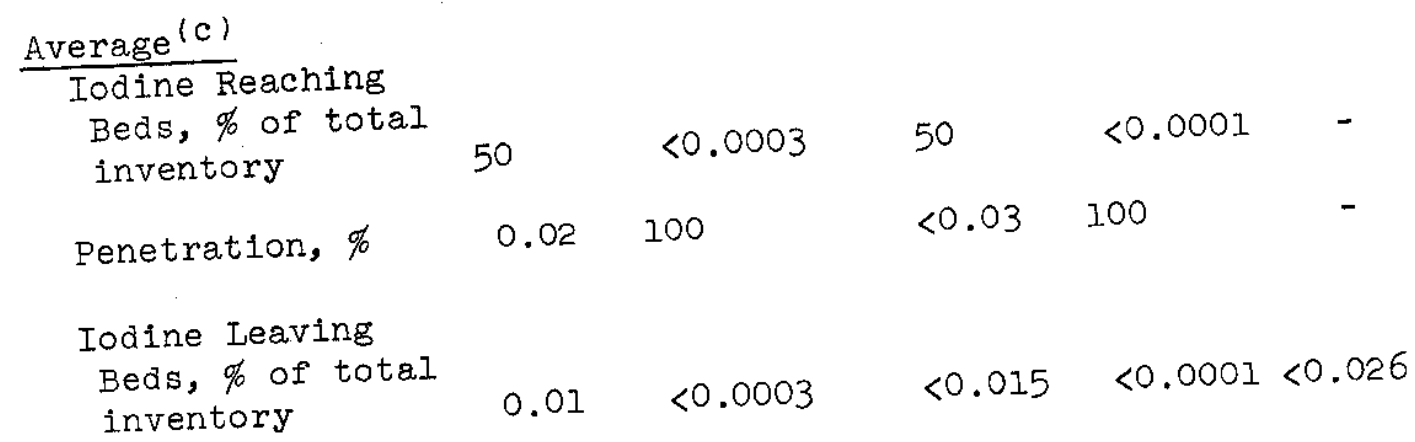

$\operatorname{Maximum}(\mathrm{c})$

Iodine Reaching

Beds, \% of total

inventory

50

0.0025

50

$<0.0001-$

Penetration, $\%$

$0.04 \quad 100$

$0.05 \quad 100$

Iodine Leaving

Beds, \% of total

inventory

$0.02 \quad 0.0025 \quad 0.025<0.0001<0.048$

(a) $50 \%$ of the lodine was assumed to remaln in the reactor.

(b) Assumes steam-a1r conditions; penctrach the carbon beds as HI. As air. Some of the lodine may reach the carbont information is discussed in Section III, $A, 3$, insuf available to permit determination of of HI in air. Because HI is as been made to distinguish between carbon as $I_{2}$, no attempt has

(c) Average refers to a minimum of three banks on line; maximum refers to a single bank.

The maximum penetration corresponds to an ingestion of 50 rem, well below the $10 \mathrm{CFR} 100$ guideline. The penetration was based on $50 \%$ of the lodine inventory in the reactor being released 
into the reactor room as vapor and $0.5 \%$ in particulate matter. A $50 \%$ release from the fuel was assumed as is customary in reactor safety analysis $(40)$, and a review of literature indicated that $50 \%$ was a typical value in experiments $(28,36)$ that were conducted under conditions favoring the release of lodine vapor. Less than a $50 \%$ release would be expected at SRP because temperatures and reaction times would be less favorable to lodine release than in the experiments. No credit was taken for solubility of lodine in $\mathrm{D}_{2} \mathrm{O}$, although the entire reactor inventory of elemental lodine is soluble in a small fraction of the $\mathrm{D}_{2} \mathrm{O}$ in the reactor tank. Most of the lodine will appear in the reactor vessel, as hydrogen lodide, which is much more soluble in water than elemental lodine(45). Solutions of hydrogen lodide, like other solutions containing lodide ion, can dissolve large quantities of elemental lodine. For example, a solution saturated with lodine at $25^{\circ} \mathrm{C}$ contains $72.85 \%$ iodine, $18.1 \%$ hydrogen lodide, and $9.05 \%$ water, with a specific gravity of $3.28^{(46)}$. Therefore the assumption of $50 \%$ release is considered highly conservative.

The four mechanisms are discussed in more detail in the following paragraphs.

\section{a. Elemental Iodine Efficiency of In-Service Activated Carbon}

The efficiency of new activated carbon in steam-air tests is greater than $99.99 \%$ for elemental lodine vapor(B). However, as discussed in section V,D, the efficiency is reduced by exposure to atmospheric impurities. The minimum efficiency that was measured on carbon from an operating reactor area was $99.96 \%(4.7)$. The carbon was removed from one of the original cadmium-plated frames of beds from $\mathrm{K}$ Area. The average efficiency, though, was $99.98 \%$. In a1r tests the minimum measured efficiency was greater than $99.99 \%$.

Efficiencies lower than $99.96 \%$ were measured on one carbon bed removed from a fliter bank in R-reactor area after 14 months of operation. The minimum measured efficiency was $99.89 \%$ in a steamair test. The R-reactor beds corroded (see Section V) much faster than those in other reactor areas; hence, there appeared to be a real difference between $R$ reactor and the other areas in the environment that the carbon beds were exposed to. Because $R$ reactor is no longer operating, the R-reactor experience was not used in calculating the maximum penetration for Table IV-I. 


\section{b. Penetration of Carbon Beds by Iodine in Particulate Matter}

Iodine can be associated with particulate matter in two forms: physically or chemically adsorbed to the particle surface after release from the reactor, or trapped in the particle at the time the particle separates from the fuel. Based on $1 \%$ of the mass of fuel released from the reactor as particles, only about $5 \times 10^{-7} \%$ of the lodine released from the reactor as vapor could adsorb on particulate surfaces as a monomolecular layer. About 1000 times this amount would be required before this mechanism would be of any consequence. If it is assumed that the particulate matter escaping the reactor retains $50 \%$ of its initial lodine content, the second mechanism becomes 1mportant in spec1fying and maintaining high efficiencies for the particulate filters. In this case, it is assumed that half of the released particulates would settle in the reactor room so that only $0.5 \%$ of the total particulate matter ( $0.25 \%$ of the total iodine inventory) would reach the particulate filters. At an efficiency of $99 \%$ (the specified minimum), $0.0025 \%$ of the total lodine inventory would pass through the filters; at an efficiency of $99.9 \%$ (average measured) only $0.00025 \%$ would pass through. Because no filtering benefits can be claimed for the carbon beds, $100 \%$ penetration of beds by particulates was assumed.

Although a much lower efficiency for the particulate filters is required to remove nonvolatiles released from the reactor, the higher efficiency of $99 \%$ is specified to retain lodine associated with particulate matter.

\section{c. Gasket Leaks}

Bypassing of the exhaust stream around the activated carbon beds is detected by the in-place "Freon-112" test discussed in Section VI,A. The average leakage flow in the five compartments of $C$ reactor was less than $0.03 \%$ of the total air flow through the compartments. A maximum leak of $0.2 \%$ was detected in one compartment. Retesting of the compartment after bolts holding the frames in place were tightened showed a leak of $0.04 \%$. Compartments 6 and 5 had leaks of less than $0.01 \%$. Compartments 4 , 3 , and 2 had leaks of $0.01,0.04$, and $0.05 \%$; respectively.

The maximum for Table IV-l was taken as $0.05 \%$ penetration and the average as $0.03 \%$. The $0.2 \%$ value was not used because it represents a one-time situation that existed because of the absence of a leak test when the carbon beds were installed. With the recently developed "Freon-112" leak test and with improved installation and maintainence techniques, $0.05 \%$ represents the maximum for future use.

\section{IV -4}




\section{d. Iodine Compound Penetration}

Details on iodine compound formation are presented in Section III and are summarized here. The quantity of methyl lodide that might be formed in the SRP system was conservatively determined to be equal to or less than $0.0001 \%$ of the total lodine inventory. Because the first contaminated vapor to reach the carbon beds probably would be in a steam-air environment; a zero efficlency for lodine compounds was assumed. The emergency light-water add1tion system in the reactor would rapidly stop steam generation; however, no credit was taken for any increase in lodine compound adsorption efficiency which might occur as the relative humidity of the exhaust alr decreased. Additional drying of the carbon would occur from decay heat released from adsorbed iodine.

Under certain conditions, however, activated carbon has a high efficiency for methyl lodide. Activated carbon removes lodine compounds efficiently from a dry air stream. Typical tests that demonstrated this were run at oak Ridge for 5 hours, at an air velocity of 25 feet per minute on a 1.5-inch-deep bed and at an lodine compound concentration of 0.05 milligram of lodine per cubic meter(36). The efficlency was dependent also upon the type of activated carbon used. Coconut carbon was more effective than either bituminous coke carbon or Whetlerite, a carbon impregnated with salts of silver, chromium, and copper. The coconut carbon had an efficiency of $99.89 \%$ for methyl lodide at room temperature and $4 \%$ relative humidity. At $100^{\circ} \mathrm{C}$ and about $0.1 \%$ relative humidity, efficiencies ranged from $99.91-99.99 \%(48)$.

Under wet steam-air conditions, the efficiency of activated carbon for removing methyl iodide was reduced. At room temperature and a relative humidity of $75 \%$, the efficiency ranged from 50 to $97 \%$, with coconut carbon being superior to the other types of carbon $(48)$. Under steam conditions at temperatures from 95 to $130^{\circ} \mathrm{C}$, the efficiency was reduced to 5 to $78 \%$.

\section{Removal of Decay Heat from Filter-Adsorber Units}

Evaluation showed that the probability of igniting the carbon in the unlikely event of a nuclear incident is acceptably low. In the critical period after a possible incident, air flow less than 10\% of normal will remove the decay heat from fission products trapped on the filters and adsorbers and maintain the carbon temperature below the ignition temperature of about $340^{\circ} \mathrm{C} .{ }^{(49)}$ 
As explained in Section II,D,2, d, two exhaust air fans are always operating and a third fan is avallable. The ignition temperature of the carbon could be approached only if all electrical power to the fans is lost after several minutes of normal operation following an accident. Power for the fans is fed in a loop circuit from two or three power plants that are widely separated. In the very unlikely event that all power plants should fall, power would be supplied by a diesel generator in each reactor area to maintain full system air flow. The exhaust fan system has never experienced an unscheduled stoppage in over $10^{\circ}$ years of operation.

\section{NOBLE GASES}

Fission products in the fuel elements of nuclear reactors include radioactive noble gases (principally krypton and xenon). The existing SRP activity confinement system has no provisions to collect or attenuate noble gases. The only dose reduction credit for the existing system arises from dispersion due to release of the noble gases from a 200-foot-high stack rather than at ground level. Thus, in the very unlikely event of an accident in which the entire core is melted, the total equilibrium noble gas content was assumed to be released from the reactor building to the environs. 


\section{OPERATING EXPERIENCE}

\section{A. FILTER COMPARTMENTS}

After 3 years of service, operating experience with the filter compartment shell has been excellent. (50) only minor corrosion on the aluminum walls of compartments in one reactor area has been observed. The maximum depth of pitting, resulting from trace nitrogen compound attack, is about 0.005 inch and is of no consequence to the structural integrity of the compartments. Minor electrical problems in the remote delatching mechanism were experienced but were readily corrected.

\section{B. MOISTURE SEPARATORS}

Because the moisture separators are fabricated of stainless steel and "Teflon", no corrosion from trace acidic compounds has been observed. Also, no degradation of the "Tefion" has been detected.

The only problem with the separators has been an accumulation of an olly substance and particulate matter on the upstream face. Units are cleaned with steam at a nozzle pressure of 15-20 psi to restore flow-pressure drop characteristics to values equal to those of new units without damaging the mat. The front face is steam-cleaned for three minutes in a vertical position, and then the back face is steam-cleaned by blowing steam downward onto the back for three minutes with the separator in a horizontal position. The separators are removed from the compartments for cleaning.

No units have been replaced because of mechanical damage. The stainless steel and "Tefion" mat is quite tough and f'lexible and is not easily damaged from handling during installation or maintenance.

With periodic steam-cleaning about once per year, an indefinite service life is expected.

\section{PARTICULATE FILTERS}

Particulate filters have a relatively short life compared to moisture separators because there is no practical method for cleaning the medium; 1 to 2 years is typical. Wet fly ash from the powerhouse stack is the primary constituent in the exhaust air that accumulates on the filters. More efficient prefilters in the 
supply air system currently are being installed to reduce the fly ash loading on the particulate filters as well as the separators. Although removal of the fly ash from the high-efficiency particulate filters is not practical, drying with electrical heaters at reduced flow and use of more efficient prefilters are expected to prolong the filter life. Experimental heaters in $\mathrm{C}$ Area proved the feasibility of drying the filters, and permanent installation of 80-kw heaters in each filter compartment has been authorized. other benefits from the heaters are discussed in section VI.

Early models of the particulate filters had no protection against puncture of the medium during installation, and the refection rate was about one percent based on dioctylphthalate (DOP) tests of each unit after installation. To protect against puncture, use of galvanized hardware cloth face guards $(51)$ is now specified.

The ability of the particulate filters to withstand the severe conditions which might exist under emergency conditions was demonstrated in typlcal tests on two filters that were exposed for 13 months to flowing, normally dust-laden exhaust air in the P-Reactor Area ventilation system. Molsture separators had not been installed in the reactor areas at the time of this test. Tests at SRL showed that molsture separators remove at least 30\% of atmospheric dust; thus the 13 months of service of the filters in the reactor area was equivalent to about 18 months of design service with separators. The filters, with molsture separators upstream, were subjected to flowing fog. Although very minor damage of one of the filters was observed, the efficlency of each filter for removing 0.6 -micron particles of DOP was $99.9+\%$ after 12 days of exposure to the flowing fog.

A test was performed also with both a dusty separator and two dusty particulate filters that were exposed for 34 weeks to flowing air that contained normal atmospheric dust. After 10 days of exposure to a fog mixture, both filters had an efficiency of 99.9+\% for 0.6-micron DOP. M1gration of the dust cake through the medium was negligible. Samples sectioned before and after the test showed a penetration of about 10\% of the medium thickness.

The required efficiency of the fliters for 0.3 -micron* or larger particles is 99\%, although measured efficlencies are greater than $99.9 \%(3)$. The high rated efficiency can be main-

* Tests by the vendor and at the Oak Ridge Filter Testing Facility are with 0.3-micron aerosols; the tests at SRP are with 0.6 micron aerosols. 
tained even though the fliters may contain a considerable number of holes. For example, four banks of 128 clean particulate filters (about 30,000 square feet total surface area) can contain about $1100 \frac{1}{4}$-inch-diameter holes, yet allow on $1 y 1 \%$ of the air stream to pass through the holes $(52)$ at normal flow.

\section{ACTIVATED CARBON BEDS}

The efficiency of activated carbon after more than $2 \frac{1}{2}$ years of continuous exposure to exhaust ventilation air from Savannah River Plant reactor buildings remains greater than the design objective of $99.9 \%$ for the removal of elemental iodine. Details of the performance of the beds are presented in DP-1028(47) and are summarized hereln. Shown in Table $\mathrm{V}-1$ are the results of elemental iodine tests on carbon exposed to reactor bullding exhaust ventilation air for about $2-1 / 2$ years $(50)$.

Although the beds continue to fulfill their function of providing protection from halogen activity, two problems have arisen. The first is that the mild steel frames which contain the carbon are corroding from nitrogen and sulfur compounds that are in the building exhaust air in trace quantities. The corrosion is intergranular which results in severe embrittlement of the metal. Both the original cadmium-plated units and the later painted frames have been attacked. Failure of the perforated metal screen of only two units has been detected, and these failures resulted in a negligible loss of carbon. New units fabricated of Type 304L stainless steel have been ordered, and replacement will begin during the summer of 1966. Details of the stainless steel units are in the Appendix.

The second problem is that of slow degradation of the carbon from adsorption of impurities, primarily $\mathrm{NO}_{2} \cdot \mathrm{NO}_{2}$ is formed by radiolytic decomposition of atmospheric nitrogen and subsequent reaction with oxygen in the space between the reactor tank and the biological shield. The 200-Area separations plant and nearby industrial plants also contribute $\mathrm{NO}_{2}$ to the atmosphere. Analysis of used carbon shows only the presence of NO(47), so it is assumed that because free $\mathrm{NO}$ would not normally exist in air, $\mathrm{NO}_{2}$ oxidizes the carbon and the residual No sorbs on available sites. NO can be removed from the carbon by drying the bed in-place at about $60^{\circ} \mathrm{C}$. The drying operation partially restores the iodine adsorption efficiency to about $99.98 \%$, and the service life of the carbon will be improved. Less than $0.01 \mathrm{~g} \mathrm{NO}_{2} / g$ carbon would be formed in the reactor during a major accident. No effect on the efficiency of the carbon for lodine would be expected for this concentration. 
Contaminants in the carbon that reduce efficlency migrate through the bed even at room temperature. Initially, the material is sorbed in greatest concentrations on the front face of the bed. Although the efficiency at the front face may be low, the overall efficlency of the bed still remains high. This was demonstrated by tests on carbon beds from $K$ Reactor Area, as shown In Table $\mathrm{v}-1$.

As would be expected, the efflciency of used carbon in air tests was higher than in steam-air tests.

As mentioned above, all carbon beds are scheduled for replacement starting in the summer of 1966 . Tests of the carbon will be made perlodically to ensure that beds will be replaced when efficiencies begin to fall below a satisfactory level. 


\section{TABLE V-1}

Iodine Tests of Used Carbon Samples from SRP Reactor Areas

\begin{tabular}{|c|c|c|c|c|c|c|c|}
\hline Test No, & Area & $\begin{array}{c}\text { Bed } \\
\text { Sertal No. }\end{array}$ & $\begin{array}{c}\text { Months } \\
\text { of Service }\end{array}$ & Tyoe Test & $\begin{array}{c}\text { Efficiency } \\
0\end{array}$ & $\begin{array}{l}\text { Bed Loading } \\
\text { mg } I_{2} / \mathrm{g} \text { carbon }\end{array}$ & Notes \\
\hline 113 & $R$ & 24 & 14 & Steam-air & 99.95 & 3.3 & $(1,2)$ \\
\hline 214 & $\mathbf{R}$ & 24 & 14 & Steam-a1r & 99.92 & 0.9 & $(3,2)$ \\
\hline 1.15 & $\mathbf{R}$ & 24 & 14 & Air & 99.99 & 0.8 & $(1,2)$ \\
\hline 127 & $\mathrm{R}$ & 24 & 14 & Steam-a1r & 99.89 & 0.6 & $(3,2)$ \\
\hline 1.19 & $R$ & 24 & 14 & Steam-alr & $99.99+$ & 0.5 & $(1,3)$ \\
\hline 122 & $R$ & 23 & 14 & Steam-ais & 99.98 & 0.5 & $(1,2)$ \\
\hline 123 & $\mathrm{R}$ & 23 & 14 & Steam-air & 99.98 & 0.4 & $(1,4)$ \\
\hline 124 & $\mathrm{R}$ & 23 & 14 & Steam-a1r & 99.98 & 0.4 & $(1,5)$ \\
\hline 1.1 .1 & $P$ & 114 & 15 & A $1 r$ & $99.99+$ & 1.6 & $(1,2)$ \\
\hline 1.22 & $P$ & 114 & 1.5 & Steam-air & $99.99+$ & 1.2 & $\langle 1,2\rangle$ \\
\hline 118 & $P$ & 1.14 & 15 & Steam-a1r & $99.99+$ & 1.2 & $(1,2)$ \\
\hline 164 & $P$ & 613 & 15 & Steam-a1r & $99.99+$ & 0.6 & $(2,15)$ \\
\hline 187 & $\mathrm{P}$ & 91 & 28 & Steam-air & 99.97 & 0.4 & $(1,2)$ \\
\hline 189 & $P$ & 91 & 28 & Steam-a.1r & 99.96 & 0.3 & $(2,15)$ \\
\hline 202 & $\mathbf{P}$ & 91 & 28 & Steam-a1r & 99.98 & 0.6 & $(2,15)$ \\
\hline 203 & $P$ & 91 & 28 & Steam-air & 99.92 & 0.4 & $(2,15)$ \\
\hline 204 & $\mathrm{P}$ & 91 & 28 & Steam-a1r & 99.98 & 0.5 & $(2,15)$ \\
\hline 205 & $P$ & 91 & 28 & Steam-air & 99.98 & 0.5 & $(2,15)$ \\
\hline 206 & $\mathrm{P}$ & 91 & 28 & A1r & 99.98 & 0.7 & $(2,15)$ \\
\hline 133 & I & 132 & 20 & Steam-air & 99.97 & 0.4 & $(1,2)$ \\
\hline 134 & I & 132 & 20 & Steam-air & $99.99+$ & 0.5 & $(1,6)$ \\
\hline 135 & $\mathrm{~L}$ & 132 & 20 & Steam-a1r & $99.99+$ & 0.5 & $(7,2)$ \\
\hline 136 & L & 132 & 20 & Steam-ajr & $99.99+$ & 0.6 & $(8,2)$ \\
\hline 137 & L & 132 & 20 & Steam-a1r & 99.99 & 0.6 & $(9,2)$ \\
\hline 138 & L & 132 & 20 & Steam-air & 99.94 & 0.6 & $(10,2)$ \\
\hline 139 & $\mathrm{~L}$ & 132 & 20 & Steam-aIr & 99.99 & 0.6 & $(11,2)$ \\
\hline 185 & I & 40 & 28 & Steam-air & 99.96 & 0.5 & \\
\hline 140 & $\mathrm{~K}$ & 76 & 20 & Steam-air & $99.99+$ & 0.6 & $(1,2)$ \\
\hline 141 & K & 76 & 20 & Steam-a1r & 99.89 & 0.7 & $(8,2)$ \\
\hline .143 & $\mathrm{~K}$ & 76 & 20 & Steam-air & 99.60 & 0.4 & $(8,2,12)$ \\
\hline 144 & $\mathrm{~K}$ & 76 & 20 & Steari-aIr & 99.93 & 0.6 & $(8,2,13,14)$ \\
\hline 145 & $\mathrm{~K}$ & 76 & 20 & Steam-ajr & 99.96 & 0.6 & $(1,2)$ \\
\hline 146 & $\mathrm{~K}$ & 76 & 20 & Steam-a.1r & 99.92 & 0.6 & $(10,2)$ \\
\hline 180 & $K$ & 185 & 28 & Air & $99.99+$ & 0.7 & $(2,15)$ \\
\hline 184 & $\mathrm{~K}$ & 185 & 28 & Steam-air & 99.98 & 0.5 & $(2,15)$ \\
\hline 120 & $\mathrm{C}$ & 668 & 7 & Steam-a1r & 99.99 & 0.6 & $(1,2)$ \\
\hline $12 I$. & C & 668 & 7 & Steam-a1r & $99.99+$ & 0.7 & $(1,2)$ \\
\hline 158 & C & 650 & 17 & Steam-a1r & 99.98 & 0.5 & $(1,2)$ \\
\hline 201 & $c$ & 650 & 17 & A $1 r$ & $99.99+$ & 0.9 & $(2,15)$ \\
\hline
\end{tabular}

\section{Notes:}

(1) Test bed was packed with 3 layerg of carbon taken from the front, middle, and back of the 1-in.-thick layer in the full-size bed.

(2) Carbon was not dried.

(3) Carbon was dried for $20 \mathrm{hr}$ at $95^{\circ} \mathrm{C}$ and 70 fpm alr flow.

(4) Carbon was aried for $24 \mathrm{hr}$ at $95^{\circ} \mathrm{C}$ and 70 fpm atr flow.

(5) Carbon was dried for $24 \mathrm{hr}$ at $65^{\circ} \mathrm{C}$ and $70 \mathrm{fpm}$ air flow.

(6) Carbon was aried for $16 \mathrm{hr}$ at $65^{\circ} \mathrm{C}$ and $70 \mathrm{fpm}$ alr flow.

(7) Test bed was packed with carbon from the front $1 / 2^{\text {If }}$ of full-size carbon bed.

(8) Test bed was packed with carbon from the front $1 / 8^{\prime \prime}$ of full-81ze carbon bed.

(9) Test bed was packed with carbon from the back $1 / 2$ " of full-81ze carbon bed.

(10) Test bed was packed w1th carbon from the center $1 / 3^{\prime \prime}$ of full-size carbon bed.

(1I) Test bed was packed with carbon from the back $1 / 8$ " of full-size carbon bed.

(12) Carbon removed from full-81ze bed 1 . wk after carbon removed for test No. 141 .

(13) Carbon for tests No. 143 and 144 identical.

(14) Carbon was dried for $16 \mathrm{hr}$ at $95^{\circ} \mathrm{C}$ and $70 \mathrm{fpm}$ a.r flow.

(15) Test bed was packed with a thoroughly mixed carbon sample removed from full-size bed.

Conditions for air test:

Duration of test: $2-1 / 2-3 \mathrm{hr}$

Face velocity: $70 \mathrm{ft} / \mathrm{m} 1 \mathrm{n}$

Temperature at test bed: $35^{\circ} \mathrm{C}\left(95^{\circ} \mathrm{F}\right)$

Isotopic dilution: $1.5 \mathrm{mCl}$, $131 \mathrm{I}$ per $100 \mathrm{mg}{ }^{127} \mathrm{I}$
Conditions for steam-air test:

Duration of test: $2-1 / 2-3 \mathrm{hr}$

Face velocity: $70 \mathrm{ft} / \mathrm{min}$

Steam flow: $1 \mathrm{rt}^{3} / \mathrm{m} 1 \mathrm{n}$

Temperature of test bed: $68^{\circ} \mathrm{C}\left(155^{\circ} \mathrm{F}\right)$

Isotopic dilution: $1.5 \mathrm{mCl}^{131} \mathrm{I}$ per $100 \mathrm{mg}^{127} \mathrm{I}$ 


\section{EXPERIMENTAL AND DEVELOPMENT PROGRAM}

\section{A. NONDESTRUCTIVE LEAK TEST OF CARBON BEDS}

The efficiency of installed beds of carbon is determined by a combination of two tests: 1) a nondestructive test to measure the magnitude of leaks past the carbon in the entire bank of beds, and 2) a destructive test of representative samples of the carbon to ensure that the carbon has a high efficiency for adsorption of iodine. The nondestructive leak tests are described in this section and the destructive iodine tests are described in Section VI, B.

\section{1. "Freon-12" Leak Tests before Installation of Carbon Beds}

The carbon beds of the SRP activity confinement system were designed to remove $99.9+\%$ of elemental iodine vapor. To achieve this high efficiency, the units were carefully designed and tested, as discussed in previous sections of this report. After manufacture of the carbon bed unit and before installation in the confinement system, evaluation of the units for absence of leak paths was desired. A nondestructive test was developed by SRL (1i) to detect leaks caused by settling or voids in the carbon beds. "Freon-12" was used as a tracer to detect any leak paths.

The "F-12" leak test was used to evaluate over 800 new carbon beds before installation in the confinement systems. The average leakage flow for a.II the beds was less than $0.01 \%$. only one bed had a leak greater than 0.1\%; inspection showed that the carbon had either settled during shipment or was not completely packed by the manufacturer during the loading operation. Carbon was added to the bed, and an "F-12" retest showed that the leakage flow was reduced to less than $0.01 \%$. These "F-12" tests demonstrated the adequacy of the SRL design of carbon beds to prevent leaks that could bypass the carbon and reduce the iodine adsorption efficiency of the bed to less than 99.9\%. The tests showed that "Freon-12" was satisfactory for new and relatively dry carbon at air velocities to 20 feet per minute.

Measurement of any leaks in a carbon bed required knowledge of three facts: I) the concentration of the tracer in the flowing air upstream of the test bed, 2) the concentration of the tracer in the flowing air downstream of the test bed, and 3) assurance that the carbon at test conditions would remove essentially a.ll (about $99.99 \%$ ) of the tracer if all the air flow passed through the 1-inch-thick bed of carbon. Therefore, any tracer that bypassed the carbon bed would be caused by leaks in the bed and/or around gasket sea.ls. Numerous tests demonstrated that the "F-12" technique would detect leaks less than $0.01 \%$ of the total air flow through the beds. "F-12" downstream of the bed was measured by an electron-capture-type detector with a gas chromatograph(II). 
"F-12" was readily desorbed by normal exposure to the exhaust air flow; however, tests showed that "F-12" adsorbed on the carbon did not interfere with the iodine adsorption characteristics of the carbon. The "Freon" compounds offer other desirable characteristics as a tracer, i.e., they are nontoxic, easy to handle, noncorrosive, and readily available.

\section{2. "Freon-112" In-Place Test of Installed Carbon Beds}

During the design of the confinement system, it was recognized that a method of testins the carbon beds in-place would be required to establish that air flow around gasket seals is insignificant. Although each carbon bed was evaluated before installation, gaskets on the carbon beds that seal the units in mounting racks of the compartment could be tested only in-place. The "F-12" technique discussed in the preceding section was unsatisfactory for used carbon beds, because impurities and moisture adsorbed on the carbon from continuous exposure to exhaust air flow interfered with "F-12" adsorption.

Because of the above Iimitations, the Savannah River Laboratory developed a nondestructive test that is generally applicable for in-place leak testing of installed carbon beds, both new and used. The limitations on air velocity and sorbed water when testing new carbon were reduced significantly by substituting the less volat1le "F-112" ( $\left.\mathrm{CCl}_{2} \mathrm{~F}-\mathrm{CCl}_{2} \mathrm{~F}\right)(53,54,55)$ for "F-12". Th1s work is being sponsored by the AEC Division of Operational Safety.

Techniques for in-place leak testing of a complete bank of installed carbon beds with "F-112" were developed and demonstrated. $(58,57)$ Tests of used carbon beds in flve SRP filter compartments showed that the average leakage flow (flow that bypasses the carbon) was less than $0.03 \%$ of the total, alr flow through the compartments. Compartments 6 and 5 had leaks of less than $0.01 \%$; compartments 4, 3, and 2 had leaks of $0.01,0.04$, and $0.05 \%$, respectively, in $C$ reactor. The results of the tests are shown in Figure VI-I. In compartment 3, an inftial leakage flow of about $0.2 \%$ was reduced to the acceptable value of $0.04 \%$, as discussed on page IV-4. "F-II2" leak testing of carbon beds in all SRP reactors is in progress.

The average leakage flow for the five banks of carbon beds corresponds to an average efficiency greater than $99.96 \%$ for removal of elemental lodine vapor, because small-scale tests (in which there were no detectable leak paths) showed that the iodine adsorption efficiency of representative samples of the carbon from C-reactor was greater than 99.99\%. The beds that were 
tested had been exposed continuously for about 2 years to exhaust air flow in the confinement system prior to the "F-112" and lodine tests.

The "F-112" leak test required only one minor modification of the compartment. A mixer was installed downstream of the carbon beds to adequately $\mathrm{mlx}$ the total compartment flow prior to sampling for "F-112" detection. Adequate mixing was essential to prevent possible channeling of any "F-112" from leak paths adjacent to the compartment walls. The effectiveness of the mixer was demonstrated by tests in one of the compartments. The device was removed before returning the compartment to normal service. A schematic of an SRP compartment and equipment used for the "F-112" leak test is shown in Figure VI-2.

The in-place "F-112" test requires a minimum knowledge of the actual conditions in the test system. The preclse values of air flow, "F-112" injection rate, and calibration of the "F-112" detectors are not required. Only the relative sensitivities of two detectors for "F-II2" are required. Ga.s chromatographs with electron-capture-type detectors are used for measuring "F-112" concentrations in the air samples. The detectors have a sensitivity of $1 \mathrm{ppb}$ (vol.) for "F-112" in air. Complete details on the "F-112" detectors are discussed in References 11 and 56.

New carbon is leak tested with "F-112" at air velocities to 70 feet per minute and with sorbed water to about $20 \%$. When testing used carbon beds in place, air velocity and sorbed $\mathrm{H}_{2} \mathrm{O}$ are reduced for a quantitative leak test. Used carbon is dried in place prior to the test by preheating the inlet air (at about $1 / 10$ normal flow) to about $60^{\circ} \mathrm{C}$.

Exposure of carbon beds to normal exhaust air flow desorbs over 95\% of the "F-112" In about three weeks; however, tests showed that a.t least 4 times the maximum concentration of "F-112" adsorbed on the carbon does not affect its efficiency for iodine removal.

The "F-112" test has been standardized for general application for in-place testing of carbon beds in other reactors in addition to those at $\operatorname{SRP}^{(58)}$. 


\section{B. IODINE TESTS}

\section{Small-Scale Tests}

Small-scale tests with elemental iodine are discussed in detall in References 8 and 47 . A photograph of the equipment is shown in Figure VI-3. Elemental ${ }^{127} I_{2}$ and tracer ${ }^{131} I_{2}$ (prepared to avold lodine compound formation( $\left.{ }^{(8)}\right)$ are deposited on a fritted glass tube, called a cold finger, and reduced in temperature with dry ice to retard sublimation. After the cold finger is mounted In the test apparatus, a small stream of warm air vaporizes the iodine and carries it into a main stream of air or steam and air. The material then passes through a molsture separator, particulate filter, test carbon bed, a second particulate filter, and three backup carbon beds. Condensate is removed at seven locations. The efficiency of a test carbon bed is calculated from the ${ }^{131} I$ disintegrations measured on the test bed compared with the disintegrations measured on all units downstream.

This equipment currently is being used for continuing tests of the lodine removal efflclency of SRP carbon beds (47), for evaluation of high ignition temperature materials (59), for determination of effects of "Freon" on lodine adsorption efficiency (58), and for testing with methyl lodide.

\section{Full-Size Tests}

A method of determining the lodine removal efficiency of full-size carbon beds is being developed. The primary purpose of the experiment is to correlate the short term "F-112" adsorption efficiency and the lodine adsorption efficiency of full-size beds. The test faclilty (Figure VI-4) used for development of the "F-112" In-place leak test will be used also for the lodine tests. The proposed test method will use ${ }^{127} \mathrm{I}$ (nonradioactive) as a tracer to minimize safety hazards and utilize existing facilities. The 127 I detection method will be activation analysis, as discussed In Section VI,B,3, of lodine traps located in sample lines upstream and downstream of the test carbon bed. A gas chromatograph will be used also to detect any methyl lodide that might be formed.

\section{Analytical Techniques}

The development of tests for iodine adsorption by full-size carbon beds requires a sensitive analytical determination for elemental iodine. Neutron activation analysis offers a rapid, sensitive method. 
An existing procedure (60) will be used to determine lodine in samples of activated carbon. Sealed capsules containing known amounts of $\mathrm{HIO}_{3}$ are embedded in the samples of iodine-containing carbon that are to be analyzed. The samples are irradiated for 1 hour at a flux of $2 \times 10^{11} \mathrm{n} /\left(\mathrm{cm}^{2}\right)(\mathrm{sec})$. Iodine is leached from the carbon with $\mathrm{NH}_{4} \mathrm{OH}-\mathrm{H}_{2} \mathrm{O}_{2}$, separated from interfering radionuclides by three cycles of oxidation-reduction and extraction into $\mathrm{CCl}_{4}$, and then precipitated as AgI. The induced ${ }^{128} \mathrm{I}$ is determined by gamma pulse height analysis of the AgI, and iodine in the carbon is calculated on the basis of comparative counting of the irradiated encapsulated $\mathrm{HIO}_{3}$. The sensitivity is 1 microgram $I_{2}$ per 100 grams of carbon.

Any methyl lodide formed during tests of full-size carbon beds will be detected by an electron capture detector used in conjunction with a gas chromatograph. The detector has a sensitivity of about $0.1 \mathrm{ppb}$ (wt) for methyl iodide in air. Detalls are presented in References $11,61,62$, and 63.

\section{METHYL IODIDE TESTS}

Testing of the efficiency of activated carbon for methyl iodide is in progress at SRL. The same apparatus (Figure VI-3) used for small-scale elemental iodine tests is being used. Initial results are shown in Table VI-1.

Tests 178 and 194 confirmed that under dry conditions, the efficiency of coconut shell activated carbon for methyl iodide is in the order of $99 \%$ and is a function of lodine loading.

Tests 196 and 197 are significant because the results indicate that for the test $\mathrm{CH}_{3}{ }^{13 I} \mathrm{I}$ was subjected to both exchange reactions and chemical decomposition. Penetrations of the test bed by $\mathrm{CH}_{3}{ }^{13} \mathrm{I}$ was not detected. The results confirm the reactions discussed in section III, A (Equation 22). About 8 times more ${ }^{127} I_{2}$ and ${ }^{129} I_{2}$ than ${ }^{1{ }^{1}} I_{2}$ would be released during an incident, and the iodine may be released either in water or a condensing steam atmosphere that would favor decomposition of $\mathrm{CH}_{3}{ }^{131} \mathrm{I}$. Further testing with methyl iodide is in progress. 
$\underline{\text { TABLE VI-I }}$ Small-Scale Methyl Iodide Tests of SRP
Activated Carbon $(a)$

\begin{tabular}{|c|c|c|c|c|c|}
\hline No. & Material & and Quantity & $\begin{array}{l}\text { Loading } \mathrm{CH}_{\mathrm{s}} \text {, } \\
\mathrm{mg} / \mathrm{s} \mathrm{C}\end{array}$ & $\begin{array}{l}\text { Loading } I_{2} \text {, } \\
\mathrm{mg} / \mathrm{g} \mathrm{C}\end{array}$ & $\begin{array}{c}\text { Efticlency } \\
\% \\
\end{array}$ \\
\hline 178 & $\begin{array}{ll}\mathrm{CH}_{3}{ }^{131} \mathrm{I} \\
\mathrm{CH}_{3}{ }^{127} \mathrm{I}\end{array}$ & $\begin{array}{r}0.11 \mathrm{mc} \\
5.7 \mathrm{mg}\end{array}$ & 0.06 & 0 & 93.4 \\
\hline 194 & $\begin{array}{ll}\mathrm{CH}_{3}{ }^{131} \mathrm{I} \\
\mathrm{CH}_{3}{ }^{127} \mathrm{I}\end{array}$ & $\begin{array}{l}0.002 \mathrm{mc} \\
0.5 \mathrm{mg}\end{array}$ & 0.008 & 0 & 99.4 \\
\hline 196 & $\begin{array}{c}\mathrm{CH}_{3}{ }^{131} \mathrm{I} \\
\mathrm{CH}_{3} 127 \mathrm{I} \\
{ }_{131} \mathrm{I}_{2} \\
12 \mathrm{I}_{2}\end{array}$ & $\begin{array}{l}0.001 \mathrm{mc} \\
0.5 \mathrm{mg} \\
0.24 \mathrm{mc} \\
100 \mathrm{mg}\end{array}$ & - & 1.0 & $99.99+$ \\
\hline 197 & $\begin{array}{c}\mathrm{CH}_{3}{ }^{131} \mathrm{I} \\
\mathrm{CH}_{3}{ }^{127} \mathrm{I} \\
2{ }^{31} \mathrm{I}_{2} \\
12 \mathrm{I}_{2}\end{array}$ & $\begin{array}{l}0.0013 \mathrm{mc} \\
10.0 \mathrm{mg} \\
0.13 \mathrm{mc} \\
100 \mathrm{mg}\end{array}$ & - & 0.8 & $99.99+$ \\
\hline
\end{tabular}

(a) Test medium: Air - precleaned by passage through a 2-footdeep bed of Type 416 carbon.

Face velocity: 70 feet per minute.

Bed temperature: $40^{\circ} \mathrm{C}$.

Test carbon: Barmebey-Cheney, Type 416, activated coconut shell.

Relative humidity: $10 \%$.

Iodine carrier: $1 \frac{1}{2}$ milliliters water.

Time of test: 1 hour. 


\section{IGNITION TEMPERATURE OF HALOGEN ADSORBERS}

The temperature of the units of a filtration-adsorption system will increase after a ma.jor accident because of heat generated by radioactive decay of trapped fission products. The increase depends primarily upon:

- Temperature and air flow through the system

- Quantity of trapped fission products

- Heat loss from the system

The distribution of the fission products among the units and the heat capacity of the system components will also affect the temperature of individual units, but to a lesser extent than the above factors. If air flow stops, the carbon beds conceivably might be heated to the ignition temperature in some confinement applications.

Studies are being made at SRL on halogen adsorbers to reduce the probability of ignition. $(50,64)$ A standardized procedure 1 s being developed to measure ignition, to evaluate new adsorber materials, and to determine the effects of such variables as air flow, particle size, internal surface area, and catalysts on ignition temperature. This work is being sponsored by the AEC Division of Operational Safety.

\section{Literature Survey of Adsorptive Materials}

Published data indicate that the iodine adsorptive properties of existing types of noncombustible substitutes for activated carbon are not satisfactory for most reactor confinement applications. Hence, work at SRL has been concentrated on raising the ignition temperature of coconut shell activated carbon. Although coconut shell carbon has a lower ignition temperature than carbon prepared from coal, the coconut shell carbon is preferred because it is more adsorptive for elemental iodine and is more resistant to erosion and abrasion.

Published ignition temperatures are inconsistent, apparently because of variations in the measuring apparatus and procedures. Conditions that affect the ignition temperature have been reviewed (5s). 


\section{Small-Scale Ignition Temperature Apporatus}

A small-scale apparatus was developed for measuring ignition temperature of carbon beds with diameters and depths up to 3 inches, as shown in Figure VI-5. The 3-inch diameter was chosen to simulate a full-size bed.

An ignition temperature of $340-350^{\circ} \mathrm{C}$ was measured for a 1-inch-thick by 3-1nch-diameter bed packed with activated carbon now used in the SRP confinement system (Type 416* coconut shell). Air veloclty had little effect on the 1gnition temperature. Exposure in the confinement system for 18-25 months increased the Ignition temperature about $60^{\circ} \mathrm{C}$. This increase is attributed to the increased concentration of lodine, chlorlne, and phosphorous in carbon, as shown by mass spectroscopic analysis. These materials (products of the combustion of coal in the vicinity) inhibit the oxidation of carbon and increase the ignition temperature.

An ignition temperature of about $550^{\circ} \mathrm{C}$ was measured for Type 592,* a new high temperature coconut shell carbon, packed in a l-inch-thick bed. Detalled evaluation of the lodine adsorption and the ignition characteristics of this promising new carbon is in progress at SRL. Preliminary tests indicate that Type 592 carbon meets SRP specifications outlined in Appendix C. The ignition temperatures of several other commercial carbons were measured also. Type BPL** (bituminous carbon) ignited at $470^{\circ} \mathrm{C}$, and Type $\mathrm{PCB}^{* *}$ (coconut carbon) ignited at $340^{\circ} \mathrm{C}$. An ignition temperature of $250^{\circ} \mathrm{C}$ was measured for Whetlexite carbon.

\section{Ignition Tests of Full-Size Carbon Bed}

The 1gnition temperature of carbon was measured in tests at the Lawrence Radiation Laboratory (LRL) in a prototype of the new SRP bed (described in Reference 47) framed with stainless steel. Figure VI-6 is a schematic diagram of the apparatus. The measured ignition temperatures were $340^{\circ} \mathrm{C}$ for Type 416 carbon at an a1r velocity of $70 \mathrm{ft} / \mathrm{min}$ and $530^{\circ} \mathrm{C}$ for Type 592 carbon at an air velocity of $105 \mathrm{ft} / \mathrm{min}$. These values are in good agreement with those obtained from the small-scale apparatus.

* Product of Barnebey-Cheney Company.

* Product of Pittsburgh Activated Carbon Company. 


\section{E. REMOVAL OF IODINE AND NOBLE GASES BY ISOTOPIC EXCHANGE}

Experiments at $\mathrm{ORNL}(85)$ showed that carbon impregnated with iodine, potassium iodide, potassium bromide, or potassium bromate removed methyl iodide efficiently from moist air. Isotopic exchange is the proposed mechanism for the efficlent removal of methyl iodide. However, carbon impregnated with potassium lodide removed five times more methyl lodide than would be expected by an exchange mechanism. Furthermore, molecular sleve and alumina impregnated with these salts removed methyl iodide from molst air at reduced efficiency. Therefore the mechanism is probably more complex than simple isotopic exchange.

Isotopic exchange of organic iodides has been described in the literature $(86,87,88,69,70,71)$ and has been applied in the confinement of iodine. The kinetics have been studied in liquid phase for the exchange of $n$-butyl and $n$-propyl iodide with zinc lodide(68); ethyl lodide $(87,68)$ and isopropyl lodide(68) with lodine; methyl lodide with silver lodide(70); and ethyl iodide with aluminum trilodide(71). In the work most nearly related to confinement $(87,88,68)$ the exchange proceeded more rapidly with decreasing lodine concentration. The half-time of the exchange was predicted to be $5 \times 10^{-2}$ second in $10^{-11}$ mole per liter of solution but $5 \times 10^{3}$ seconds in $10^{-8}$ mole per liter of solution. Additional study of the published literature is in progress.

The isotopic exchange of noble gases with noble gas compounds may have an application for confinement. No work has been reported on this exchange in the literature. In preliminary work at SRL, the exchange of xenon with sodium perxenate was tested at room temperature in a helium atmosphere. No exchange was detected.

The planned work on isotoplc exchange at SRL includes completion of the literature survey, selection and testing of promising compounds for exchange of lodine and noble gases, experiments designed to clarify the mechanism of the retention of radiolodine atoms of methyl iodide on activated carbon, and an engineering evaluation of the feasibility of impregnating carbon beds with xenon compounds. This work is being sponsored by the AEC Division of Operational Safety. 


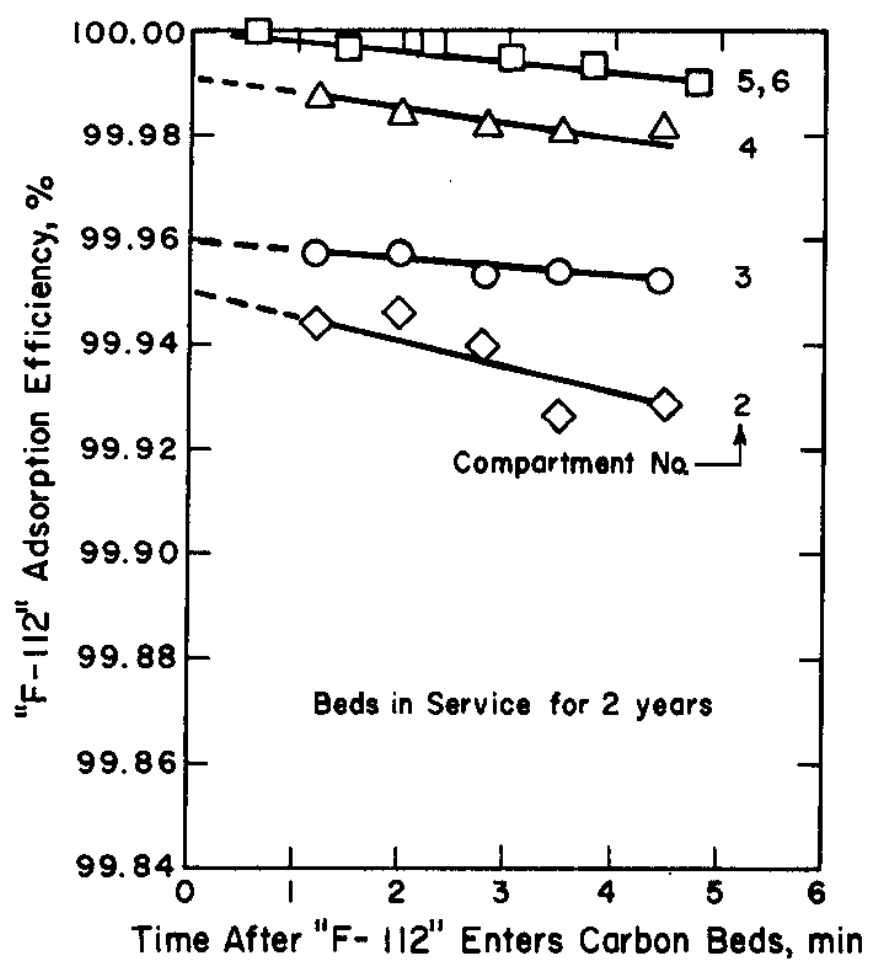

FIG. VI-1 "F-112" ADSORPTION EFFICIENCY OF BANKS OF CARBON BEDS INSTALLED IN C REACTOR. The per cent of flow bypassing the carbon beds (leak path) equals $100 \%$ minus the " $F-112$ " absorption efficiency' at zero time.

VT-10 


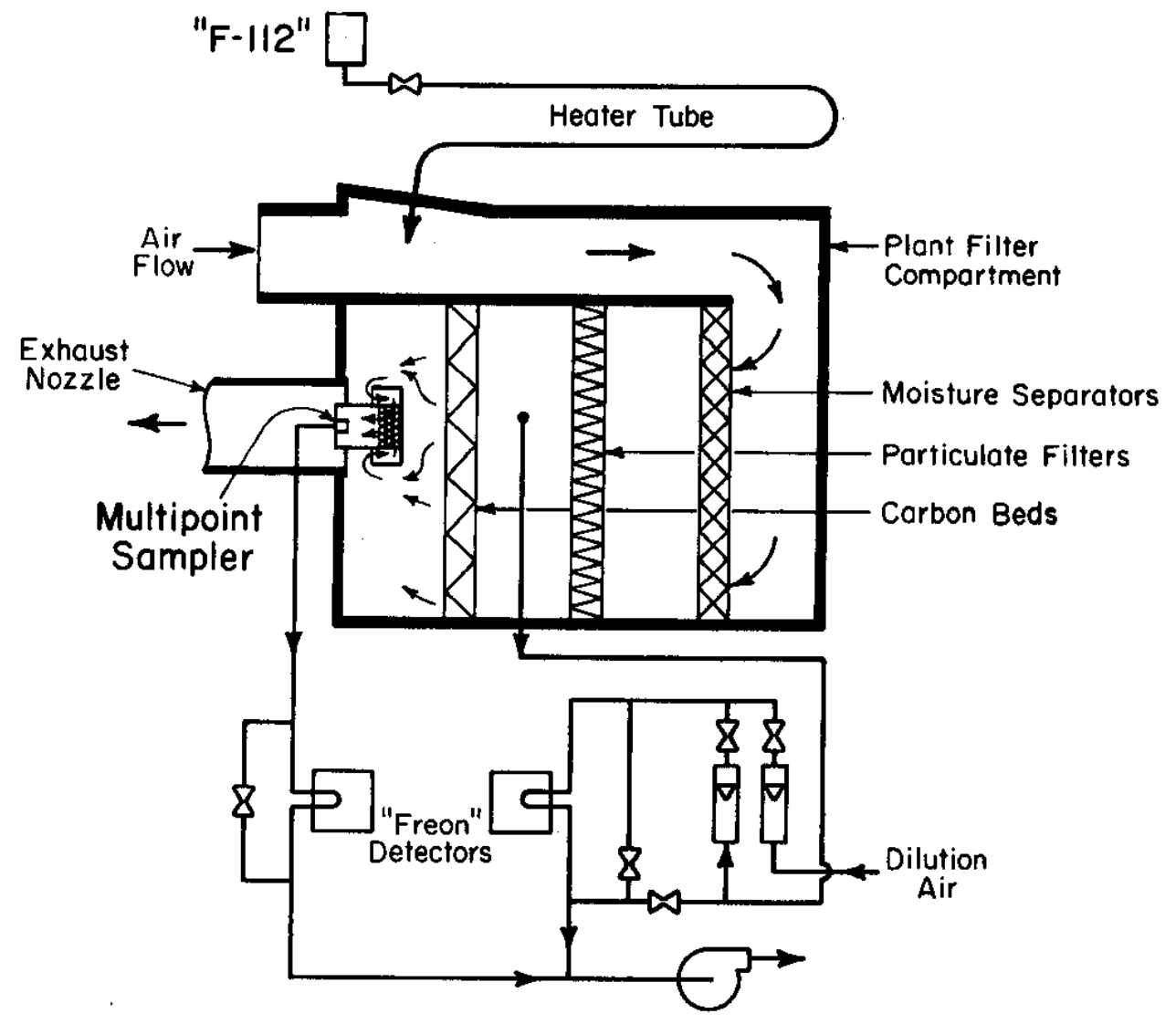

FIG. VI-2 EQUIPMENT FOR IN-PLACE TESTING OF PLANT CARBON BEDS 


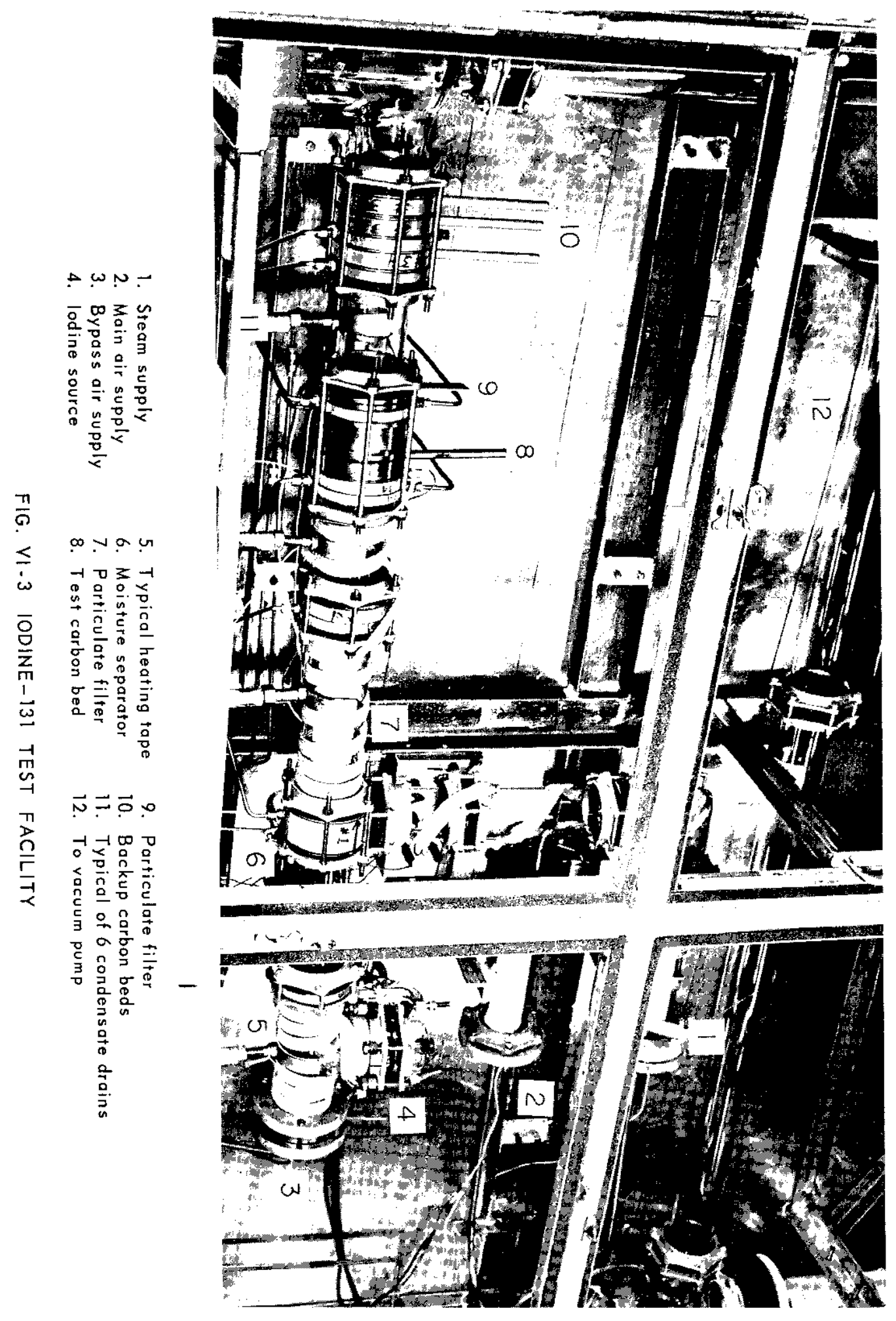




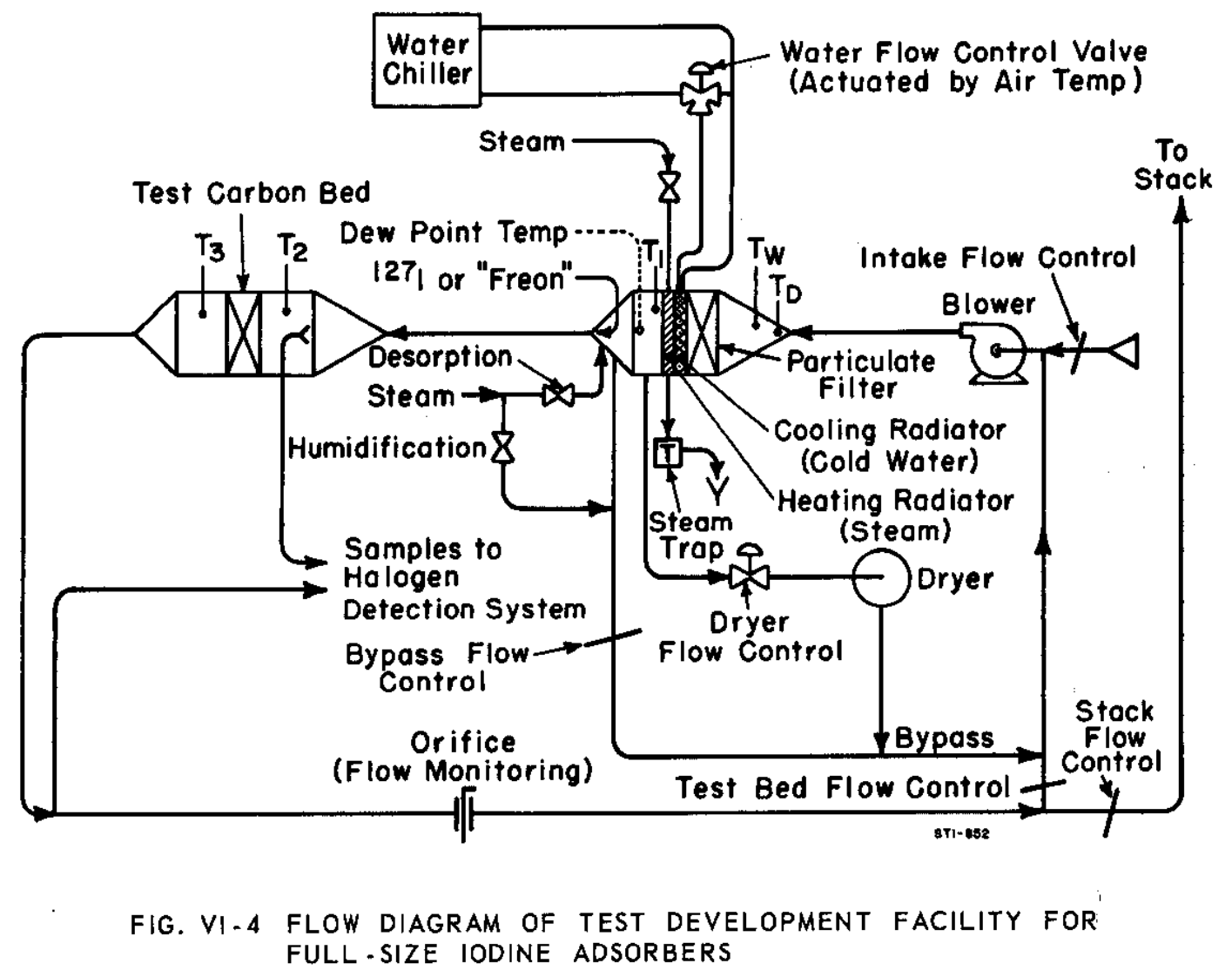

VI-13 


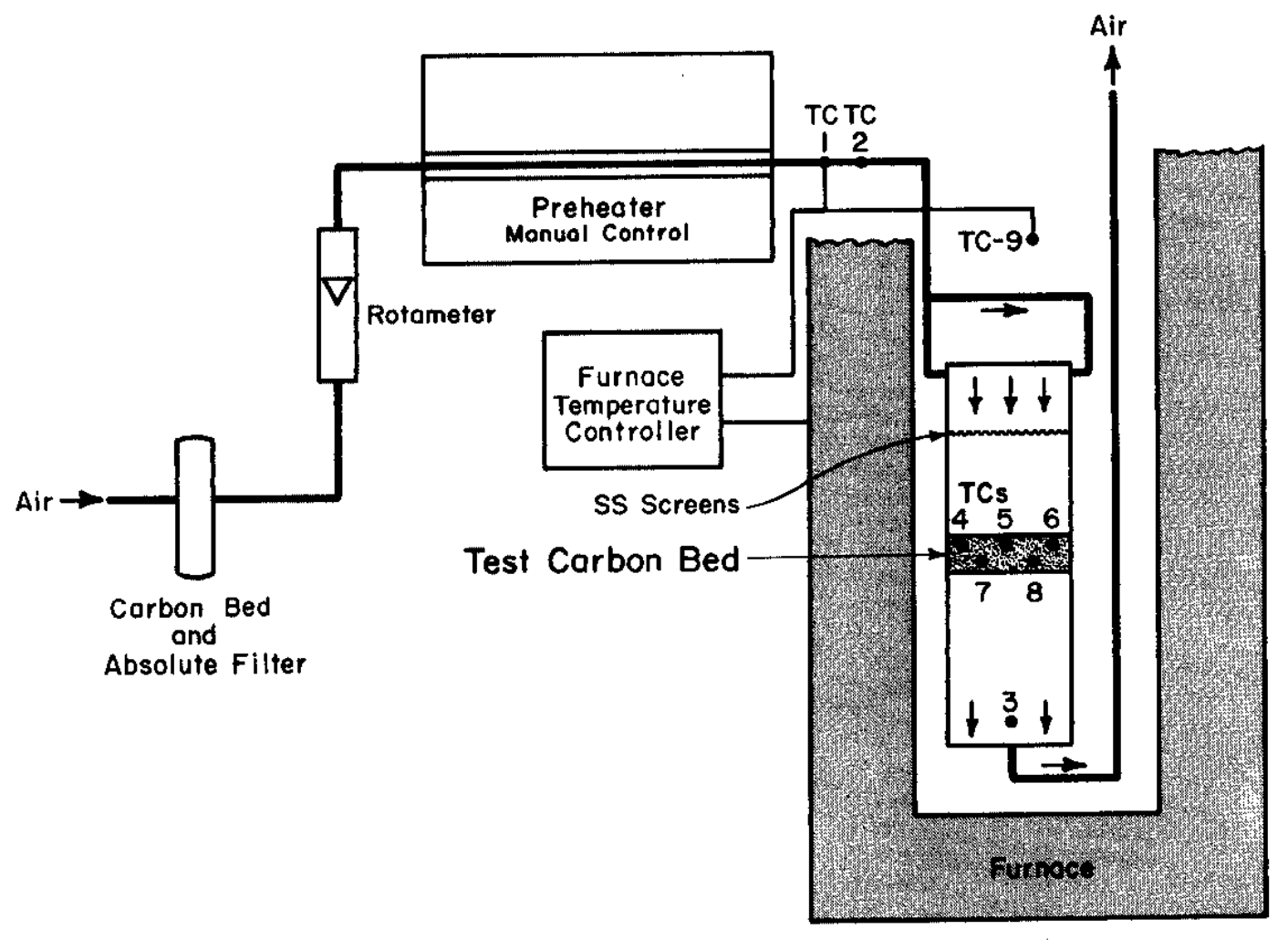

FIG. VI.5 SMALL-SCALE IGNITION TEST EQUIPMENT

VI-14 


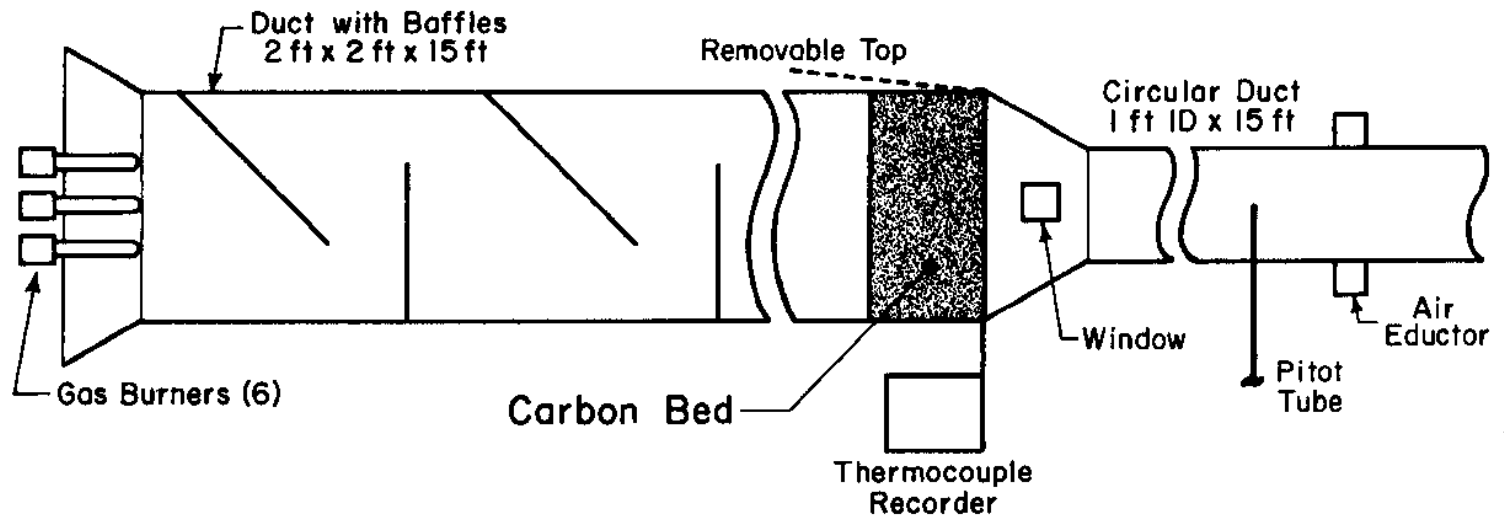

FIG. VI.6 FULL-SIZE IGNITION TEST EQUIPMENT 


\section{REFERENCES}

1. J. L. Crandall, et al. The Savannah River H1gh Flux Demonstration. USAEC Report DP-999, E. I. du Pont de Nemours \& Co., Savannah River Laboratory, A1ken, S. C. (1965).

2. J. A. List. "The SRP Production Reactor Containment Program." Elghth AEC Alr Cleaning Conference, TID-7677, 273 (Oct 1963).

3. A. H. Peters. Application of Demisters and Particulate Filters in Reactor Containment. USAEC Report DP-812, E. I. du Pont de Nemours \& Co., Savannah River Laboratory, Aiken, S. C. (1962).

4. J. W. Walker and A. H. Peters. "Use of Fllters in Reactor Containment." Mech. Eng. 85 (9) 46 (1963) (TID-17548).

5. J. B. Hays. "Performance of High Efficiency Particulate Filters Subject to Steam-A1r Mixtures." Summary of the Seventh AEC Air Cleaning Conference. oct 10-12, 1961 (Aug 1963).

6. H. W. Knudson and White Locke. Development of Smoke Penetration Meters. U. S. Naval Research Laboratory Report P-2642, (Sept 1945).

7. Filter Units, Protective Clothing, Gas Mask Components and Related Products, Performance Test Methods. Method 102.9.1 p 33, MII Std. 282, (28 May, 1956).

8. G. H. Prigge. Application of Activated Carbon in Reactor Containment. USAEC Report DP-778, E. I. du Pont de Nemours \& Co., Savannah River Laboratory, A1ken, S. C. (1962).

9. M. Dole and I. M. Klotz. "Sorption of Chloropicrin and Phosgene on Charcoal from a Flowing Gas Stream." Ind. Eng. Chem. 38, 1289 (1946).

10. Military Specification, MIL-C-13724A, (4 May, 1960).

11. A. H. Peters and D. R. Muhlbaier. Nondestructive Test of Carbon Beds for Reactor Containment Applications. Progress Report - June 1962 to December 1963. USAEC Report DP-870, E. I. du Pont de Nemours \& Co., Savannah River Laboratory, Aiken, S. C. (1964).

12. A. E. J. Eggleton and D. H. F. Atkins. "Iodine Compounds Formed on Release of Carrier-Free Iodine-131." Trans. Am. Nucl. Soc. 6, 129 (1963). 
13. A. W. Castleman, Jr., I. N. Tang, and H. R. Munkelwitz. "Chemical Reactions and Transport Behavior of F1ssion Product Iodine." International Symposium on Fission Product Release and Transport Under Accident Cond1tions. Oak Ridge, Tenn., Apr 5-7, 1965, CONF-650407, 325 (1965).

14. A. W. Castleman, Jr., I. N. Tang, and H. R. Munkelwitz. "Chemlcal State of Iodine Released from Irradiated Fuels into Steam." International Symposium on Fission Product Release and Transport Under Accident Conditions. Oak Ridge, Tenn., Apr 5-7, 1965, CONF-650407, 1118 (1965).

15. D. H. F. Atkins and A. E. J. Eggleton. Iodine Compounds Formed on Release of Carrier-Free Iodine-131. AERE-M-1211, United Kingdom Atomic Energy Authority, Research Group, Atomic Energy Research Establishment, Harwe11, Berks, England. (May 1963).

16. J. F. Croft and R. S. Iles. Experimental Release of RadioIodine in the Zenith Reactor Containment. AEEW-R 172, United Kingdom Atomic Energy Author1ty, Reactor Group, Atomic Energy Establishment, Winfr1th, Dorset, England (Sep 1962).

17. M. L. Perlman and G. K. Rollefson. "High Temperature Vapor Density of Iodine." J. Chem. Phys. 2, 362 (1941).

18. S. W. Benson. "Kinetics of the Pyrolysis of Organtc Iodides." J. Chem. Phys. 38 ()), 1945 (1963).

19. J. W. T. Spinks and R. Woods. An Introduct1on to Radiation Chemistry. John Wiley \& Sons, New York (1964).

20. S. C. Lind, C. J. Hochanadel, and J. A. Ghormley. Radiation Chemistry of Gases. Reinhold Publishing Corp., New York (1961).

21. Nuclear Safety Program Semiannual Progress Report for Period Ending December 31, 1964. ORNL-3776, Oak Ridge National Laboratory, Oak Ridge, Tennessee (Mar 1965).

22. S. W. Benson and E. O'Neal. "Kinetics of Reactions of Alkyl Iodides with HI." J. Chem. Phys. 34 (2), 514 (1961).

23. A. H. Taylor and R. H. Crist. "Rate and Equilibrium Studies on the Thermal Reaction of Hydrogen and Iodine." J. Am. chem. Soc. 63, 1377 (1941). 
24. S. W. Benson and M. C. Flowers. "Kinet1cs of the Gas-Phase Reaction of $\mathrm{CH}_{3} I$ and $\mathrm{HI} . "$ J. Chem. Phys, 38, 882 (1963).

25. A. W. Castleman, Jr. "Chemical Considerations in Reactor Safety: The Chemical State of Fission Products Released from Uranium at High Temperature." Trans. Am. Nucl. Soc. 6 (1), 128 (1963).

26. A. W. Castleman, Jr. and F. J. Salzano. "Current Studies of Fission Product Behavior at BNL." Eighth AEC A1r Cleaning Conf. ORNL. Oct 22-25, 1963, 16, TID-7677 (1964) 1, BNL-7423 (1963).

27. Annual Report Nuclear Engineering Department, BNL 954 (S-68), Brookhaven National Laboratory, New York (Dec 31, 1965).

28. Nuclear Safety Program Semiannual Progress Report for Period Ending December 31, 1963. ORNL-3547, Oak Ridge National Laboratory, Oak Ridge, Tennessee (Mar 1964).

29. ORNL Status and Progress Report, ORNL-3953, Oak Ridge National Laboratory, Oak Ridge, Tennessee (1966).

30. G. W. Parker, W. J. Martin, G. E. Creek, and C. J. Barton. "Behavior of Radioiodine in the Contalnment Mockup Facility." Inter. Sym. on Fission Product Release and Transport Under Accident Conditions. Oak Ridge, Tenn., 212, CONF-650407, (1965)

31. D. M. Golden, R. Walsh, and S. W. Benson. "The Thermochemistry of the Gas-Phase Equilibrium $\mathrm{I}_{2}+\mathrm{CH}_{4} \rightleftharpoons \mathrm{CH}_{3} \mathrm{I}+\mathrm{HI}$." J. Am. Chem. Soc. 87, 18, 4053 (1965).

32. D. A. Collins, et al. Experiments Relative to the Control of Fission-Product Release from Advanced Gas-Cooled Reactors. TRG Report 956(W) United Kingdom Atomic Energy Authority, p 7 (May 1965).

33. D. A. Collins, R. Taylor, and W. D. Yuille. "Sampling and Characterization Techniques Used in the Study of Iodine Release From Irradiated Fuel Elements." Eighth AEC Air Cleaning Conference, TID-7677, p 102 (Oct 1963).

34. R. D. Collins and H. Hillary. "Some Experiments Relating to the Behavior of Gas-Borne Iodine." International Symposium of Fission Product Release and Transport Under Accident Conditions. Oak Ridge, Tennessee, Apr 5-7, 1965. CONF650407, Vo1 2, p 830 (1965). 
35. R. K. Hilliard and J. W. McCormack. "Fission-Product Simulation in the Containment Systems Experiment." International Symposium on Fission Product Release and Transport Under Accident Conditions, Oak Ridge, Tenness, CONF-650407, Vo1 1, p 588 (1965).

36. Nuclear Safety Program Semiannual Progress Report for Period Ending June 30,1964 . ORNL-3691, Oak Ridge National Laboratory, Oak Ridge, Tennessee (Nov 1964).

37. Nuclear Safety Program Semiannual Progress Report for Period Ending June 30,1965 . ORNL-3843. Oak Ridge National Laboratory, Oak Ridge, Tennessee (Sept 1965).

38. J. J. Hillary and J. C. Taylor. A High-Activity Iodine

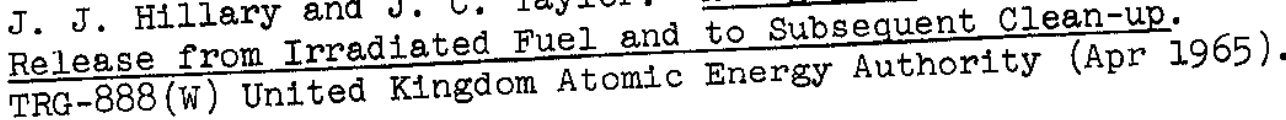

9. J. F. Croft, et al. Experiments on the Surface Deposition of Airborne Iodine of High Concentration. AEEW-R 265. United Kingdom Atomic Energy Authority, Reactor Group, Winfrith, Dorset, England (June 1963).

40. J. J. DiNunno, et al. Calculation of Distance Factors for Power and Test Reactor Sites. TID-14844 (1962). SL-I, Final Report on the SL-1 Recovery Operation. General

42. "Reactor Site Criteria," Title 10, Code of Federal Regulations, Part 100 (10 CFR 100) (Feb 11, 1961).

43. W. J. Megaw, et al. "The Oxidation and Release of Iodine-131 from Uranium Slugs oxidizing in Air and Carbon Dioxide." Reactor Science and Technology 15, No. 4, 176-84 (Dec 1961). 44. G. W. Parker. "A Review of Fission Product Release Research." Trans. Am. Nuclear Soc. 6 (1):120-121 (June 1963).

45. R. E. Kirk and D. F. Othmer. Encyclopedia of Chemical Vol. 7, Interscience Encyclopedia, Inc., New York (1951).

46. C. F. Powell and I. E. Campbell. J.Am. Chem. Soc. 69, 1227 (1947).

47. W. S. Durant. Performance of Activated Carbon Beds in SRP Reactor Confinement Facilities. Progress R. I. du Pont 1962 - Sept 1965. USAEC Report DP-1028, Ery, Aiken, S. C. (1966).

$R-4$ 
48. R. E. Adams and W. E. Browning, Jr. "Removal of Iodine and Volatile Iodine Compounds from Air Systems by Activated Charcoal." International Symposium on Fission Product Release and Transport Under Accident Cond1tions. Oak Ridge, Tennessee, Apr 5-7, 1965. CONF-650407, Vol 2, p 869 (1965).

49. O. A. Hougen and C. R. Wilke. "Mass Transfer in the Flow of Gases Through Granular Solids Extended to Low Modified Reynolds Numbers." Trans. Am. Inst. Chem. Engrs. 41, 445 (1945).

50. W. S. Durant. "Performance of Activity Confinement Systems in Savannah River Plant Bulldings." gth AEC Air Cleaning Conference, Sept 13-16, 1966, Boston, Mass.

51. Military Specifications: Filter Particulate, High Efficiency, Fire Resistant. MIL-F-51068A, (23 Apr 1964).

52. J. W. Thomas and G. D. Crane. "Aerosol Penetration Through 9 Mil HV-70 Filter Paper With and Without Pinholes." Elghth AEC A1r Cleaning Conference, TID-7677 (Oct 1963).

53. D. R. Muhlbaier. Nondestructive Test of Carbon Beds for Reactor Containment Application - Prosress Report. USAEC Report DP-910, E. I. du Pont de Nemours \& Co., Savannah River Laboratory, Aiken, S. C. (1964).

54. D. R. Muhlbaier. Nondestructive Test of Carbon Beds for Reactor Containment Application - Progress Report. USAEC Report DP-920, E. I. du Pont de Nemours \& Co., Savannah River Laboratory, Aiken, S. C. (1964).

55. D. R. Muhlbaier. Nondestruct1ve Test of Carbon Beds for Reactor Containment Application - Prosress Report. USAEC Report DP-950, E. I. du Pont de Nemours \& Co., Savannah River Laboratory, Aiken, S. C. (1965).

56. D. R. Muhlbaier. Nondestructive Test of Carbon Beds for Reactor Confinement Applications. Progress Report Sept 1964 - Sept 1965. USAEC Report DP-1053, E. I. du Pont de Nemours \& Co., Savannah R1ver Laboratory, A1ken, S. C. (1966).

57. D. R. Muhlbaier. "In-Place Non-Destruct1ve Leak Test for Iodine Adsorbers." 2th AEC Air Cleaning Conferences, Sept 13-16, 1966, Boston, Mass.

58. D. R. Muhlbaier. Standardized Nondestructive Test of Carbon Beds for Reactor Confinement Application - Final Progress 
Report. USAEC Report DP-1082, E. I. du Pont de Nemours \& Co., Savannah River Laboratory, Alken, S. C. (to be issued).

59. R. C. Milham. High Temperature Adsorbents for Iodine. USAEC Report DP-1075, E. I. du Pont de Nemours \& Co., Savannah River Laboratory, Alken, S. C. (to be issued).

60. ORNL Master Analytical Manual, TID-7015 (Supplement 6) Method 5, 11391.

61. D. West and S. Smith. "Determination of Volatile Compounds of Fission Product Iodine Released from a Radiochemical Plant." The 150th National Meeting of the American Chemical Society held in Atlantic C1ty, N. J. on Sept 14, 1965.

62. J. E. Lovelock. "Ionlzation Methods for the Analysis of Gases and Vapors." Anal. Chem. 33, 162 (1961).

63. J. E. Lovelock. "Electron Absorption Detectors and Technique for use in Quantitative and Qualitative Analysis by Gas Chromatography." Ana1. Chem. 32, 474 (1963).

64. R. C. Milham. "HIgh Temperature Carbon for Iodine Adsorption." 2th AEC A1r Cleaning Conference, Sept 13-16, 1966 Boston, Mass.

65. Reactor Chemistry Division Annual Progress Report for Period Ending December 31, 1965, ORNL-3913, Oak Ridge National Laboratory, Oak Ridge, Tennessee (Mar 1966).

66. B. F. F. Howe11. A Kinetic Study of the Isotope-Exchange Between Zinc Iodide and Various Alkyl Iodides in Acetonitrile. Thesis, University of Missouri (1964).

67. E. D. Cohen. Exchange Reaction of Alkyl Iodides and Iodine. Thesis, University of Delaware (1964).

68. E. D. Cohen and C. N. Trumbone. "The Exchange Reaction of Ethyl Iodide and Iodine." J.Am. Chem. Soc. 87, 964 TID-20960 (1965).

69. E. D. Cohen and C. N. Trumbone. "Alkyl Iodide-Iodine Exchange and the Szilard-Chalmers Effect." Sclence 148, 1460 (1965).

70. I. Galiba, I. Latzkovits, and D. Gal. "Investigations on AgI Catalyst Surface Structure by Isotope Exchange Reactions." J. Inorg. Nucl. Chem. 27, 2279 (1965). 
71. A. Polacyk and A. Kaminsk1. "The Donor-Acceptor Interaction of Aluminum Trilodide with Organic Molecules, Effect of Addition of Various Organic Compounds on the Isotopic Exchange of Iodine in the Aluminum Iodide-Ethyl Iodide Iiquid System." J. Inors. Nucl. Chem. 27, 2585 (1965). 


\title{
APPENDIX A
}

\author{
SPECIFICATIONS FOR MOISTURE SEPARATORS FOR \\ REACTOR CONFINEMENT FACILITIES
}

\section{GENERAL}

\subsection{DRAWINGS}

Fabrication of the moisture separators shall be in accordance with these specifications and drawing number W-234059, E. I. du Pont de Nemours \& Co.

\subsection{APPLICATION}

1.2.1 Mo1sture separators are installed in casings that are erected in a process ventilation system to remove entrained liquid water particles from steam-air mixtures. Separator efficlency shall be adequate, about $99 \%$, to prevent the blinding of a water repellent particulate filter (described in Appendix B) by 1 to 5 micron entrained water particles when exposed in series to the standard steam-air mixture test described in Section III.

II. CONSTRUCTION

\subsection{SUPPORT MECHANISM AND CASING}

\subsubsection{General}

The units shall be built in accordance with the highest standards of workmanship and finish and shall be free from obscure and obvious flaws.

\subsubsection{Materials}

\subsubsection{Casing}

Unless otherwise specified on drawing number $W-234059$, all material shall be type 304 stainless steel. The support mechanism must be capable of withstanding a $\Delta \mathrm{P}$ of $12 \mathrm{in.}$ $\mathrm{H}_{2} \mathrm{O}$ across the separator. 


\section{APPENDIX A (Continued)}

\subsubsection{Separator Material}

The separator material shall be fabricated from "Teflon"* yarn** and stainless steel wire woven into a mat. Separator material shall be composed of a number of layers, each approximately $24 \times 24$ inches. Minimum and maximum edge compression of the material when installed in the case shall be $3 / 8$ and $1 / 2$ inch, respectively, at each edge. The number of layers of material used in each nominal 2-inch-thick unit shall be determined by the number of layers necessary to meet the flow resistance requirement. Layers shall be held together by 16 gauge (approximate) stainless-steel wire for adequate support when separator is in vertical position for horizontal air flow.

\subsubsection{Gaskets}

Flange gasket on the upstream face of the separator case shall be $1 / 4 \times 3 / 4$ inch neoprene sponge (15-20 durometer). Gaskets shall have tight-butted joints at corners and shall be firmly and continuously cemented to flange with a neoprene-base adhesive. Gasket material shall maintain its integrity and resilient properties when subjected to air at $120^{\circ} \mathrm{C}\left(250^{\circ} \mathrm{F}\right)$.

\subsubsection{Adhesive}

The adhesive used for the gasketing shall be neoprene base and cured. It shall be resilient, water resistant, and resistant to a minimum temperature of $120^{\circ} \mathrm{C}$ for 8 hours when cured. If capable of ignition, it shall be selfextinguishing and shall meet all operating conditions without change in physical properties and without loss of seal or strength. Adhesive shall not show cracks, checks, "alligatoring", or separation.

* Registered trademark of E. I. du Pont de Nemours \& Co. ** "Teflon" yarn or equal. 


\section{APPENDIX A (Continued)}

III. TESTING AND INSPECTION

3.1 All units shall be inspected by purchaser's representative for quality of construction and freedom from obvious and obscure flaws. Particular attention will be directed to the flow resistance test, 3.2 .

3.2 Each assembled separator shall exhib1t a resistance to flow of $0.95 \pm 0.05$ inch $\mathrm{H}_{2} \mathrm{O}$, at an air flow of 1600 cfm at 22 to $25^{\circ} \mathrm{C}$. Each unit shall be individually tested by the manufacturer.

3.3 In addition to the test described in Section 3.2, the manufacturer must conduct a steam-air mixture test (at his own expense) on one representative separator to qualify under this specification. The test consists of exposing a dustloaded particulate filter (described in Appendix B) (with the moisture separator upstream) to wet steam flowing at a maximum rate of $8000 \mathrm{cfm}$ for 30 seconds, following by 10 days continuous exposure to steam-air mixtures at flows up to $1000 \mathrm{cfm}$. Detalls of the equipment and procedures for conducting such a test are available on request.

\section{MARKING AND SHIPPING}

4.1 Each unit shall have indelibly stamped on the installation case the following information:
a) ModeI number
b) Serial number
c) Resistance to flow
d) Flow rate and conditions
e) Material run number

4.2 Each unit shall be individually packed for shipment in substantial containers completely enclosing and protecting the units from physical damage during storage and shipping. They shall be palletized for convenience and economy in handling and shipping. 


\title{
APPENDIX B
}

\author{
SPECIFICATIONS FOR WATER-REPELIENT PARTICULATE \\ FIITERS FOR REACTOR CONFINEMENT FACIIITIES
}

\section{CONSTRUCTION}

\subsection{GENERAL}

This specification is for high efficiency particulate filters with a high strength, water-repellent medium. The filters are used in confinement facilities for removing radioactive particles that might be released in the event of a reactor accident. Under accident conditions, the filters could be exposed to air at $120^{\circ} \mathrm{C}\left(250^{\circ} \mathrm{F}\right)$; wet steam at $100^{\circ} \mathrm{C}$; or mixtures of steam, a1r, and entrained water particles.

Complete filter assembly shall be of fire-resistant construction for operating temperatures up to $120^{\circ} \mathrm{C}$ and shall pass all tests described in section II.

In addition to tests described in Section II, the manufacturer must conduct a steam and steam-air mixture test (at his own expense) on one representative filter to qualify under this specification. The test consists of exposing a dust loaded filter (with a moisture separator upstream) to wet steam flowing at a maximum rate of $8000 \mathrm{cfm}$ for 30 seconds, followed by 10 days continuous exposure to steam-air mixtures at flows up to $1000 \mathrm{cfm}$. Details of the equipment and procedures for conducting such a test are available on request.

The filter shall be constructed by pleating a continuous sheet of filter medium into closely spaced pleats separated by corrugated inserts. Pleated medium and separators shall be enclosed in a flanged, steel box and fastened at all boundaries with adhesive so that under test and rated conditions gas stream will pass through medium without bypassing.

Filter shall be assembled in accordance with highest workmanship standards to provide uniformity of materials and construction, finish, cleanliness, and freedom from obscure or obvious flaws. 
APPENDIX B (Continued)

\subsection{FRAME}

Cadmium-plated 16-gauge steel sheet with double turned inlet and outlet flanges. Dimensions, exclusive of gaskets, shall be 24 by 24 by $11-1 / 2$ inches plus or minus $1 / 16$ inch, and square within $1 / 8$ inch measured diagonally.

\subsection{FILTER MEDIUM}

Glass-asbestos fibers containing a minimum of $7 \%$ asbestos fibers, and with a minimum thickness of $18 \mathrm{mils}$. No substitution allowed.

Filter medium shall contain not more than $5 \%$ combustible matter and shall not contain holes, cracks, slits, or other physical imperfections. In completed filter unit the medium may not contain more than one splice. All splicing must be from same lot of filter medium. Splices must conform in all respects to paragraphs 3.3 .2 of Military Standard MIL-F-5I068A and 3.3 of MIL-F-51079.

Medium binder shall conform to Military Standards MIL-F51079 and shall withstand a minimum temperature of $120^{\circ} \mathrm{C}$ for 8 hours.

Medium shall be treated with a maximum of $1 \%$ sillcone-base water-repellent material to achleve wet strength characteristics 1 sufficient to pass tests of Sections 2.2.5 and 2.3.

Patching of medium not allowed.

\subsection{SEPARATORS}

Full-hardened aluminum with 0.0015 inch minimum thickness. Ref: Military Standard MIL-F-51068A.

\subsection{ADHESIVE}

Neoprene base, cured. Adhesive shall be resilient and water resistant and shall resist a minimum temperature of $120^{\circ} \mathrm{C}$ for 8 hours. If capable of ignition, it shall be self-extinguishing and shall meet all general operating conditions without change in physical properties and without loss of seal or strength. Adhesive shall not show cracks, checks, "alligatorlng", or separation. 
APPENDIX B (Continued)

\subsection{GASKETS}

$1 / 4$ inch thick by $3 / 4$ inch wide, ozone-resistant neoprene, 15-20 durometer, in gasket pieces which shall be die-cut for dovetall mating. Mating surface of die-cut ends shall be coated with rubber-based adhesive and interlocked to present a workmanlike appearance. Gaskets shall be attached firmly and continuously to upstream flange surface of frame with adhesive and shall provide a continuous seal around filter face.

\subsection{FACE GUARDS}

Fabricated from galvanized hardware cloth, 23 gage $4 \times 4$ mesh, 1/4 inch opening, shall be installed on both faces of each filter. Face guards shall be fitted flat against aluminum separators but shall not contact filter medium.

\section{TESTING}

\subsection{GENERAL}

These tests control quality, reliability, unfformity, and performance characteristics of filters procured by this specification.

Purchaser's representative shall witness all factory tests. The vendor shall not1fy the purchaser when tests are to be run.

Each roll of medium is qualifled by subjecting representative samples to tests described in Section 2.2. Acceptable rolls shall be identified with a code legend and cross-referenced to a document with the following information: (1) date and results of tensile tests, (2) serial numbers of filter assembled from roll of medium, (3) signatures of tester and witness, (4) medium manufacturer's name, lot and order numbers, and (5) any other pertinent background information describing history of medium. Rolls that do not pass tests shall be rejected.

A group of filters shall be assembled from each roll of medlum that successfully passed tests; each filter shall be marked with appropriate code legend and serial number. 


\section{APPENDIX B (Continued)}

A sample filter shall be selected randomly by purchaser's representative from each group. Sample filter shall be destructively tested in accordance with sequence of tests described in section 2.3. Results of these tests shall be recorded on appropriate document, dated, and signed by tester and witness. This filter may then be discarded. Reject any group of filters whose samples fail any tests.

Each unit of remaining groups of filters qualified for production by passing sequence of tests, shall be subjected in turn to Flow Resistance Tests and Penetration Efficiency Test (DOP), both witnessed, described in Section 2.4. Reject any units that fail either test. Mark each filter as directed in section 3.3 and pack for shipment in accordance with Section 3.2.

Test results shall be recorded on appropriate document adjacent to respective serial number of each fliter, dated, and signed by tester and witness.

\subsection{MEDIUM TENSILE STRENGTH}

2.2.1 Samples of each roll of medium shall be prepared for each of the following witness tests. Each test result shall be the average of three samples selected across width of the medium at free end of roll.

2.2.2 Filter medium shall exhibit a minimum tensile strength of 2.5 pounds per inch of width when tested with tensile force perpendicular to normal direction of fibers in medium ("Across Machine Direction").

2.2.3 After a flat fold is made in sample perpendicular to normal direction of fibers in medium, sample shall be subjected to a tensile test parallel with normal direction of fibers in medium ("With Machine Direction"); minimum tensile strength shall be 1.5 pounds per inch of width.

2.2.4 Minimum elongation before rupture in both of above tests shall be $1.0 \%$.

2.2.5 Soak samples of medium for 2 hours in room temperature water and repeat tests of Section 2.2.2 and 2.2.3. Wet medium shall exhibit minimum tensile strengths of $60 \%$ of dry medium readings. 


\section{APPENDIX B (Continued)}

\subsection{SEQUENCE TESTS ON RANDOM SAMPLE FILTERS}

\subsubsection{Moisture Resistance}

One random sample filter assembled from each roll of filter medium shall be exposed to $2000 \mathrm{cfm}$ of wet steam at 14.7 psia (measured upstream of the filter) and with water injected about $15 \mathrm{ft}$ upsteam of the filter, at a rate of $8 \mathrm{lb} \mathrm{H}_{2} \mathrm{O}$ per minute.

Water shall be injected with nozzle No. 1/8G-6SQ or 1/8GG/6SQ, manufactured by Spraying Systems Company, 3201 Randolph St., Bellwood, Illinols. Only unentrained moisture shall be drained from test facllity upstream of filter. No devices for removing entrained molsture or particulate matter from stream, such as roughing filters, separators, etc., shall be used in test facility upstream of filter.

Only one filter shall be tested in test facllity at any one time. Filter shall be exposed to these conditions for 15 minutes and $\Delta P$ across filter obtained under these conditions shall not exceed 4 inches $\mathrm{H}_{2} \mathrm{O}$.

Filters that successfully pass the above test shall be dried with air between 20 and $25^{\circ} \mathrm{C}$.

\subsubsection{Flow Resistance}

Dried samples from the test of Section 2.3.1 shall be individually tested for alr-flow resistance in callbrated, standard DOP test apparatus w1thout generation of DOP aerosol. Initial resistance of filters (when clean) shall not exceed 1.00 inch $\mathrm{H}_{2} \mathrm{O}$ when passing rated air flow of $1000 \mathrm{cfm}$.

\subsubsection{Dust Capacity}

A dust capacity test shall be conducted on sample filters that passed molsture and flow resistance tests of Sections 2.3.1 and 2.3.2. Test shall be conducted using NBS Standard Dust Loading Test with NBS Cottrell Precipitate (without linters) while air is flowing through filter at rated capacity of $1000 \mathrm{cfm}$. 


\section{APPENDIX B (Continued)}

Filter must hold a minimum of 4 ib dust per filter, before initial resistance ( 1.00 Inch $\mathrm{H}_{2} \mathrm{O}$ or less at $1000 \mathrm{cfm}$ ) doubles.

\subsubsection{Ultimate Strength}

Sample filters that passed dust capacity test shall be subjected to an Ultimate Strength Test with deposited dust still on filter. A sufficient alr flow shall be passed through filter to increase and maintain for ten minutes a $\Delta P$ of 6 inches $\mathrm{H}_{2} \mathrm{O}$ across filter.

\subsubsection{Efficiency-Penetration (DOP)}

Vendor must perform an encapsulated-Type dioctylphthalate (DOP) test to detect frame, gasket, or filter medium leakage.

Sample filters that passed Ultimate Strength Test, st1ll carrying 1ts load of dust, shall be tested according to Military Standard MIL-STD-282, May 28, 1956.

Penetration shall not exceed $0.1 \%$ for 0.3 -micron diameter homogeneous particles of dioctylphthalate.

\subsection{PRODUCTION TESTS}

For final acceptance, each filter in the groups that are acceptable (because the sample from the group successfully qualified by passing sequence tests 2.3.1-2.3.5) shall pass the following two tests:

\subsubsection{Flow Resistance Test}

This test is identical to that described in Section 2.3.2.

2.4.2 Efficiency-Penetration Test (DOP)

This test is identical to that described in section 2.3.5 except that DOP penetration shall not exceed $0.03 \%$. Also filters shall be tested at $20 \%$ of rated flow as well as $100 \%$ of rated flow.

B-6 


\section{SHIPPING}

\subsection{PACKAGING}

Each filter shall be packed for shipment in substantial hardboard or wooden containers, completely enclosed with extra protection for both open faces of the cell. Package shall support and completely protect filter whether handled in vertical or horizontal position. Container shall be designed so that it may be opened and cell removed without damage to contalner or filter cell, so that contalner may be reused for shipment to ultimate destination.

\subsection{PALLETIZING}

Containers shall be shipped as individual units without palletizing or fastening together in any multiple.

\subsection{MARKING}

Results of test penetration, test resistance, test flow rate, together with direction of test air flow, manufacturer's name, model number, serial number of the filter cell, and code legend of roll of medium used in production of cell shall be registered legibily and indelibly on the top of the frame of the filter unit. Serial number of unit shall be so registered by machine.

On top of frame opposite serial number stencil FOR REACTOR CONFINEMENT USE ONIY. Letters to be $3 / 4$ " high. 


\title{
APPENDIX C
}

\author{
SPECIFICATIONS FOR ACTIVATED CARBON BEDS \\ FOR REACTOR CONFINEMENT FACILITIES
}

I. GENERAL

\subsection{DRAWINGS}

Fabrication of the activated carbon beds shall be in accordance with these specifications and drawing number ST5-10545

(F1gure C-1). Savannah River Plant, E. I. du Pont de Nemours \& Co.

\subsection{APPLICATION}

1.2.1 Carbon beds are installed in casings that are erected in process ventilation exhaust systems. They are mounted with pleats horizontal on a vertical holding frame which is arranged with supporting and clamping devices so that $100 \%$ of the horlzontal air stream flows through the beds.

1.2.2 The carbon beds are used in confinement facilities for radioactive lodine vapor that might be released in the event of a reactor accident. The units are to be constructed with alrtight joints so that all of the alr contacts the one-inch-thick carbon beds. Slight bypassing of the beds, permissible in conventional applications for odor control, is unacceptable for the subject carbon units.

1.2.3 The assembled carbon unit, when fully charged with activated carbon, shall pass 1000 scfm of alr with a pressure drop of about $0.8 \mathrm{in} . \mathrm{H}_{2} \mathrm{O}$. The direction of flow shall be indelibly marked on one of the casing members that is permanently welded to the pleated section. This side will be designated TOP and so marked for shipping and installation. 


\section{APPENDIX C (Continued)}

\section{CONSTRUCTION}

\subsection{CASING}

\subsection{General}

The units shall be built in accordance with the highest standards of workmanship and finish and be free from obscure and obvious flaws. Welds at flange and gasket surfaces shall be ground flush. Particular care shall be taken when installing gaskets that are required to prevent air from bypassing the carbon beds. Spacers shall not be installed within the carbon bed except as shown on drawing ST5-10545 (F1gure C-1).

\subsubsection{Alrtight Seals}

To prevent air from bypassing the carbon beds, airtight seals shall be provided at all edges of the carbon bed in contact with the enclosing casing as follows:

Where the two end legs of the pleated carbon bed join their respectlve casing surfaces, the bed walls shall not be perforated. They shall be lapped into a flange and spot welded to the casing surface before assembling gaskets and neoprene sealing pads.

The two slde casing surfaces shall be furnished with internal neoprene pads that are cemented to the casing flanges with the specified adhesive. These pads shall bear jointly on the flanged edges of the pleated carbon bed walls and on the mating casing flanges such that when assembled and bolted, compression of the pads will form the required airtight seals.

\subsubsection{Materials}

\subsubsection{Casing}

The casing shall be fabricated of either type $304 \mathrm{I}$ stainless steel or cold-rolled carbon steel, whichever is specifled on the purchase order. Stainless steel should be specifled for use in areas where $\mathrm{NO}_{2}$ or $\mathrm{SO}_{2}$ are present, even in trace quantities. 


\section{APPENDIX C (Continued)}

\subsubsection{Gasketing Materials}

Gasket material shall maintain its integrity and resilient properties when subjected to air at $120^{\circ} \mathrm{C}\left(250^{\circ} \mathrm{F}\right)$. The flange gasket shall be 1/4-1nch thick by 3/4-inch wide, ozone-resistant neoprene sponge (15-20 durometer) of 1dentical material specifled below for the sealing pads. It shall be formed from die-cut gasket pieces for dovetail mating. Mating surfaces of diecut ends shall be coated with the specified adhesive and interlocked to form a flawless joint. Gaskets shall be firmly and continuously cemented to the upstream flange surface with the specified adhesive.

The sealing pads, cemented to the 24 inch by ll-1/2 inch casing flanges, shall be fabricated of neoprene sponge 3/8-inch thick. They shall be completely cemented to the inner surfaces of their casing pieces with the specified adhesive.

\subsubsection{Adhesive}

The adhesive used for the gasketing and sealing pads shall be neoprene base, cured. It shall be resilient, water resistant, and resistant to a minimum temperature of $120^{\circ} \mathrm{C}$ for 8 hours when cured. If capable of ignition, it shall be selfextinguishing and shall meet all operating conditions without change in physical properties and without loss of seal or strength. Adhesive shall not show cracks, checks, "alligatoring", or separation.

\subsubsection{Fin1sh}

This section is applicable only to carbon steel units. Dip all subassemblies in phenolic coating (Tithcoat LC24 or Hanna XB8081, or equal), air dry, and then subsequently dry parts in oven. All parts are then sprayed with at least two coats of moisture-resistant paint (Reliance 150-HBI-63 or Hanna XB-4357 Epon Black, or equal) and baked in oven until dried. (Exception: mask areas which are to be spot welded of arc welded in subsequent operations.) 


\section{APPENDIX C (Continued)}

After final assembly of parts, clean and neutralize welds, brush-coat bare spots with phenolic coating, and then apply at least two additional coats of moisture resistant paint and bake in oven until dried.

\subsection{ADSORBENT MEDIA}

The adsorbent shall be new activated carbon made from coconut shells in accordance with the following:

\subsubsection{Physical Properties}

a. Particle size*: 10-14 range, Tyler mesh size, as per following distribution:

\begin{tabular}{|c|c|}
\hline Mesh & Retention \\
\hline 8 & $0.1 \%$ Maximum \\
\hline 10 & $10.0 \%$ Maximum \\
\hline 14 & $88.9 \%$ Minimum \\
\hline Through 14 & 1.0\% Maximum \\
\hline
\end{tabular}

b. Packing Density: $34 \mathrm{lb} / \mathrm{ft}^{3}$ nominal, bone dry carbon based on apparent density measurement method (laboratory measurement, $32-36 \mathrm{lb} / \mathrm{ft}^{3}$ "free fall").

c. Charge per unit: $57 \mathrm{lb}$ (actual filled weight based on bone dry carbon) minimum welght to be adjusted for water content measured at time of filling units - one test at the beginning of the use of each batch and repeated at the beginning of each day when a batch is used that was held over from the work the preceding day.

*As per methods described in Military Specification, MIL-C-13724A, dated May 4, 1960. 


\section{APPENDIX C (Continued)}

d. Fines: After packing, carbon fines and dust shall be blown from the unit with compressed air at a minimum nozzle velocity of $5000 \mathrm{ft} / \mathrm{min}$. Compressed air supply shall be free of oil, dust, and other contaminants. Nozzle orifice area shall be $0.8-$ in $^{2}$ minimum. Nozzle shall be fishtailshaped and arranged so that the upstream screen surface of the entire pleated carbon bed, including the crevice at the apex of each pleat, can be blown with air. The direction of flow shall be the same as the installed air flow as marked on the top of the unit and specified in Section 1.2 .3 .

e. Hardness*: 97\% minimum.

\subsubsection{Chemical Properties**}

a. Iodine number: Minimum of $1050 \mathrm{mg}$ per gram of carbon.

b. Activity for carbon tetrachloride: 50\% by weight, minimum.

c. Activity, Standard Accelerated Chloropicrin Test: 50 minutes minimum.

d. Retentivity for carbon tetrachloride: $30 \%$ by weight, minimum.

e. Ash content: $4 \%$ by weight, maximum.

\section{2 .3 Loading}

The purpose of this section is to ensure that each carbon bed is packed firmly and with a uniform distribution of the carbon particles. The hopper used for loading the carbon unit shall provide a minimum of $3 \mathrm{ft}$ of "free fall" for the carbon granules (excluding the height of the unit). There shall be at least three dispersal screens or baffles for scattering the falling granules in this $3 \mathrm{ft}$ "free fall".

* As per methods described in Military Specification, MIL-C-13724A, dated May 4, 1960.

* For definition of tests, see Adsorption, C. L. Mantell, McGrawHill Book Co., New York, N. Y., 2nd Edition, 1951. 


\section{APPENDIX, $C$ (Continued)}

The feed rate of the carbon through the hopper shall be as small as practically possible. Other loading methods are acceptable provided that the new method is proven to purchaser's satisfaction to provide equal or better distribution of the carbon particles throughout the bed.

During the initial filling operation, the unit shall be completely filled but not vibrated. The final step of the loading operation shall be vibration of the carbon unit on a packing machine built in accordance with MIL STD 282, Method 105.9. The packing machine shall operate at a frequency of 200 cycles/min with an amplitude of $3 / 4$ inch and with the lifting cams operated in phase. The carbon unit shall be vibrated for 1.5 minutes while mounted rigidly on the packing machine platform. During the complete time of vibration, the unit must be kept full of carbon and in addition, the uppermost layers of carbon must be subjected to a packing force equivalent to a minimum helght of 6 inches of carbon that is maintained above the top carbon layers in the unit. As an alternative, the packing force may be provided by a spring loaded device (with a force equivalent to 6 inches of carbon) to force carbon into the unit while it is vibrated. As stated in section 4.1, this operation shall be witnessed by purchaser's representative.

\section{TESTING}

3.1 Physical and chemical tests specified in Sections 2.2.1 and 2.2.2 need not be witnessed by purchaser's representative. Tests confirming the specified properties shall be performed by the vendor on a representative sample from each 2000-Ib carbon lot, and the certified results submitted to purchaser.

3.2 The carbon must have a high efficiency for the removal of lodine. The units are used in a confinement faclitty for removing radioactive lodine that might be released during a reactor incident. Under incident conditions, the carbon could be exposed to air at $120^{\circ} \mathrm{C}$, wet steam at $100^{\circ} \mathrm{C}$, or mixtures of steam and air. In addition to the tests specified in Sections 2.2.1 and 2.2.2, the vendor shall submit a $5 \mathrm{lb}$ 


\section{APPENDIX C (Continued)}

representative sample of carbon to the purchaser for testing of iodine removal efficiency and ignition temperature. This carbon shall be certifled as being representative of that carbon which the vendor will use in the carbon beds. The carbon shall remove $99.99+\%$ of the lodine when exposed to a steam-air mixture at $70^{\circ} \mathrm{C}$ and flowing at a face velocity of $70 \mathrm{ft} / \mathrm{min}$ and with an iodine loading of $1 \mathrm{mg}$ per gram of carbon.

The carbon must have an 1gnition temperature greater than $330^{\circ} \mathrm{C}\left(625^{\circ} \mathrm{F}\right)$ under the following conditions:
Air velocity: $70 \mathrm{ft} / \mathrm{min}$
Rate of heating: $2-4^{\circ} \mathrm{C} / \mathrm{min}$
Bed thickness: 1 inch
Bed diameter: $3-1 / 2$ inches with $1 / 4-1$ nch-wide baffle on front and back sides

Apparatus: Stainless steel construction

3.3 All units shall be tested for leaks with "Freon"*, or equal, by the purchaser prior to installation in the confinement system. Testing shall be in accordance with that specified In AEC Research and Development Report, DP-870, "Nondestructive Test of Carbon Beds for Reactor Containment Application, Progress Report, June 1962 - December 1963". Those units which are not acceptable (leaks greater than $0.1 \%$ of total bed flow) shall be returned to the vendor at the vendor's expense, for repair.

\section{SHIPPING}

Each carbon unit shall be packed for shipment in substantial containers completely enciosing and protecting the units from physical damage during storage and shipping. They shall be palletized for convenience and economy in handling and shipping, and shall be stored and shipped with the TOP side up, as defined in Section 1.2.3. The carbon weight, carbon lot number, and bed serial number shall be indelibly marked on the casing.

\subsection{INSPECTION}

All units shall be inspected by purchaser's representative for quality construction and freedom from obvious and obscure flaws, before, during, and after charging. Particular attention will be directed to construction details affecting quality of airtight seals and the loading operation.

\footnotetext{
* Du Pont's registered trademark for its fluorinated hydrocarbons.
}

$$
c-7
$$


8-0

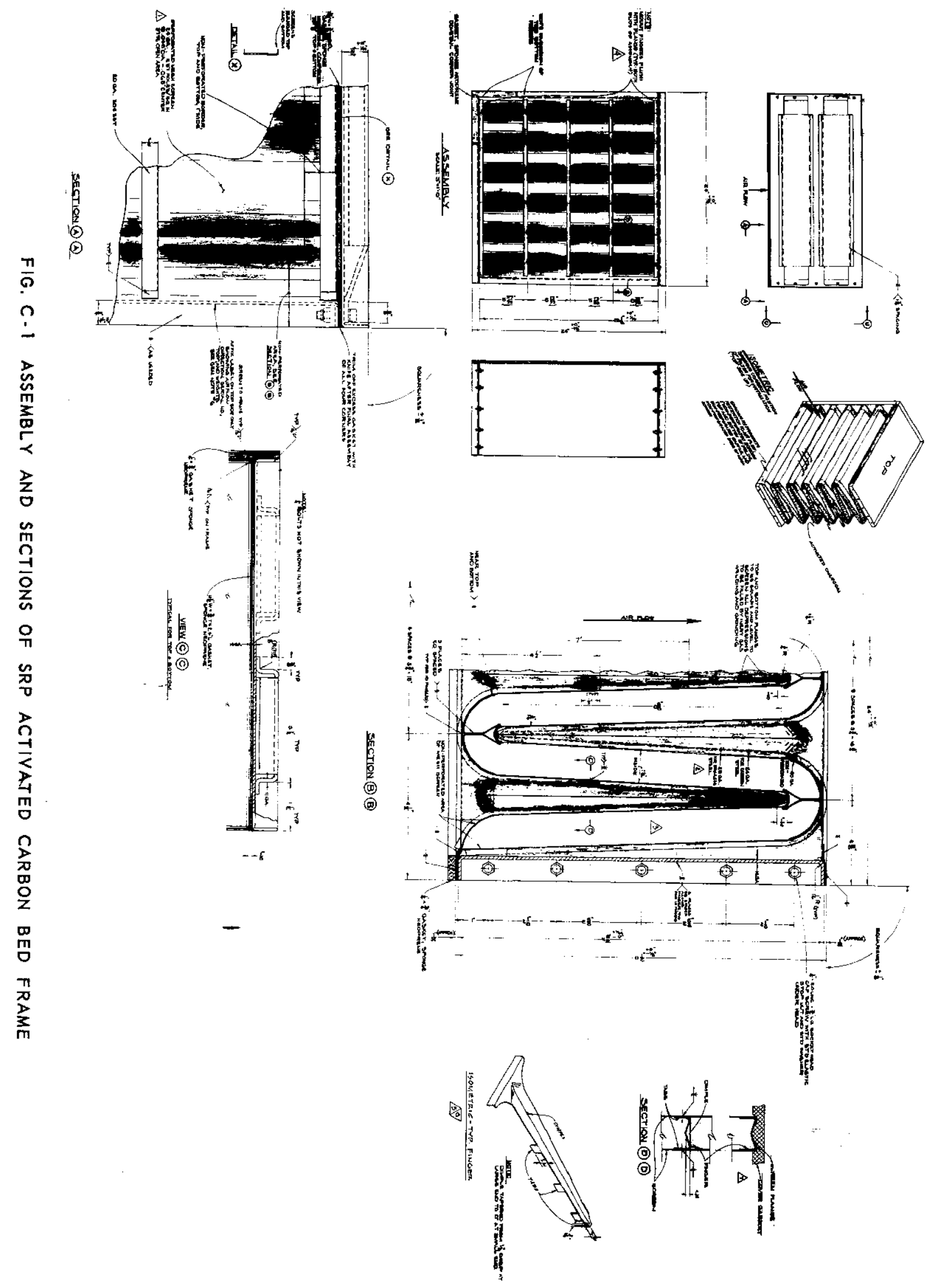

